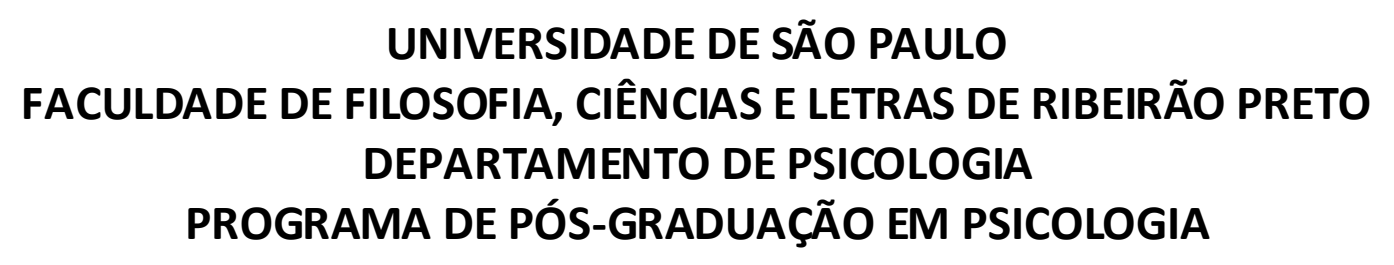

\title{
Perfil neuropsicológico e comportamental de crianças com doença falciforme
}

\author{
Katiusha de Cerqueira Abreu
}

Ribeirão Preto - SP 



\title{
Katiusha de Cerqueira Abreu
}

\section{Perfil neuropsicológico e comportamental de crianças com doença falciforme}

\author{
Dissertação apresentada ao Programa de Pós- \\ Graduação em Psicologia da Faculdade de \\ Filosofia, Ciências e Letras de Ribeirão Preto da \\ Universidade de São Paulo, como parte das \\ exigências para a obtenção do título de Mestre em \\ Ciências.
}

Área de concentração: Psicologia.

Orientadora: Prof ${ }^{a}$. Dra ${ }^{a}$. Sonia Regina Pasian

\section{Ribeirão Preto - SP}


Autorizo a reprodução e divulgação total ou parcial deste trabalho, por qualquer meio convencional ou eletrônico, para fins de estudo e pesquisa, desde que citada a fonte.

Abreu, Katiusha de Cerqueira

Perfil neuropsicológico e comportamental de crianças com doença falciforme. Ribeirão Preto, 2013.

148p. : il. ; $30 \mathrm{~cm}$

Dissertação de Mestrado, apresentada à Faculdade de Filosofia Ciências e Letras de Ribeirão Preto/USP. Área de concentração: Psicologia.

Orientadora: Pasian, Sonia Regina.

1. Doença falciforme. 2. Criança. 3. Avaliação Neuropsicológica.

4. Avaliação do Comportamento. 5. NEPS Y II.

Apoio: Capes e Fapesp 


\section{FOLHA DE APR OVAÇÃO}

\section{Nome: Katiusha de Cerqueira Abreu}

Título: Perfil neuropsicológico e comportamental de crianças com doença falciforme

Dissertação apresentada ao Programa de Pós-Graduação em Psicologia da Faculdade de Filosofia, Ciências e Letras de Ribeirão Preto da Universidade de São Paulo, como parte das exigências para a obtenção do título de Mestre em Ciências.

Área de concentração: Psicologia.

Aprovado em:

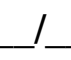

\section{Banca Examinadora}

Prof. Dr.

Instituição: Assinatura:

Prof. Dr.

Instituição: Assinatura:

Prof. Dr.

Instituição: Assinatura: 



\section{Dedicatória}

A todas as crianças com doença falciforme que merecem respeito e o devido tratamento, ao seu bem maior, sua saúde física e emocional. 



\section{Meus sinceros agradecimentos...}

À Deus, por guiar meus caminhos, acalentar meu coração nos momentos de tormenta e tornar minha vida repleta de luz.

Ao meu marido, Renato, companheiro de tantos anos, pelo seu amor, alegria contagiante e apoio constante. Agradeço pelas precisas orientações e discussões que foram fundamentais para a qualidade desse trabalho.

À minha querida família que, mesmo distante, se faz constantemente presente em minha vida, sendo fonte de apoio e amor mútuo. Aos meus pais, Aguimael e Selma Kátia, por me ensinar o valor de uma verdadeira família, por tamanha dedicação e encorajmento para seguir meus sonhos. Aos meus irmãos, Alan, Indira e Aguimael Jr., por me mostrar a importância da união e amor fraternos.

À minha orientadora, Prof ${ }^{a}$. Dra . Sonia Pasian, pelo acolhimento oferecido e pelos importantes direcionamentos que ultrapassam a realização desse trabalho, mas que contribuiram de maneira enriquecedora para minha formação acadêmica, profissional e pessoal.

Ao Prof. Dr. Octávio Pontes Neto, pela oportunidade oferecida de explorar esse novo campo de estudo, viabilizando o presente trabalho.

À $D^{a}$. Millene Camilo, pelo imenso auxílio prestado, tornando esse trabalho possível de ser concretizado.

À toda equipe do Hemocentro, em especial a Dr. Ivan, Dr ${ }^{a}$. Ana Cristina e Dra . Denise e as assistentes sociais, Dora e Regiane, pela dedicação oferecida aos cuidados dessas cria nças e pelo apoio e incentivo na condução desse trabalho.

À todas as crianças $\boldsymbol{e}$ familiares que participaram do presente estudo, pela confiança depositada e pelo ensinamento de vida adquirido nessa caminhada juntos. 
À banca do Exame de Qualificação, a Prof ${ }^{a}$. Dr $\boldsymbol{r}^{\mathbf{a}}$. Alessandra Seabra, pelas sugestões oferecidas que puderam enriquecer a versão final dessa dissertação, e a $\boldsymbol{P r o f}^{\mathbf{a}}$. $\boldsymbol{D r}^{\mathbf{a}}$. Nayara Argollo, por me incentivar na área de conhecimento da neuropsicologia, pelo seu exemplo de determinação e pela confiança depositada, disponibilizando material para realização desse trabalho.

Às minhas queridas colegas da Pós-graduação, Joana Barroso, Fabiana Freitas, Marcelle Louise, Veridiana Ferrari, Carolina Longato, pela ajuda e torcida oferecida e por dividirmos momentos de angústias e também de vitórias.

Aos colegas do Centro de Pesquisa em Psicodiagnóstico (CPP), pelo companheirismo e troca de experiência.

À todos do Programa de Pós-graduação em Psicologia da Faculdade de Filosofia Ciências e Letras de Ribeirão Preto - USP, pelos ensinamentos, e a CAPES e a FAPESP, pelo apoio financeiro.

À equipe do Hospital Sarah - Belo Horizonte, pela experiência profissional e por possibilitar meu caminhar com tranquilidade.

À todos meus amigos e familiares que fazem parte da minha história e que, de algum modo, contribuíram para condução da minha vida e realização desse projeto. 
"Cada pessoa que passa em nossa vida passa sozinha, e não nos deixa só, porque deixa um pouco de si e leva um pouquinho de nós. Essa é a mais bela responsabilidade da vida e a prova de que as pessoas não se encontram por acaso".

(Charles Chaplin) 



\section{RESUMO}

Abreu, K. C. (2013). Perfil neuropsicológico e comportamental de crianças com doença falciforme. Dissertação de Mestrado, Faculdade de Filosofia, Ciências e Letras de Ribeirão Preto, Universidade de São Paulo, Ribeirão Preto.

A Doença Falciforme (DF) constitui patologia hematológica que leva a diversas complicações sistêmicas, sobretudo sequelas neurológicas e déficits cognitivos. Algumas pesquisas têm correlacionado exames de Imagem por Ressonância Magnética (IRM) e Doppler Transcraniano (DTC) com avaliações neuropsicológicas em crianças com DF, sinalizando prejuízos cognitivos específicos e déficit intelectual geral que tendem a predispor ao baixo desempenho acadêmico e maior índice de retenção escolar. No Brasil há alta prevalência dessa doença, tornando-se importante a realização de estudos em crianças, visto que o diagnóstico precoce de dificuldades neuropsicológicas possibilita intervenções de caráter preventivo e formulação de programas de reabilitação em quadros de disfunção cerebral. Objetivo: Caracterizar o desempenho neuropsicológico e comportamental de crianças com DF, na faixa de 7 a 12 anos. Pretende-se avaliar e descrever as principais funções cognitivas (atenção/função executiva, aprendizagem e memória, linguagem, processamento visoespacial, função sensoriomotora) e possíveis dificuldades comportamentais e correlacionar esses resultados com variáveis sociodemográficas e clínicas. Método: Participaram dessa pesquisa 60 crianças, compondo dois grupos de 30 voluntários (clínico e controle), pareados em função do sexo, origem escolar e idade. Foram utilizados como instrumentos de avaliação psicológica: QI Estimado do WISC III e Matrizes Progressivas Coloridas de Raven, NEPSY II - Avaliação Neuropsicológica do Desenvolvimento e o Child Behavior Checklist (CBCL). O Grupo Clínico realizou exame neurológico clínico, IRM, DTC e hemograma. Resultados: As crianças com DF apresentaram significativos prejuízos no desempenho intelectual geral e déficits em diversos domínios neuropsicológicos específicos, principalmente função executiva, linguagem, memória visoespacial e habilidade visoespacial, comparativamente ao Grupo Controle. Nos exames médicos do Grupo Clínico, todos DTC foram considerados dentro da faixa normal e na IRM houve prevalência de $24 \%$ da a mostra com infarto cerebral silencioso (ICS). O comprometimento na capacidade intelectual geral, na memória narrativa e visoespacial e no processamento fonológico foram mais significativos no Grupo com ICS. Essas diversas alterações neuropsicológicas no Grupo Clínico tendem a predispor a dificuldades no desempenho acadêmico e maior repetência escolar. Além disso, houve evidências de significativos índices de problemas comportamentais e emocionais nas crianças com DF. Observou-se declínio cognitivo em distintas funções neuropsicológicas com o aumento da idade cronológica, porém não foi evidenciada influência das variáveis como sexo, tipo genético, tipo de medicação e índices do hemograma nos resultados neuropsicoló gicos e comportamentais das crianças. Esses resultados trazem relevantes implicações para o tratamento dos portadores de DF, pois ressaltam a importância do acompanhamento multiprofissional e a necessidade da realização da avaliação neuropsicológica e de adequada intervenção em centros de reabilitação, com objetivo de promover melhor qualidade de vida e cond ições favoráveis ao desenvolvimento dessas crianças (CAPES e FAPESP).

Palavras-chave: Doença falciforme; Criança; Avaliação neuropsicológica; Avaliação do comportamento; NEPSY II. 



\begin{abstract}
Abreu, K. C. (2013). Neuropsychological and behavioral profile of children with sickle cell disease. Dissertação de Mestrado, Faculdade de Filosofia, Ciências e Letras de Ribeirão Preto, Universidade de São Paulo, Ribeirão Preto.

The Sickle Cell Disease (SCD) is a haematological pathology that leads to several systemic complications, especially neurological sequelae and cognitive deficits. Some studies have correlated exams of Magnetic Resonance Imaging (MRI) and Transcranial Doppler (TCD) ultrasonography with neuropsychological assessment in children with SCD, indicating specific cognitive impairments and general intellectual deficit that tend to predispose to poor academic performance and higher rates of school retention. In Brazil there is a high prevalence of this disease, making it important to conduct studies in children, since early diagnosis of neuropsychological difficulties enables preventive interventions and formulation of rehabilitation programs in frames of brain dysfunction. Objective: To characterize the behavioral and neuropsychological performance of children with SCD, in the range 7-12 years. Aims to assess and describe the main cognitive functions (attention / executive function, learning and memory, language, visuospatial processing, sensorimotor function) and possible behavioral difficulties and to correlate these results with clinical and sociodemographic variables. Method: In this study, participated 60 children, also composing two groups of 30 volunteers (clinical and control) matched for sex, age and school origin. Were used as instruments of psychological assessment: IQ Estimate the WISC III and Raven's Coloured Progressive Matrices, NEPSY II - Neuropsychological Development and Child Behavior Checklist (CBCL). The Clinical Group conducted clinical neurological examination, MRI, TCD and blood count. Results: Children with SCD in neuropsychological profile showed impairments in general intellectual functioning and deficits in several specific neuropsychological domains, especially executive function, language, visuospatial memory and visuospatial skills compared to the Control Group. In medical examinationof Clinical Group, all TCD were considered within the normal range and prevalence of MRI was $24 \%$ of the sample with silent cerebral infarction (ICS). The impairment in general intellectual ability, narrative and visuospatial memory and phonological processing were more significant in the Group with ICS. These diverse neuropsychological deficits in Clinical Group tend to predispose to difficulties in academic performance and increased school failure. Furthermore, there was evidence of significant levels of behavioral and emotional problems in children with SCD. Observed cognitive decline in various neuropsychological functions with increasing chronologic age, but it has not shown the influence of variables such as gender,iables such as gender, genetic type, type of medication and the blood count indices in neuropsychological and behavioral outcomes in these children. These results provide relevant implications for the treatment of patients with SCD, because it emphasizes the importance of multidisciplinary monitoring and the need to conduct neuropsychological assessment and adequate intervention in rehabilitation centers with the aim of promoting a better quality of life and favorable conditions for the development of these children. (CAPES e FAPESP).
\end{abstract}

Keywords: Sickle cell disease; Child; Neuropsychological assessment; Behavior assessment; NEPSY II. 



\section{LISTA DE TABELAS}

Tabela 1 - Distribuição dos participantes por sexo e idade

Tabela 2 - Distribuição do desempenho intelectual no WISC III e Raven nos Grupos Clínico e Controle.

Tabela 3 - Distribuição dos participantes em relação ao desempenho escolar...... Tabela 4 - Distribuição dos Grupos Clínicos e Controle em função do NSE e escolaridade dos pais.

Tabela 5 - WISC III e Raven: Comparação entre os Grupos Clínico e Controle..

Tabela 6 - NEPSY II: Comparação entre os Grupos Clínico e Controle nas diferentes funções neuropsicológicas.

Tabela 7 - Análise de Regressão Logística Multivariada entre os Grupos Clínico e Controle com variáveis sociodemográficas

Tabela 8 - Resultados da Análise de Regressão Logística Multivariada entre os Grupos Clínico e Controle após correção do modelo em função da escolaridade da mãe e do NSE.

Tabela 9 - WISC III e Raven: Comparação entre as faixas etárias de 7-9 anos e 10-12 anos nos Grupos Clínico e Controle.

Tabela 10 - WISC III e Raven: Correlação com a idade (7 - 12 anos) nos Grupos Clínico e Controle

Tabela 11 - NEPSY II: Comparação entre 7-9 anos e 10-12 anos nos Grupos Clínico e Controle

Tabela 12 - NEPSY II: Correlação dos testes neuropsicoló gicos com a idade (7 - 12 anos) nos Grupos Clínico e Controle

Tabela 13 - WISC III e Raven: Comparação entre os Grupos Clínico e Controle em função do sexo

Tabela 14 - NEPSY II: Comparação entre os Grupos Clínico e Controle em função do sexo

Tabela 15 - WISC III e Raven: Comparação entre os subgrupos genéticos da amostra clínica

Tabela 16 - NEPSY II: Comparação entre os subgrupos genéticos da amostra clínica

Tabela 17 - Distribuição (em frequência simples e porcentagem) dos informantes do CBCL dos Grupos Clínico e Controle

Tabela 18 - Comparação dos problemas comportamentais do CBCL entre os Grupos Clínico e Controle

Tabela 19 - Comparação da frequência dos casos "clínicos" identificados no CBCL nos Grupos Clínico e Controle

Tabela 20 - Variáveis sociodemógrafica, escolares e clínicas do Grupo Clínico: Comparação entre subgrupos IRM normal e ICS

Tabela 21 - Hemograma do Grupo Clínico: Comparação entre subgrupos IRM normale ICS

Tabela 22 - WISC III e Raven do Grupo Clínico: Comparação entre subgrupos IRM normal e ICS

Tabela 23 - Classificação intelectual do Grupo Clínico a partir do QI Estimado do WISC III e do Raven: Comparação entre subgrupos IRM normal e ICS 



\section{LISTA DE SIGLAS}

ABAS Artéria basilar

ABEP

Associação Brasileira de Empresas de Pesquisa

ACA

Artéria cerebral anterior

$\mathrm{ACI}$

Artéria carótida interna

$\mathrm{ACM}$

Artéria cerebral média

$\mathrm{ACP}$

Artéria cerebral posterior

$\mathrm{ADM}$

Assessment Data Manager

$\mathrm{AF}$

Anemia falciforme

AngioRM Angiografia por ressonância magnética

APA

American Psychological Association

AVC

Acidente vascular cerebral

AVC-I Acidente vascular cerebral isquêmico

CBCL Child Behavior Checklist

CFP Conselho Federal de Psicologia

CONEP Conselho Nacional de Ética em Pesquisa

CSSCD Cooperative Study of Sickle Cell Disease

DF Doença falciforme

DP Des vio Padrão

DTC Doppler transcraniano

EF Ensino Fundamental

Estat. Estatística

FFCLRP Faculdade de Filosofia, Ciências e Letras de Ribeirão Preto

FMRP Faculdade de Medicina de Ribeirão Preto

$\mathrm{Hb} \quad$ Hemoglobina

HPLC Cromatografia líquida de alta resolução

Ht Hematócrito

HU Hidroxiureia

ICS Infarto cerebral silencioso

IDH Índice de Desenvolvimento Humano

IEF Eletroforese por focalização isoelétrica

IRM Imagem por ressonância magnética

IRMf Imagem por ressonância magnética funcional

MS Ministério da Saúde

NEPSY II NEPSY II: Avaliação Neuropsicoló gica do Desenvolvimento

NSE Nível socioeconômico

PCR Parada cardiorrespiratória

QI Quociente de inteligência

Raven Matrizes Progressivas Coloridas de Raven - Escala Especial

SATEPSI Sistema de Avaliação de Testes Psicológicos 


$\begin{array}{ll}\text { SM } & \text { Sensoriomotor } \\ \text { SNC } & \text { Sistema nervoso central } \\ \text { SPSS } & \text { Statistical Package for Social Sciences } \\ \text { TCE } & \text { Traumatismo cranioencefálico } \\ \text { TDAH } & \text { Transtorno do Déficit de Atenção/ Hiperatividade } \\ \text { Teste } \rho & \text { Teste de correlação de Spearman } \\ \text { Teste F } & \text { Teste Exato de Fisher } \\ \text { Teste } t & \text { Teste } t \text { de Student } \\ \text { Teste } U & \text { Teste } U \text { de Mann-Whitney } \\ \text { Teste } \chi^{2} & \text { Teste do Qui-dradrado } \\ \text { UFBA } & \text { Universidade Federal da Bahia } \\ \text { UNIFESP } & \text { Universidade Federal de São Paulo } \\ \text { USP } & \text { Universidade de São Paulo } \\ \text { VE } & \text { Visoespacial } \\ \text { VFSC } & \text { Velocidade do fluxo sanguíneo cerebral } \\ \text { WISC III } & \text { Escala de Inteligência Wechs ler para Crianças } \\ \text { WPPSI } & \text { Wechsler Preschool }\end{array}$




\section{SUMÁRIO}

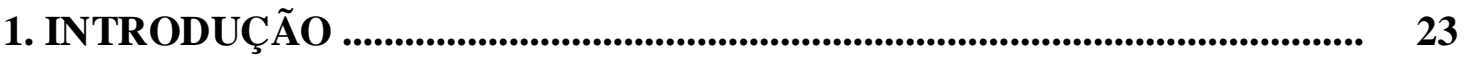

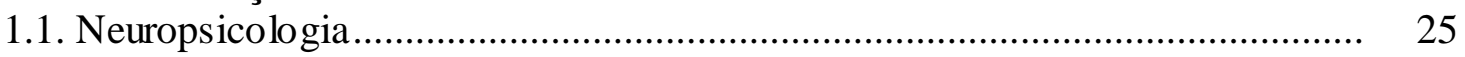

1.1.1.Avaliação ne uropsicoló gica..................................................................... 26

1.1.2. Avaliação ne uropsicológica infantil....................................................... 28

1.1.3. Instrumentos de avaliação neuropsicoló gica para crianças.......................... 31

1.2. NEPSY II: Avaliação Neuropsicoló gica do Desenvolvimento ........................ 34

1.3. Doença falciforme ..................................................................................... 37

1.3.1. Doença falciforme e avaliação neuropsicológica infantil............................ 39

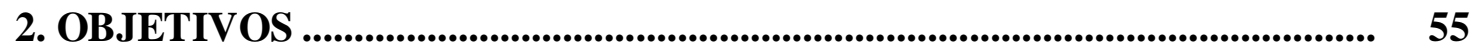

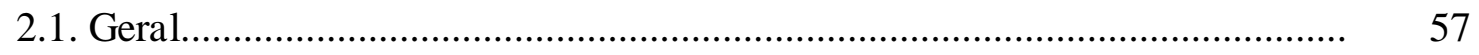

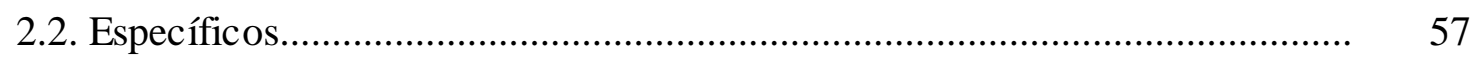

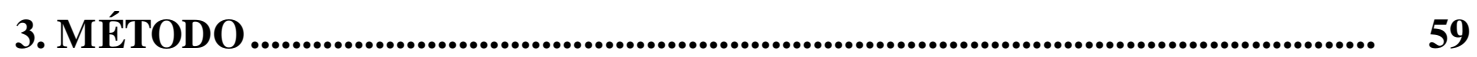

3.1. Participantes ......................................................................................... 61

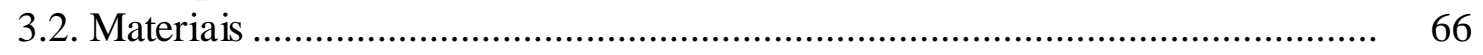

3.2.1. Instrumentos de avaliação psicológica..................................................... 66

3.2.2. Instrumentos de avaliação sociodemo gráfica.......................................... $\quad 70$

3.2.3. Exames médicos.............................................................................. $\quad 70$

3.3. Procedimentos ........................................................................................ $\quad 72$

3.3.1. Cuidados éticos e coleta de dados........................................................ $\quad 72$

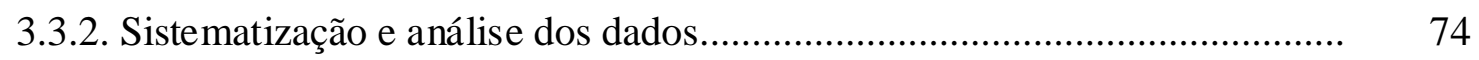

4. RESULTADOS ................................................................................................... 77

4.1. Relativos aos testes neuropsicológicos......................................................... 79

4.2. Relativos à avaliação do comportamento...................................................... 92

4.3. Relativos aos exames médicos do Grupo Clínico......................................... 94

5. DISCUSSÃ O............................................................................................... 101

6. CONSIDERAÇÕES FINAIS ............................................................................ 113

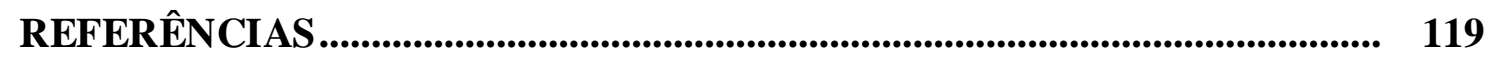

ANEXOS............................................................. 133

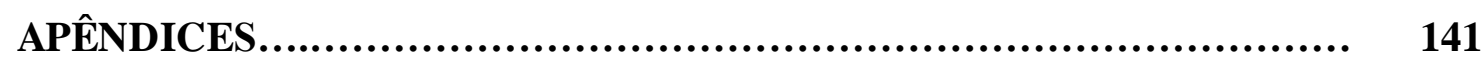



1. INTRODUÇÃO 


\subsection{Neuropsicologia}

A Neuropsicologia constitui-se como disciplina científica que estuda relações entre cérebro, cognição e comportamento diante de condições normais ou patológicas. Busca compreender como o sistema nervoso central (SNC) modula os diferentes processos mentais, tais como inteligência, atenção, função executiva, memória e aprendizagem, linguagem, habilidades acadêmicas como aritmética, leitura e escrita, percepção, função visoespacial e visoconstrutiva, função sensoriomotora, comportamentos manifestos, expressão emocional e características de personalidade (Lezak, Howieson, \& Loring, 2004; Cosenza, Fuentes, \& Malloy-Diniz, 2008).

O estudo inicial das relações cérebro e comportamento, que fundou o campo de atuação da neuropsicologia, buscava topografar áreas cerebrais envolvidas em diferentes e específicas funções cognitivas, mas sofreu importantes mudanças. Com os avanços das técnicas de neuroimagem que permitem localizar as lesões e disfunções mais sutis, foi necessário reestruturar seu foco de investigação (Camargo, Bolognani, \& Zuccolo, 2008). Passou-se a ter maior interesse na compreensão do processo de desenvolvimento e da emergência de distúrbios cognitivos, emocionais, comportamentais e de personalidade diante de alterações cerebrais decorrentes de alguma patologia, levando em consideração as influências de fatores genéticos e ambientais (Ciasca, Guimarães, \& Tabaquim, 2005; Malloy-Diniz, Fuentes, Mattos, Abreu et al., 2010; Miranda, 2005).

Essas manifestações cognitivas e comportamentais podem ser decorrentes de diversas doenças que atingem primária ou secundariamente o SNC, tais como traumatismo cranioencefálicos (TCE), patologias vasculares, desordens neurodegenerativas como demências e esclerose múltipla, processos infecciosos, hipoxemia, intoxicação, tumor cerebral, doenças endócrinas e metabólicas, epilepsia, transtornos do desenvolvimento e psiquiátricos, dentre outros. As manifestações podem ocorrer em períodos distintos na evolução da patologia, como na fase aguda, no decorrer da evolução dessa patologia, durante seu tratamento, ou do próprio processo de desenvolvimento humano (Lezak et al., 2004).

Haase et al. (2008) apresentaram quatro etapas no processo de diagnóstico neuropsicológico. A primeira seria a do diagnóstico funcional que consiste em descrever sinais e sintomas de forma funcional, eventualmente caracterizando uma síndrome, e enfatizar possíveis dissociações entre funções cognitivas comprometidas e preservadas. A segunda etapa é o diagnóstico topográfico: o neuropsicólogo localiza o déficit funcional identificado num modelo cognitivo e, a seguir, correlaciona-o à localização lesional, baseado em modelos 
de estrutura anatomofuncional do cérebro e mente. O diagnóstico nosoló gico que correlaciona o padrão de associação ou dissociação funcional com a etiologia, prognóstico ou resposta ao tratamento clínico constitui a terceira etapa. Por fim, ocorre o diagnóstico ecológico que visa avaliar o impacto dos transtornos sobre o funcionamento adaptativo psicossocial do paciente em termos de suas percepções sobre a qualidade de vida e participação familiar, social, profissional ou acadêmica.

No Brasil, o desenvolvimento da Neuropsicologia cristalizou-se a partir da última década do século passado, sendo oficialmente reconhecida como importante área de pesquisa e prática clínica com a fundação da Sociedade Brasileira de Neuropsicologia em 1989 (Camargo, 2008). Desde então, observa-se rápido avanço do conhecimento científico nessa área, com esforços de diferentes centros de pesquisa em todo o país.

A partir dessa crescente valorização da Neuropsicologia, o Conselho Federal de Psicologia (CFP), por meio da Resolução 002/2004, reconheceu essa área de conhecimento como especialidade da Psicologia. Por meio dessa resolução regulamentou como dever do neuropsicólogo atuar no diagnóstico, no acompanhamento, no tratamento e na pesquisa da cognição, emoção, comportamento e personalidade, e na relação destes com o funcionamento cerebral. Para realização efetiva do seu trabalho, o neuropsicólogo deve utilizar diferentes métodos de avaliação psicológica, tema a seguir abordado.

\subsubsection{Avaliação Neuropsicológica}

A avaliação neuropsicológica refere-se a um processo de avaliação psicológica que focaliza métodos de exame do funcionamento cerebral por meio de comportamentos manifestos em tarefas propostas. O processo de diagnóstico neuropsicológico segue diferentes etapas, iniciando-se com uma entrevista clínica onde o histórico do paciente deve ser investigado. Essas informações serão essenciais para a análise dos resultados e interpretação do impacto cognitivo das doenças neurológicas. A estimativa do funcionamento pré-mórbido, nos casos de lesões cerebrais adquiridas, é fundamental para relacionar com o desempenho atual e chegar a conclusões sobre possível declínio ou alteração cognitiva (Mader-Joaquim, 2010).

A partir da entrevista inicial são estabelecidas as demandas do paciente ou do profissional que solicitou a avaliação. Lezak et al. (2004) definem seis objetivos principais para a realização do exame neuropsicológico: 1) diagnóstico; 2) cuidados e orientações ao paciente; 
3) planejamento de tratamento; 4) avaliação do tratamento; 5) pesquisa; e 6) questões forenses, descritos a seguir.

No tocante ao objetivo diagnóstico, a avaliação neuropsicológica constitui importante recurso para diferenciar sintomas psiquiátricos e neurológicos, identificar possível desordem neurológica em pacientes não psiquiátricos, distinguir condições neurológicas e prover dados sobre a localização da lesão ou disfunção cerebral. Embora tenha ocorrido diminuição da utilização da Neuropsicologia como ferramenta para auxiliar no diagnóstico clínico, em decorrência do desenvolvimento das técnicas de neuroimagens e exames laboratoriais, existem certas condições neuropatológicas (tais como encepalopatia, processo demencial, TCE leve e transtorno do desenvolvimento) que não são facilmente detectáveis por meio dessas técnicas, sendo essencial a avaliação neuropsicológica. Ademais, apesar dos exames de neuroimagem poderem detectar a localização e a extensão da lesão cerebral, não conseguem evidenciar as consequências comportamentais e cognitivas decorrentes da mesma, além de existirem pacientes com achados de lesões neuroanatômicas que são inconsistentes com a avaliação cognitiva.

Em relação aos cuidados e orientações ao paciente, na investigação neuropsicológica obtém-se dados sobre funções cognitivas e emocionais, alterações comportamentais e características de personalidade, sendo possível compreender melhor capacidades e limitações desse indivíduo. Em posse dessas informações, pode-se orientar o paciente sobre atividades de vida diária e de vida prática que tem potencial para realizar, bem como apontar eventual necessidade de reestruturações ambientais para maior nível de independência funcional e qualidade de vida.

Por meio do exame neuropsicológico é possível estabelecer um plano de tratamento adequado a cada paciente. Para formular o programa de reabilitação, é fundamental basear-se nas limitações e nas potencialidades do indivíduo. Novas avaliações devem ser realizadas com intuito de analisar o tratamento inicial e as mudanças dele decorrentes, verificando o alcance dos objetivos inicialmente propostos e a necessidade de reformular o programa de reabilitação.

No que diz respeito à avaliação do tratamento, o exame neuropsicológico pode evidenciar os efeitos positivos e negativos de tratamentos cirúrgicos e testar a eficácia ou efeitos colaterais de uma medicação. $\mathrm{Na}$ pesquisa, as técnicas de mensuração neuropsicológica podem se constituir como ferramentas valiosas para estudar alterações cognitivo-comportamentais subjacentes a patologias cerebrais, contribuindo também na prática clínica. 
Finalizando as considerações relativas aos objetivos postulados por Lezak et al. (2004) para a avaliação neuropsicológica, tem-se a possibilidade de sua aplicação em questões forenses. Esta pode ser solicitada em processos legais envolvendo danos corporais e perda funcional em casos associados à lesão cerebral. Já em casos criminais, o réu pode ser avaliado quando há suspeita de que a disfunção cerebral pode ter contribuído para o delito cometido ou quando há questionamento sobre a capacidade mental do sujeito.

A partir dessas premissas, Mader-Joaquim (2010) orienta o profissional a selecionar técnicas adequadas às questões a serem respondidas, em função das hipóteses sobre o distúrbio do paciente, levantadas a partir da entrevista inicial e de procedimentos diagnósticos de outros profissionais (Seabra, Macedo \& Capovilla, 2012). Essas informações irão definir as áreas de investigação, estabelecendo prioridades e fundamentando a seleção de estratégias a serem utilizadas (Cunha, 2000). Geralmente, o examinador inicia a avaliação com uma bateria neuropsicológica que investiga as principais funções cognitivas. Posteriormente, podem ser introduzidos demais instrumentos específicos e refinados, a depender do desempenho inicial do paciente (Seabra et al., 2012).

A interpretação dos instrumentos utilizados deve considerar os resultados quantitativos, os aspectos qualitativos da avaliação e devem ser inter-relacionados com as informações da história clínica, da história pessoal e de outros dados relevantes apontados durante a entrevista e no decorrer das avaliações (Cunha, 2000). Esses resultados precisam ser comunicados ao paciente e aos familiares, numa entrevista de devolução. As alterações observadas devem ser traduzidas em exemplos das situações práticas, e oferecidas orientações e indicações para acompanhamento profissional, nos casos em que se fizer necessário (Cunha, 2000; MaderJoaquim, 2010).

Por fim, o relatório da avaliação é o resultado final do processo de avaliação, e a abertura das orientações para a reabilitação. Este constitui meio de comunicação oficial que responde à demanda inicial e pode ter diversos desdobramentos. No relatório, deve-se incluir a descrição e a interpretação das eventuais alterações cognitivo-comportamentais. Convém incluir comentários sobre a condição do paciente de exercer suas atividades escolares, ocupacionais ou necessidade de atendimento especial (Mader-Joaquim, 2010).

\subsubsection{Avaliação neuropsicológica infantil}

A avaliação neuropsicológica voltada para a infância possui objetivos específicos, visto que a criança se encontra em processo de formação, e suas funções cognitivas estão em franco 
desenvolvimento. De acordo com Simões (2002), deve-se considerar a perspectiva desenvolvimental nesse domínio, pois o conhecimento do desenvolvimento normal e patológico é fundamental para distinguir entre atraso (no aparecimento de uma capacidade cognitiva ou na aquisição de uma função) e uma perturbação neurodesenvolvimental (quando se verifica uma alteração da própria organização das etapas de aquisição das funções).

Simões (2002) ressalta, que devido à própria natureza do desenvolvimento da criança, comportamentos que parecem patoló gicos podem ser reabsorvidos com a idade, na medida em que ocorre a maturação das estruturas cerebrais. Para este pesquisador, a avaliação neuropsicológica infantil não teria seu centro de interesse em correlações anatomoclínicas, mas na identificação de funções e processos cognitivos em sofrimento. Isso porque na criança existe maior variabilidade entre o substrato neuroanatômico e as manifestações comportamentais, visto que funções cognitivas podem estar menos lateralizadas e não são tão permanentes na criança mais nova.

As características das alterações estruturais, apesar de importantes, devem ser analisadas com cautela, já que um dano estrutural no cérebro infantil pode não corresponder ao comprometimento funcional esperado em um adulto. Essa modificação nas tradicionais correlações estrutura e função pode estar associada ao mecanismo da prioridade funcional na reorganização cerebral, ou seja, algumas funções cognitivas como a linguagem, diante de uma lesão cerebral precoce, são preferencialmente preservadas em detrimento de outras funções. Além disso, o potencial para adaptação e plasticidade do cérebro é acentuado na infância (Ferreira, Coutinho, Freitas, Malloy-Diniz, \& Haase, 2010).

O diagnóstico infantil precoce de ordem ne uropsicológica é fundamental para formular tratamentos visando aumentar a probabilidade de recuperação funcional do cérebro e promoção da reestruturação da organização cerebral e da plasticidade neuronal (Ferreira et al., 2010). Apresenta papel preventivo para a criança não desenvolver dificuldades em outras etapas da vida. A partir do exame neuropsicológico é possível, por exemplo, oferecer orientações aos professores sobre estratégias de ensino que favoreçam a aprendizagem da criança, compensando as dificuldades. A intervenção precoce visa minimizar consequências no desenvolvimento cognitivo, emocional e social da criança (Costa, Azambuja, Portuguez \& Costa, 2004).

A avaliação neuropsicológica infantil constitui num processo que implica na investigação do comportamento da criança e fatores ambientais, por meio de entrevista, questionários e testes psicológicos adequados. É importante averiguar variáveis que possam ter implicações na organização cerebral infantil, como história de vida, contexto psicossocial 
(fatores familiares, educacionais e socioeconômicos), características físicas, gênero, fase do desenvolvimento e possíveis danos cerebrais, especificando sua extensão, localização e tempo de lesão (Capovilla, 2007; Cunha, 2000; Ferreira et al., 2010).

Os instrumentos a serem utilizados devem obter visão geral das funções cognitivas e respeitar as características do indivíduo, nível de escolaridade e contexto socioeconômico e cultural ao qual pertence (Cunha, 2000; Miranda, 2005). Lefévre (2004) ressalta que os testes neuropsicológicos devem abranger a avaliação das funções cognitivas de acordo com o processo maturacional do cérebro, uma vez que a criança em desenvolvimento expressa ampla variação comportamental e que a metodologia utilizada variará conforme a idade da criança e analisada de forma quantitativa e qualitativa. Os resultados dos instrumentos devem ser interpretados à luz das etapas de desenvolvimento correspondentes a cada faixa etária (Costa et al., 2004).

Para conduzir de maneira apropriada essa investigação é importante realizar uma observação detalhada das respostas gerais do paciente diante da prova e da situação da avaliação. Deve-se efetuar o registro qualitativo da responsividade do paciente, reconhecimentos dos próprios erros, respostas emocionais e características de execução das tarefas (Capovilla, 2007; Seabra et al., 2012). Precisa existir, por parte do examinador, a compreensão de que os protocolos de avaliação neuropsicológica não devem ser estáticos, visto que função ou disfunção cognitiva pode se expressar em vários contextos em que se desenvolve, como, por exemplo, refletir fatores culturais, familiares, escolares e do desenvolvimento cerebral (Miranda, Borges \& Rocca, 2010).

Visando a adequada avaliação das funções neuropsicológicas infantis é preciso dispor de instrumentos precisos, validados e normatizados para essa população. No Brasil, pesquisadores e clínicos se deparam com uma carência de testes psicológicos desenvolvidos e padronizados para o contexto sociocultural e linguístico do país, levando a prejuízo e limitação do uso adequado de instrumentos sistematizados para auxiliarem no diagnóstico neuropsicológico (Fonseca et al., 2008; Seabra et al., 2012).

Diante desse contexto, o CFP por meio da Resolução 002/2003, buscou regulamentar a elaboração, o uso e a comercialização de testes psicológicos. Esta resolução visa avaliar a qualidade técnica dos testes psicológicos por meio do estabelecimento de alguns requisitos obrigatórios como fundamentação teórica, validade e precisão (propriedades psicométricas do instrumento), sistema de aplicação, interpretação e correção dos escores, reunindo todas essas informações em um manual. O CFP criou também o Sistema de Avaliação dos Testes Psicológicos (SATEPSI) com objetivo de sistematizar e divulgar informações sobre a 
avaliação dos testes psicológicos, incluindo dados relativos aos instrumentos considerados favoráveis para uso no país. Esse sistema tornou-se um importante auxílio ao psicólogo para consultar a adequação psicométrica e científica de instrumentos psicológicos a serem utilizados na sua prática clínica.

\subsubsection{Instrumentos de avaliação neuropsicológica para crianças}

De acordo com Ferreira et al. (2010), a avaliação neuropsicológica infantil pode se constituir em um grande desafio, vista a escassez de instrumentos atuais disponíveis para a atuação do neuropsicólogo no Brasil. Em pesquisa realizada em Novembro de 2012, foram encontrados 15 testes psicológicos considerados favoráveis no SATEPSI (CFP, 2012) e que contribuem para o exame neuropsicológico em crianças, avaliando específicos domínios cognitivos. Para avaliação da inteligência geral encontram-se disponíveis: Escala de Maturidade Mental Colúmbia - CMMS (Alves \& Duarte, 2001), DFH - Desenho da Figura Humana - Escala Sisto (Sisto, 2005), Matrizes Progressivas Coloridas de Raven - Escala Especial (Angelini, Alves, Custódio \& Duarte, 1999), TEI- Teste Equicultural de Inteligência (Andrade \& Alves, 2002), TIG-NV - Teste de Inteligência Geral Não Verbal (Tosi, 2006), TNVRI - Teste Não Verbal de Raciocínio para Crianças (Pasquali, 2005), TONI-3 (Forma A) -Teste de Inteligência Não Verbal (Santos, Noronha \& Sisto, 2006), R2 -Teste Não Verbal de Inteligência para Crianças (Rosa \& Alves, 2000), RIn -Teste de Raciocínio Inferencial (Sisto, 2007), WISC III - Escala de Inteligência Wechsler para Crianças (Figueiredo, 2002). Referente à avaliação da atenção consta o Teste D2 de Atenção Concentrada (Bittencourt, 2000). Para função executiva, o Teste Wisconsin de Classificação de Cartas (Cunha et al., 2004). Na investigação de memória é possível utilizar o teste de reprodução de memória das Figuras Complexas de Rey (Oliveira \& Rigoni, 2008). Como instrumentos da percepção visual e visoconstrução, o B-SPG - Teste Gestáltico Visomotor de Bender - Sistema de pontuação gradual (Sisto, Noronha \& Santos, 2006) e teste de cópia das Figuras Complexas de Rey (Oliveira \& Rigoni, 2008). Na avaliação de lateralidade e orientação direita-esquerda existe a Bateria Piaget-Head (Toni, 2006).

É possível constatar a existência de poucos instrumentos neuropsicológicos disponíveis no país voltados para a faixa etária infantil, apesar dos grandes avanços observados na Neuropsicologia nos últimos anos e da criação de diferentes instrumentos de avaliação psicológica em outros países. Ferreira et al. (2010) e Miranda (2005) relatam que foram realizados poucos estudos de validação e normatização de testes psicológicos para a 
população brasileira, limitando a pesquisa e a prática clínica em neuropsicologia infantil. Muitas vezes os testes utilizados nessa área são simplesmente traduzidos, não respeitando critérios técnicos adequados.

Vale ressaltar, que alguns grupos de pesquisa em diferentes regiões no país vêm reunindo esforços para construir ou padronizar instrumentos neuropsicológicos para avaliações de algumas funções cognitivas específicas. Capovilla (2007), Malloy-Diniz et al. (2010) e Hutz (2012) relacionam alguns instrumentos em fase de pesquisa no contexto brasileiro que abrangem a faixa etária infantil.

$\mathrm{Na}$ avaliação de memória destacam: Teste de Aprendizagem Auditivo-Verbal de Rey RAVTL (Oliveira e Charchat-Fichman, 2008) que avalia memória recente e de reconhecimento, aprendizagem e suscetibilidade a interferências. Para memória operacional e esboço visoespacial, os Blocos de Corsi (Miranda et al., 2007). A Bateria Memo (Abreu \& Mello, 2008) examina o uso de estratégias de categorização em memória de curta e longa duração.

Para atenção vem sendo desenvolvidos estudos com os seguintes instrumentos: Teste de Atenção por Cancelamento (Montiel \& Capovilla, 2006a) avalia atenção seletiva e alternada; Teste de Trilhas - Partes A e B (Montiel \& Capovilla, 2006b) investiga manutenção da atenção e capacidade de alternar entre estímulos relevantes; Teste de Atenção Visual -TAVIS3 (Coutinho, Mattos, Araújo, Borges \& Alfano, 2008) avalia atenção visual seletiva, alternada e sustentada; Conner's Continuous Performance Test - CPT (Miranda, Sinners, Pompeia \& Bueno, 2008) examina a sustentação da atenção e controle inibitório.

$\mathrm{Na}$ avaliação das funções executivas são destacados: Teste de Stroop (Capovilla, Montiel, Macedo, \& Capovilla, 2005) investiga atenção seletiva, flexibilidade mental e controle inibitório; Teste da Torre de Londres (Malloy-Diniz et al., 2008) e Torre de Hanói (Gonsalez, Rocca, Malloy-Diniz \& Rodrigues, 2005) avaliam planejamento e solução de problemas; Children Gambling Task (Mata et al., 2010) verifica estágios iniciais do processo de tomada de decisões; Matching Familiar Figures Test 20 - MFFT-20 (Rodrigues, Rocca \& Fuentes, 2010) avalia reflexibilidade e impulsividade.

Os testes desenvolvidos para avaliação de linguagem são: Lista de Avaliação de Vocabulário Expressivo (Capovilla \& Capovilla, 1998) verifica a linguagem oral expressiva; Teste Informatizado de Nomeação de Figuras por Escolha (Capovilla et al., 2004b) examina a capacidade de nomeação; Teste de Fluência Verbal - FAS (Capovilla, 2007) avalia a fluência verbal fonológica; Teste de Vocabulário por Imagens Peabody (Capovilla \& Capovilla, 1998), Token Test (Malloy-Diniz et al., 2007) e Bateria Informatizada de Linguagem Oral - BILOv3 
(Joly, 2009) avaliam a compreensão verbal; Avaliação Neuropsicológica do Processamento Lexical para Crianças - BANPLE (Freitas, 2010) investiga o processamento lexical.

Os instrumentos para avaliação da leitura e escrita e processos afins como Prova de Consciência Fonológica (Capovilla \& Capovilla, 1998) e Sintática (Capovilla \& Capovilla, 2006) e Teste de Consciência Fonológica são: Instrumento de Avaliação Sequencial CONFIAS (Moojen et al., 2003); Teste de Competência de Leitura de Palavras e Pseudopalavras TCLPP (Seabra \& Capovilla, 2010); Teste de Competência de Leitura de Sentenças (Capovilla et al., 2004a); Protocolo Cognitivo-Linguístico - PACL (Capellini \& Smythe, 2008); Prova de avaliação dos processos de leitura -PROLEC (Capellini, Oliveira \& Cuetos, 2010); Bateria de avaliação de habilidades cognitivas preditoras da leitura; Teste de Desempenho Escolar - TDE (Stein, 1994).

Para o processamento visoespacial existem: Teste de Organização Visual Hooper (Tosello, 2005) e Teste de Avaliação de Habilidade Visoespacial -TAHLVES (Alves, Morávia, Campos, Paula, \& Malloy-Diniz, 2010) que avaliam a capacidade de análise e síntese visoespacial, rotação mental e reorganização conceitual; e o Teste Imagética Baby (Lopes, Capovilla, Berberian, Capovilla \& Macedo, 2006).

Esses instrumentos de avaliação psicológica têm sido pesquisados em suas possíveis aplicações no campo da neuropsicologia, sobretudo na área infantil. No entanto, em muitos casos esses trabalhos encontram-se restritos em específicas instituições de pesquisa, vinculados a demandas inerentes da prática clínica desses centros. Mader-Joaquim (2010) ressalta que as questões culturais e educacionais merecem atenção especial nessa área. Refere que, apesar da unidade da língua em todo o Brasil, existe imensa diversidade cultural e importantes diferenças educacionais relacionadas às condições econômicas, já que áreas economicamente bem desenvolvidas dos grandes centros contrastam com regiões extremamente pobres. Nessa perspectiva, o intercâmbio científico entre pesquisadores brasileiros desta área, procurando-se examinar os instrumentos de avaliação neuropsicológica em diferentes contextos socioculturais, torna-se uma necessidade diante da dimensão territorial brasileira. 


\subsection{NEPSY II: Avaliação Neuropsicológica do Desenvolvimento}

Entre as pesquisas na área de avaliação neuropsicológica infantil na população brasileira, destaca-se o estudo em andamento com a bateria NEPSY II: Avaliação Neuropsicológica do Desenvolvimento, originalmente publicado por Korkman, Kirk e Kemp (2007). Esse teste encontra-se em processo de validação no Brasil, já traduzido e adaptado, e atualmente, em fase de coleta de dados para normatização, sendo o estudo coordenado no Brasil por Argollo (2010) da Universidade Federal da Bahia (UFBA) em parceria com a Universidade Federal de São Paulo (UNIFESP).

O NEPSY II é uma bateria de testes neuropsicológicos que avalia crianças e adolescentes entre 3 a 16 anos de idade, sendo a primeira edição desse instrumento publicada em 1998 (Korkman, Kirk \& Kemp, 1998). A segunda edição do NEPSY foi formulada para avaliar seis domínios cognitivos: atenção/função executiva, aprendizagem/memória, linguagem, percepção social, processamento visoespacial, e sensoriomotor. Esse instrumento encontra-se descrito detalhadamente no tópico relativo a "materiais".

A fundamentação teórica do NEPSY é baseada no pensamento luriano, pressupondo que o sistema cerebral trabalha em conjunto para gerir funções cognitivas complexas, sendo necessário incorporar, na administração e interpretação dos testes, flexibilidade e aspectos qualitativos. Foi construído e normatizado para avaliar o desenvolvimento neuropsicológico infantil, apresentando quatro aplicações principais: a) detectar possíveis déficits individuais que interferem na aprendizagem; b) avaliar lesão e disfunções cerebrais, sua extensão no desenvolvimento e funcionalidade dos domínios cognitivos; c) proporcionar aos pesquisadores e clínicos indicadores que possibilitem acompanhar, longitudinalmente, os pacientes para identificar e clarificar a dinâmica do desenvolvimento de tipos específicos de lesões ou disfunções cerebrais; d) constituir-se como instrumento válido e fidedigno para avaliar o desenvolvimento neuropsicológico infantil normal e atípico (Ahmad \& Warriner, 2001).

O NEPSY II constitui importante instrumento na avaliação neuropsicológic a infantil, pois abrange diversas funções cognitivas, permite flexibilidade de aplicação e oferece dados quantitativos e qualitativos. A utilização de uma bateria neuropsicológica que avalia uma larga faixa etária pediátrica possibilita realizar avaliações repetidas em intervalos regulares de tempo. Essas diferentes avaliações promovem dados objetivos e confiáveis sobre o desenvolvimento do processo cognitivo e permite acompanhar o curso de uma desordem cerebral, auxiliando na avaliação de eventual tratamento. As investigações científicas com o 
NEPSY II podem ainda estabelecer paralelos entre diversos grupos clínicos, permitindo análise comparativa com evidências da literatura internacional. No entanto, por ser um instrumento recente no Brasil, fazem-se necessários diversos estudos para avaliar sua adequação técnica e na prática clínica, sobretudo relativa às possibilidades de aplicação em tipos específicos de patologias.

Diferentes pesquisas na literatura internacional têm utilizado o NEPSY na a valiação neuropsicológica de diversos grupos clínicos. No estudo com 172 crianças ex-prematuras extremas com idade média de cinco anos, Mikkola et al. (2005) utilizaram os instrumentos Wechsler Preschool (WPPSI) e NEPSY. Foram identificados resultados de Quociente de inteligência (QI) geral, verbal e de execução na média, porém abaixo do Grupo Controle. Todos os domínios cognitivos avaliados pelo NEPSY estavam abaixo da média, principalmente as habilidades visoespacial e sensoriomotora. Marlow, Hennessy, Bracewell, Wolke e EPICure Study Group (2007) compararam 180 crianças ex-prematuras (idade média de seis anos) com 160 crianças de desenvolvimento típico, examinando as funções motora e executiva por meio da Kaufman Assessment Battery for Children e o NEPSY. O Grupo Clínico apresentou dificuldade em habilidades motora, visoespacial e perceptomotora, e tendiam a cometer mais erros de omissão e a não finalizar as tarefas de atenção visual e função executiva. Lind et al. (2010) estudaram 97 crianças com 5 anos de idade que nasceram com muito baixo peso $(<1501 \mathrm{~g})$ comparando com 161 controles, por meio WPPSI e NEPSY. O Grupo Clínico tinha capacidade intelectual média, ainda que menor do que o Grupo Controle, e todas as funções neuropsicológicas, com excepção de memória verbal, apresentaram resultados significativamente inferiores.

Perner, Kain e Barchfeld (2002) realizaram investigação com 24 crianças entre 4 a 6 anos de idade, sendo constatada baixa performance no domínio de função executiva/atenção do NEPSY, sinalizando risco para Transtorno do Déficit de Atenção/ Hiperatividade (TDAH). Na pesquisa de Korkman e Pesonen (1994) foram avaliadas 21 crianças com TDAH, 12 com problemas de aprendizagem e $27 \mathrm{com}$ TDAH e problemas de aprendizagem. O grupo com TDAH teve dificuldade em controle e inibição de impulso, enquanto o grupo com problemas de aprendizagem sinalizou dificuldade em processamento fonológico, span de memória verbal e narrativa e QI verbal. O grupo com TDAH e problema de aprendizagem evidenciou dificuldades similares aos grupos anteriores, além de prejuízo na atenção concentrada e problema visomotor.

Crianças com dificuldade de leitura foram avaliadas por Crews e D'Amato (2010) por meio dos subtestes de linguagem e memória/aprendizagem do NEPSY, sugerindo 
envolvimento do processo de memória e não apenas do processo fonológico nessa inabilidade. Em outra pesquisa com 26 surdos submetidos a implante coclear entre 6 e 14 anos, observouse escores na média nos subtestes sensoriomotor e visoespacial do NEPSY e leitura, porém baixo desempenho em compreensão de vocabulário e memória operacional (Fagan, Pisoni, Horn, \& Dillon, 2007).

Joseph, McGrath e Tager-Flusberg (2005) investigaram 37 crianças autistas com QI verbal e não verbal na média comparando-as com 31 crianças saudáveis, procurando avaliar a relação entre função executiva e linguagem. Constatou-se dificuldade em função executiva como planejamento, memória operacional e inibição no grupo de autistas, porém não houve correlação estatisticamente significativa entre função executiva e linguagem. Outro estudo apóia a utilidade de NEPSY II como instrumento sensível para descrever o perfil neuropsicológico de crianças com transtorno do espectro autista de alto funcionamento. Narzisi, Muratori, Calderoni, Fabbro e Urgesi (2012) compararam 22 crianças do Grupo Clínico com 44 crianças saudáveis. Os resultados mostraram que no Grupo Clínico apenas o processamento visuoespacial foi relativamente preservado, enquanto foram observados déficits na atenção/ função executiva, aprendizagem e memória, processamento sensoriomotor e percepção social.

No Brasil, o único estudo clínico publicado com o NEPSY, até o momento, foi realizado por Nunes et al. (2010) com dois casos clínicos de crianças com anemia falciforme. $\mathrm{O}$ primeiro tinha história de acidente vascular cerebral (AVC) com hemiparesia à esquerda, apresentando desempenho intelectual médio inferior, baixo desempenho acadêmico e extenso prejuízo de funções cognitivas como atenção visual, memória operacional, linguagem, flexibilidade cognitiva, habilidades sensoriomotora, visoespacial e visoconstrutiva. O segundo teve ataque isquêmico transitório, constatando-se dispraxia motora e oromotora, diminuição da atenção visual e memória verbal.

Em síntese, pode-se identificar pelos estudos descritos, que a bateria NEPSY tem se mostrado útil e adequada para identificar informações relevantes sobre o funcionamento neuropsicológico em diferentes situações, favorecendo a proposição de intervenções na prática clínica. No entanto, carece de novas investigações científicas de modo a fortalecer suas possibilidades informativas, sobretudo no contexto nacional e em grupos clínicos, razão da atual proposta de pesquisa que focalizará crianças com doença falciforme, patologia a seguir explanada. 


\subsection{Doença falciforme}

A oferta de oxigênio às células é de fundamental importância para o bom funcionamento de todo o organismo, bem como do cérebro. O oxigênio é transportado pela corrente sanguínea, liga-se de modo reversível às hemácias por meio da hemoglobina. Essa é composta do grupo heme e de quatro cadeias de globina (duas unidades $\alpha$ e duas unidades $\beta$ ). A doença falciforme (DF) decorre da mutação do gene da cadeia $\beta$ da hemoglobina, sendo doença hereditária com transmissão autossômica recessiva. As mutações podem ser homozigóticas formando a hemoglobina S (Hb SS), denominada de anemia falciforme (AF), ou heterozigóticas desencadeando as variantes da hemoglobinopatia $\mathrm{SC}(\mathrm{Hb} \mathrm{SC})$ e $\mathrm{S} \beta$ talassemia $(\mathrm{Hb} \mathrm{S} \beta)$ que se divide em $\mathrm{S} \beta+\mathrm{e} \mathrm{S} \beta^{\circ}$.

O diagnóstico normalmente é suscitado ao nascimento por meio de triagem neonatal (teste do pezinho). Inicialmente, eram utilizados dois procedimentos eletroforéticos associados: a eletroforese em acetato de celulose e $\mathrm{pH}$ alcalino, seguida da eletroforese em ágar citrato em $\mathrm{pH}$ ácido. Atualmente, a maioria dos programas de triagem neonatal substituiu os métodos convencionais pela eletroforese por focalização isoelétrica (IEF) e/ou pela cromatografia líquida de alta resolução (HPLC) (Ferraz \& Murao, 2007). Segundo dados do Programa Nacional de Triagem Neonatal (Mistério da Saúde [MS], 2006), estima-se que nasça, por ano no Brasil, cerca de 3.500 crianças com DF, com maior prevalência em negros, pardos e afrodescendentes, principalmente nas regiões Norte e Nordeste (MS, 2010).

$\mathrm{Na} \mathrm{DF}$, a hemácia perde sua capacidade de reversibilidade e de adequar-se ao calibre do vaso sanguíneo e voltar à forma bicôncava, passando a apresentar forma em foice. Essa hemácia falcêmica não realiza o adequado transporte de oxigênio e se torna mais aderente ao endotélio. Esses fatores acarretam destruição prematura das hemácias caracterizada por anemia hemolítica, vaso-oclusão de microvasculatura (crises falcêmicas) que causa isquemia em vários órgãos, e síndrome torácica. O tratamento é determinado por critérios médicos, sendo utilizados como principais fármacos: penicilina benzatina como forma profilática contra infecções; ácido fólico para hematopoiese; hidroxiureia (HU) que constitui um agente indutor da síntese de hemoglobina fetal; e hemotransfusão (MS, 2002, 2010).

Os portadores de DF podem ser subdivididos de acordo com a composição genética e implicações clínicas. Os subtipos genéticos $\mathrm{SS}$ e $\mathrm{S} \beta^{\circ}$ são associados ao maior risco para complicações clínicas precoces, menor nível de hemoglobina, crises de dor mais frequentes e tendem a apresentar mais problemas neurológicos. Assim, esse grupo é denominado de alto 
risco, quando comparado aos subtipos $\mathrm{SC}$ e $\mathrm{S} \beta+$, considerados de baixo risco (Grueneich et al., 2004; Puffer, Schatz \& Roberts, 2010; Schatz, Puffer, Sanchez, Stancil \& Roberts, 2009).

Dentre as complicações associadas à DF ressalta-se o AVC. Estima-se que ocorra em 6\% das crianças com AF (MS, 2006), havendo maior incidência entre 2 a 9 anos e após os 20 anos, levando a diversas sequelas neurológicas e déficits cognitivos (Angulo, 2007). É bem estabelecido na literatura o comprometimento cognitivo decorrente do AVC em crianças com DF, associando-se a baixo funcionamento intelectual geral, verbal e de execução (Wang et al., 2001; Gold, Johnson, Treadwell, Hans \& Vichinsky, 2008), e prejuízos de funções específicas como linguagem (Armstrong et al., 1996), atenção e função executiva (Brown et al., 2000; Nabors \& Freymuth, 2002; Wang et al., 2001), organização perceptiva (Bernaudin et al., 2000), habilidade visomotora (Armstrong et al., 1996; Bernaudin et al., 2000; Gold et al., 2008) e desempenho acadêmico (Nabors \& Freymuth, 2002; Wang et al., 2001; Gold et al., 2008). Entretanto, mesmo na ausência de evidências clínicas para AVC, têm sido mencionadas alterações cognitivas associadas a es se Grupo Clínico.

Estudos utilizando neuroimagem por Ressonância Magnética (IRM) encontraram crianças portadores de DF com alteração nesse exame, mesmo sem his tória prévia de AVC e com exame neurológico normal. A partir desse achado, foi definido pelo Cooperative Study of Sickle Cell Disease - CSSCD (Wang et al., 2001) três grupos principais de crianças com DF baseados nos resultados da IRM: infarto cerebral clínico (AVC), infarto cerebral silencioso (ICS) ou sem infarto (normal). Esse último é constituído por crianças sem alteração na IRM e no exame neurológico. De acordo com Angulo (2007), o ICS é a lesão cerebral mais frequente, ocorrendo na $\mathrm{Hb} \mathrm{SS}$ em $11 \%$ até os 4 anos e $22 \%$ até 14 anos, no $\mathrm{Hb} \mathrm{SC}$ em $6 \%$ e na $\mathrm{S} \beta$ talassemia em $15 \%$ dos casos.

Doppler Transcraniano (DTC) também é usado nas avaliações das crianças com DF. Esse exame consegue predizer maior risco para infarto cerebral, pois detecta estenose cerebrovascular, baseado no aumento da velocidade do fluxo sanguíneo cerebral (VFSC) na artéria estreitada. Em geral, os portadores de DF apresentam aumento da VFSC entre 40-50\%, e quando excede a velocidade de $170 \mathrm{~cm} / \mathrm{seg}$ há maior probabilidade de infarto cerebral. A partir disso, foram estabelecidas orientações técnicas para padronização dos valores do DTC em crianças com DF, considerando-se velocidade normal $<170 \mathrm{~cm} / \mathrm{seg}$, condicional entre 170-200 cm/seg, e anormal > $200 \mathrm{~cm} / \mathrm{seg}$ (Kral \& Brown, 2004). A VFSC é inversamente proporcional ao diâmetro da artéria, valores mais altos estão associados à hipope rfusão na vasculatura distal, ocasionando hipóxia crônica em algumas regiões cerebrais, e por isso é considerada importante preditor do funcionamento cognitivo infantil. 


\subsubsection{Doença falciforme e avaliação neuropsicológica infantil}

Houve crescimento das investigações de crianças com DF na tentativa de caracterizar o perfil neuropsicológico nesse Grupo Clínico. Para caracterizar esse contexto, foi realizada revisão de literatura científica sobre o tema, incluindo estudos transversais e/ou longitudinais, cujo Grupo Clínico envolvesse criança (entre 6 a 12 anos) com DF. Esse levantamento bibliográfico englobou o período entre 1963 e 2013 nas bases de dados PubMed e PsychInfo, utilizando como palavras-chave: "sickle cell disease" AND "child" AND "neuropsychology", "psychometrics", "cognition", "mental processes", "intelligence”, "attention", “executive function", "memory", "language", "visual spatial", "spatial skill”, “motor skill”, "visual motor", "learning", “academic" e "education". Foram excluídas pesquisas com amostra restrita a idade pré-escolar ou adolescência, e aquelas que faziam referência exclusiva às crianças com AVC. Desse modo, foram recuperados 40 artigos científicos, integralmente examinados com a finalidade de se identificar tendências gerais dos estudos e variáveis relevantes para a compreensão e a intervenção junto a crianças com DF.

O tamanho das amostras clínicas teve grande variação de 15 a 222 pacientes, com média de 57 casos. Algumas pesquisas incluiram Grupo Controle $(n=23)$, sendo o tamanho médio dessas amostras composto por 31 crianças, com variação entre 10 a 81 participantes, formados por irmãos (10 estudos), crianças da comunidade (quatro estudos), escolares (quatro estudos), irmãos e colegas (um estudo), filhos de funcionários do hospital (dois estudos) e outros Grupos Clínicos (dois estudos). Ressalta-se que houve justaposição de participantes entre algumas investigações.

Alguns estudos buscaram associação dos resultados neuropsicológicos com exames neurológicos, principalmente IRM estrutural (20 trabalhos) e DTC (6 estudos). Resultados da IRM para definirem grupos mais específicos, sugeriram que a DF em si mesma não tem efeitos significativos no desenvolvimento cognitivo, mas que déficits neuropsicológicos encontrados nesses pacientes sem hitórico evidente de AVC podem se dever à inclusão de indivíduos com ICS (Craft, Schatz, Glauser, Lee, \& DeBaun, 1993). Dessa forma, novas investigações tem sido realizadas com objetivo de comparar esse Grupo Clínico com IRM normale aquelas com ICS.

Foram analisadas 18 investigações científicas que ofereceram dados suficientes para verificar a incidência de ICS por meio da técnica de IRM convencional. As amostras de crianças com DF sem evidência clínica de AVC variaram em termos quantitativos de 15 a 212 participantes, com média de 67 casos. A amostra com ICS teve prevalência média aproximada 
de $24 \%$, variando entre 13 a $67 \%$ nos diferentes estudos. A maioria das lesões estruturais identificadas no ICS foi situada nos lobos frontais, isoladas ou associadas com outras áreas (Scantlebury et al., 2011; Gold et al., 2008), chegando a acometer 90\% desse grupo (Brown et al., 2000). Infartos frontais foram frequentemente associados com lesões nas regiões cerebrais subcorticais, correspondendo a $85 \%$ do ICS encontrados por White et al. (2006) ou relacionados a lesões na substância branca (Schatz, Brown, Pascual, Hsu, \& DeBaun, 2001; Kral et al., 2006). Alguns observaram lesões envolvendo essencialmente a substância branca (Grueneich et al, 2004; Bernaudin et al., 2000). Comprometimentos em outras regiões cerebrais foram menos reportados, como lobo parietal ou lobo occipital (Gold et al., 2008), gânglios da base ou substância branca do lobo parietal (Schatz et al., 2001; Kral et al., 2006) e tálamo (Schatz et al., 2001).

Em relação às pesquisas com DTC, o tamanho das amostras clínicas sem AVC variou entre 25 a 132, com média aproximada de 53 participantes. Cinco estudos ofereceram dados suficientes para averiguar a prevalência de alteração esse exame no Grupo Clínico. Foram classificados como DTC anormal de zero a $48 \%$ da amostra nesses diferentes estudos e como DTC condicional de 6 a 33\% dos participantes (Bernaudin et al., 2000; Kral et al., 2003, 2006; Sanchez, Schatz, \& Roberts, 2010; Hijmans, Grootenhuis et al., 2011). As velocidades patológicas foram identificadas por Kral et al. (2003, 2006), principalmente na artéria cerebral média (ACM) e na artéria carótida interna (ACI). Ruffieux et al. (2013) encontraram alteração também na artéria oftálmica, na artéria cerebral anterior (ACA) e na artéria basilar (ABAS). Nos estudos que utilizaram DTC, foi verificado que alteração da VFSC ocorreu quase que igualmente entre os dois hemisférios cerebrais (Kralet al., 2003; 2006; Ruffieux et al., 2013).

Em relação aos resultados específicos obtidos com os testes neuropsicológicos identificados na presente revisão bibliográfica, serão mencionados a partir dos seguintes domínios cognitivos: inteligência, atenção/função executiva, memória, linguagem, habilidade visoespacial, função sensoriomotora e desempenho acadêmico. Em cada função cognitiva foram descritas as pesquisas com crianças com DF de forma geral e, posteriormente, foram especificadas aquelas que utilizaram dados dos exames neurológicos como IRM e DTC.

\section{- Inteligência}

Quociente Intelectual (QI) total tem sido utilizado como principal medida para avaliar a inteligência, sendo as escalas Wechsler o instrumento mais utilizado nos trabalhos aqui encontrados, correspondendo a 86\% dos estudos que avaliaram esse domínio. Acrescido da informação sobre QI total, alguns autores oferecem dados sobre o QI verbal e de execução. 
Diversos estudos apontam para prejuízo cognitivo generalizado nas crianças com DF quando comparadas ao Grupo Controle (Schatz, Finke, \& Roberts, 2004; Steen et al, 2005; Hijmans, Fijnvandraat et al., 2011; Noll et al., 2001). Esse dano foi descrito como suave por Swift et al. (1989), pois constataram que $19 \%$ dos pacientes tiveram QI total abaixo de 70, apesar de apresentarem diferença média de quase 19 pontos com irmãos saudáveis. Já para Steen, Xiong, Mulhern, Langston e Wang (1999) e Hijmans, Fijnvandraat et al. (2011) a incidência de deficiência mental leve foi maior, aproximadamente 33\%. Puffer et al. (2010) verificaram pontuação cognitiva mais baixa, cerca de 10 pontos, somente no grupo DF de alto risco, não observando discrepância entre o grupo de baixo risco com Grupo Controle. Wasserman, Wilimas, Fairclough, Mulhern e Wang (1991) observaram que os Grupos Clínico e Controle tiveram pontuação abaixo da média normativa em todos os subtestes da escala de inteligência, ainda assim, o QI total foi significativamente menor no grupo DF.

Em referência ao QI verbal e de execução, Swift et al. (1989) e Steen et al. (2003, 2005) verificaram menor desempenho no Grupo Clínico. Por sua vez, Noll et al. (2001) constataram pior desempenho no Grupo Clínico apenas no QI verbal e, Wasserman et al. (1991), apenas no QI de execução.

Divergente dos dados anteriores, três estudos utilizando como Grupo Controle irmãos saudáveis, sugeriram que a DF em si não afeta o funcionamento intelectual, visto que não foi encontrada diferença entre os grupos (Chodorkoff \& Whitten, 1963; Brown et al., 1993; Goonan, Goonan, Brown, Buchanan, \& Eckman, 1994). Alguns autores têm enfatizado que os déficits cognitivos devem-se ao AVC ou ICS freqüentemente associados com DF. Craft et al. (1993) avaliaram crianças com AF com IRM normal, não encontrando evidência de comprometimento neuropsicológico. De forma complementar, Thompson et al. (2003) identificaram que as crianças com ICS ou AVC tiveram escores mais baixos do que o Grupo IRM normal, diminuindo em média, no QI geral, 3,8 pontos para ICS e 14,4 pontos para AVC. Por sua vez, Bernaudin et al. (2000) mostraram duas distribuições na escala de QI geral em pacientes com ICS: uma com baixo QI e uma com QI normal, indicando influência de outros fatores no funcionamento cognitivo global.

Essa tendência dos dados foi confirmada por Steen et al. $(1999,2003)$ que verificaram que as crianças com ICS tiveram menor rendimento intelectual quando confrontados com o Grupo IRM normal. No entanto, Steen et al. (2005) encontraram diferenças entre os grupos e detectaram baixo desempenho nos escores de QI em crianças sem qualquer anomalia detectada por IRM, sugerindo que esse exame neurológico não é sensível a certos tipos de danos que podem produzir deterioração cognitiva na DF. Essas achados são corroborados por 
Wang et al. (2001) que constataram pior desempenho cognitivo geral no Grupo ICS na maioria das faixas etárias entre 6 a 18 anos, com cerca de cinco pontos a menos nos QI total, verbal e de execução. E também certificaram que as crianças com hemoglobina SS com IRM normal apresentaram alterações cognitivas, sendo que 9\% dessa amostra, aos 10 anos de idade, manifestaram deficiência intelectual.

O padrão dos escores de QI foi diferente nos estudos examinados, a depender dos resultados da IRM. No Grupo IRM normal, o QI verbal foi significativamente maior do que o QI de execução, porém no Grupo ICS o desempenho em ambos foi reduzido (Steen et al., 2003). Demais pequisas observaram prejuízo no funcionamento verbal do Grupo ICS quando comparados com pacientes com IRM normal (Armstrong et al., 1996; Bernaudin et al., 2000; Wang et al., 2001). De forma divergente, Steen et al. (2003) encontraram diferença entre os grupos avaliados somente no QI de execução.

Schatz, White, Moinuddin, Armstrong e DeBaun (2002) relacionaram o funcionamento cognitivo com resultados da IRM por meio da mensuração da quantidade de perda tecidual no ICS identificada pelo volume das lesões cerebrais e ventriculares. Crianças com ICS com maior volume de lesão tecidual tiveram menor desempenho no QI total do que os Grupos IRM normal e ICS com baixo volume de lesão. Em relação ao volume ventricular, verificaram pior escore no QI de execução para o Grupo ICS com grande volume ventricular, em relação aos Grupos IRM normal e ICS com pequeno volume ventricular. Esses dados sugerem que o tipo de lesão cerebral desenvolve diferentes associações e efeitos em distintas áreas do funcionamento cognitivo, visto que o volume de lesão cerebral parece estar mais associado com QI total, enquanto o tamanho do ventrículo lateral apresentou relação mais forte com QI de execução. Outros estudos não observaram diferença significativa na capacidade cognitiva global entre os Grupos IRM normal e ICS (Gold et al., 2008; McCauley \& Pedroza, 2010; Hijmans, Grootenhuis et al., 2011).

No DTC, o grupo classificado como anormal apresentou pior desempenho do que grupo condicional na inteligência verbal (Kral et al., 2003). Inversamente, Bernaudin et al. (2000) e Hijmans, Grootenhuis et al. (2011) não encontraram diferença no funcionamento cognitivo relacionados aos valores do DTC, após exclusão de pacientes com AVC ou quando a idade foi controlada. Na investigação científica de Strouse et al. (2006), todas as crianças tinham DTC normal, não sendo encontradas correlações significativas entre a VFS e QI total.

Zou et al. (2011) investigaram o efeito da DF na ativação cerebral no córtex visual primário pela IRM funcional (IRMf), comparando-as com crianças que tiveram meduloblastoma, verificando-se menor reposta ao estímulo visual no grupo DF. A amplitude 
do sinal nessse exame foi positivamente associada a escores de inteligência verbal e de execução, sugerindo que o efeito adverso da DF sobre a função cerebral é mediado pela incapacidade de oferecer resposta hemodinâmica apropriada diante do aumento da atividade neural. Assim, a IRMf pode ajudar a esclarecer fatores médicos, hemodinâmicos e neurais sobre os efeitos adversos da DF na função neurocognitiva.

A utilização apenas do QI para compreensão do funcionamento cognitivo traz restrições para o conhecimento detalhado da capacidade intelectual dessas crianças, visto que oferece uma única vertente de informação. As medidas de domínios cognitivos mais específicos parecem ser mais sensíveis do que medida apenas de QI (Schatz et al., 2002).

\section{- Atenção / função executiva}

Estudos apontam os domínios da atenção e função executiva como mais vulneráveis na DF (Ruffieux et al., 2013), especialmente por envolver o circuito frontocortical, área cerebral mais afetada nessa patologia (Brown et al., 2000; Schatz et al., 2001). Em consonância a essa afirmação, diversas pesquisas encontraram menor desempenho em atenção sustentada nas crianças com DF quando comparadas ao Grupo Controle (Swift et al., 1989; Brown et al., 1993; Hijmans, Fijnvandraat et al., 2011; Strouse et al, 2006).

As funções executivas envolvem um conjunto de processos cognitivos tais como planejamento, inferência, resolução de problemas, organização de estratégias, tomada de decisão, controle inibitório, seleção, memória operacional, categorização, a utorregulação, flexibilidade mental, velocidade de processamento e criatividade (Santos, 2004; Lezak et al., 2004; Malloy-Diniz et al., 2010). Investigações com crianças com DF têm focalizado diferentes aspectos desse complexo domínio cognitivo. Berg, Edwards e King (2012) constataram que essas crianças tiveram baixo rendimento em resolução de problema, flexibilidade mental e velocidade de processamento verbal diante do aumento da complexidade da tarefa. Durante a execução de uma tarefa na cozinha, apresentaram prejuízo na iniciação, conclusão e organização da tarefa. Quando avaliadas pelos pais e professores, verificou-se comprometimento na metacognição e no índice global, que inclui as habilidades de iniciação, memória de trabalho, planejamento, organização de materiais e monitoramento. Além disso, neccessitaram de maior tempo de latência no teste de controle inibitório (Noll et al., 2001) e exibiram velocidade de processamento mental mais lenta (Nabors \& Freymuth, 2002; Scantlebury et al., 2011).

$\mathrm{Na}$ avaliação de memória operacional, span de dígitos foi o teste mais utilizado dentre os estudos aqui analisados, sendo composto por duas tarefas: dígito direto que representa 
principalmente a capacidade atencional e manutenção da informação e, em seguida, dígito inverso que está relacionado com componentes da função executiva central como armazenamento, manipulação ativa da informação e controle inibitório. $\mathrm{Na}$ memória operacional alça fonológica, Berg et al. (2012) verificaram diferenças significativas com o Grupo Controle em dígitos diretos, contudo, não houve diferença para dígito inverso. De maneira divergente, Schatz et al. (2004), Schatz e Roberts (2005) e Ruffieux et al. (2013) constataram prejuízo somente em dígito inverso, tarefa mais exigente em termos de recursos cognitivos. Em relação à memória operacional com esboço visoespacial, Hijmans, Fijnvandraat et al. (2011) detectaram pior desempenho nas crianças com DF.

Contriamente aos dados anteriores, outros estudos demonstraram níveis semelhantes com o Grupo Controle em manter a atenção sustentada (Goonan et al., 1994; Nabors \& Freymuth, 2002; Scantlebury et al., 2011), na capacidade de controle inibitório (Goonan et al., 1994; Hijmans, Fijnvandraat et al., 2011; Berg et al., 2012), bem como em outros aspectos da função executiva como nível de precisão na tarefa (Berg et al., 2012; Noll et al., 2001), memória operacional alça fonológica (Hijmans, Fijnvandraat et al., 2011) e esboço visoespacial (Schatz e Roberts, 2005). Diante da atividade prática na cozinha, não houve diferença entre os grupos no tempo e número total de pistas necessárias para finalizar a atividade planejada e fazer julgamento em relação a situações de segurança, e não houve quaisquer problemas de regulação comportamental (Berg et al., 2012).

Em referência ao ICS, o domínio da atenção sustentada foi considerado como mais sensível e específico para identificar esse grupo (DeBaun et al., 1998). Outros estudos corroboram esses dados, referindo que não somente a presença da lesão cerebral, mas também sua localização, são associadas a déficits nesse domínio. Para Schatz et al. (2001), déficits na atenção e função executiva têm sido frequentemente relacionados com ICS que envolvem lesões do lóbulo frontal. Por sua vez, Craft et al. (1993) enfatizaram que crianças com ICS na região anterior tiveram mais intrusões e maior quantidade de erros em medidas de atenção auditiva sustentada do que o Grupo ICS com lesão difusa e Grupo Controle.

Wang et al. (2001) encontraram menor desempenho no Grupo ICS em dígito verbal (escore total) nas faixas etárias entre 6-12 anos quando comparado com Grupo IRM normal. No entanto, Brandling-Bennett, White, Armstrong, Christ e DeBaun (2003) notaram que a simples extensão de dígito no ICS frontal foi comparável às crianças com IRM normal, mas houve baixo rendimento em dígitos inversos no Grupo ICS frontal. Entretanto, Scantlebury et al. (2011) referem que, mesmo as crianças com DF com IRM normal parecem cursar com prejuízo na memória operacional, quando comparadas com crianças saudáveis. As demais 
pesquisas não encontraram diferenças entre crianças com IRM normal e ICS no domínio da atenção sustentada (Scantlebury et al., 2011) e atenção/função executiva (Berg et al., 2012), observando apenas que o Grupo ICS foi mais lento (Brown et al., 2000).

No DTC, Kral et al. (2003) verificaram que o grupo com valor anormal teve pior desempenho do que o grupo com valor condicional em função executiva, e este foi pior do que o grupo normal em atenção sustentada e função executiva. Valores do DTC podem, portanto, prever memória operacional alça fonológica, respondendo por $41 \%$ da variância, de acordo com es ses pesquisadores.

\section{- Memória}

Na avaliação da memória verbal e visoespacial, Swift et al. (1989) encontraram menor desempenho no grupo AF quando comparados com irmãos saudáveis, porém em ambos os grupos a pontuação da memória verbal foi relativamente maior do que a memória visoespacial. De forma controversa, Noll et al. (2001) não acharam diferença significativa entre os grupos nesse domínio.

White et al. (2006) apontam a medida de curva de aprendizagem de lista de palavras como melhor preditor de ICS. A acurácia preditiva do modelo resultante desse estudo, utilizando essa medida e a pontuação no subteste de cubos, foi de $75,4 \%$ nos casos ICS e $85,7 \%$ nos casos com infartos confinados a regiões frontais cerebrais. Brandling-Bennett et al. (2003) encontraram dados semelhantes: o Grupo ICS frontal exibiu deficiências tanto na curva de aprendizagem de lista de palavras, quanto na recordação livre após intervalos de curto ou longo prazo. Contudo, na tarefa de reconhecimento houve melhora no desempenho, equiparando-se ao Grupo IRM normal, indicando que as funções mnemônicas de codificação e armazenamento estavam intactas, mas a recuperação livre prejudicada. Além disso, essas crianças geraram espontaneamente estratégia de agrupamento semântico que pareceu facilitar a codificação e o armazenamento, apesar de não usarem dessa estratégia para facilitar a recuperação. Dessa forma, verificou-se que crianças com ICS frontal demonstraram comprometimento na utilização de estratégias do processamento executivo que facilitam a memória de longo prazo e memória operacional.

De forma antagônica, Craft et al. (1993), DeBaun et al. (1998) e Grueneich et al. (2004) não observaram efeitos significativos do ICS nos escores de memória verbal e visual. Apesar disso, Grueneich et al. (2004) sugeriram que crianças com ICS demonstram maior discrepância entre nível intelectual geral e medidas de memória verbal e visual em 
comparação ao Grupo IRM normal, indicando maior variabilidade intraindividual no desempenho neuropsicológico, particularmente relacionado à capacidade mnemônica.

Investigação da memória prospectiva foi encontrada apenas em uma pesquisa no atual levantamento bibliográfico (McCauley \& Pedroza, 2010), que não achou correlação entre a memória geral e precisão de resposta na memória prospectiva. O Grupo IRM normal não diferiu do Grupo Controle na memória retrospectiva, mas expressou deficiência no funcionamento da memória prospectiva. Já crianças com alteração na IRM (ICS e AVC) apresentaram pior desempenho nessa tarefa. No entanto, os resultados apontaram que a memória prospectiva pode ser melhorada, usando-se pistas perceptualmente distintas na maioria das crianças com DF (com a possível exceção de crianças com AVC), para um nível comparável ao Grupo Controle.

Valores do DTC predisseram, principalmente, desempenho da memória verbal, sendo que pacientes com exame anormal tiveram escores inferiores (Kral et al., 2006; Ruffieux et al., 2013), correspondendo a 13\% da variância (Kral et al., 2006). De acordo com Ruffieux et al. (2013), déficit na memória verbal pode estar associado à dificuldade no processamento da linguagem.

\section{- Linguagem}

Poucos estudos foram realizados no domínio da linguagem, segundo o levantamento bibliográfico aqui desenvolvido. Schatz e Roberts (2005) verificaram que crianças com DF sem AVC tiveram menor escore em vocabulário, processamento auditivo e velocidade de processamento quando comparadas ao Grupo Controle. Outros estudos demonstraram menor desempenho em compreensão verbal (Swift et al., 1989; Steen et al., 2005). Por sua vez, Sanchez et al. (2010) e Puffer et al. (2010) constataram que o Grupo Controle teve pontuação significativamente mais alta do que grupo DF de alto risco em todos os testes de linguagem (semântica, sintática, processamento fonológico e velocidade de processamento), correspondendo a quase nove pontos de diferença. Entretanto, não foi observada discrepância significativa entre os Grupos Controle e DF de baixo risco. Inversamente, Brown et al. (1993) não encontraram diferenças na linguagem expressiva e receptiva.

Na comparação entre pacientes com e sem ICS, não houve diferença significativa nos testes de linguagem (Craft et al., 1993; DeBaun et al., 1998; Schatz et al., 2001).

No DTC, a maior VFSC foi associada a pior desempenho no quociente sintático e de processamento fonológico, porém não esteve relacionada com quociente semântico ou outros 
domínios cognitivos. Além disso, DTC foi capaz de predizer apenas quociente sintático (Sanchez et al., 2010).

\section{- Habilidade visoespacial}

Os estudos sobre habilidade visoespacial e função motora mostraram-se sobrepostos, muitas vezes, por não utilizarem instrumentos específicos para cada domínio. Na avaliação do funcionamento visomotor (que constitui habilidades como percepção visual, praxia construcional e coordenação motora), foi verificado comprometimento nas crianças com DF (Puffer et al., 2010; Hijmans, Fijnvandraat et al., 2011). Esse déficit na função visomotora foi associado a prejuízo na memória operacional - esboço visoespacial, levando a especular que esse Grupo Clínico pode ter alteração específica na percepção de informações visoespacias (Hijmans, Fijnvandraat et al., 2011).

Swift et al. (1989) demonstraram menor rendimento no grupo com DF em organização perceptual e Schatz et al. (2004) e Schatz e Roberts (2005) para correspondência visual (velocidade de processamento). Outras pesquisas não observaram diferença entre DF e Grupo Controle em habilidade visomotora (Brown et al., 1993; Swift et al., 1989; Noll et al., 2001).

ICS com lesão difusa sinalizou prejuízo significativo em relação a ICS com lesão anterior e Grupo Controle em testes de medidas espaciais (Craft et al., 1993). No estudo de White et al. (2006), a velocidade de raciocínio visoespacial foi considerada como melhor preditor para ICS. No entanto, DeBaun et al. (1998) não identificaram diferenças entre os grupos nesse domínio.

\section{- Função sensoriomotora}

A maioria dos estudos presentemente identificados não encontraram alteração significativa do funcionamento sensoriomotor nas crianças com DF (Ruffieux et al., 2013; Noll et al., 2001). Igualmente, não foram observados efeitos significativos entre IRM normal e ICS para velocidade e coordenação motora (Craft et al., 1993; DeBaun et al., 1998; Armstrong et al., 1996). No estudo de Gold et al. (2008), de forma semelhante, não houve discrepância entre esses grupos de DF, porém os escores médios da velocidade motora, coordenação e percepção tátil encontraram-se abaixo do padrão normativo.

\section{- Desempenho acadêmico}

$\mathrm{O}$ conjunto de investigações anteriormente descritas supõe que baixo desempenho intelectual geral e déficits neuropsicológicos nas crianças com DF predispõem ao baixo 
rendimento acadêmico, maior índice de retenção escolar e necessidade de serviços de educação especial. Nessa revisão de literatura houve importante variabilidade no percentual de amostras de crianças com DF que necessitaram de algum serviço de educação especial, com indicadores variando entre 14 a 70\% (Hijmans, Fijnvandraat et al., 2011; Berg et al., 2012; Kral et al., 2003; 2006; Strouse et al., 2006), assim como daquelas que repetiram alguma série na escola, com índices entre $21 \%$ a 40,7\% dos casos (Strouse et al., 2006; Kral et al., 2006). Wasserman et al. (1991) destacam que a própria cronicidade da doença pode levar a hospitalizações recorrentes e consequente falta escolar.

Aprendizado acadêmico foi avaliado, principalmente, por atividades de matemática e leitura. Swift et al. (1989) verificaram menor desempenho no grupo DF em ambos os testes. O mesmo foi observado por Puffer et al. (2010), que encontraram diferença de quase 12 pontos entre DF de alto risco e Grupo Controle, porém não houve diferença com DF de baixo risco e crianças saudáveis. De maneira mais precisa, no teste de leitura, Brown et al. (1993) demonstraram menor rendimento do grupo com DF na decodificação de leitura, porém não houve diferença na tarefa de compreensão. Outros estudos que avaliaram leitura e escrita não encontraram diferença entre os grupos (Noll et al, 2001; Wasserman et al., 1991). Com relação à aritmética, Noll et al. (2001) e Wasserman et al. (1991) referiram pior desempenho no grupo DF.

No estudo de Richard e Burlew (1997) foram comparados pacientes com DF a crianças atendidas no mesmo hospital porém sem doença crônica, verificando-se que ambos os grupos tiveram altas taxas de absenteísmo escolar, sendo os escores médios percentuais em matemática e leitura abaixo da média nacional para a idade, não se constatando diferença estatisticamente significativa entre eles. Dessa forma, o baixo desempenho acadêmico em crianças com DF pode estar mais relacionado às faltas escolares, já que o conhecimento em leitura e matemática é construído paulatina e gradativamente, sendo fortemente afetado pelo absenteísmo escolar (Wasserman et al., 1991). Outras pesquisas não verificaram diferença estatística entre os Grupos Clínicos e Controle no desempenho acadêmico (Brown et al., 1993; Wasserman et al., 1991), na necessidade de educação espacial (Wasserman et al., 1991) e no grau de escolaridade (Chodorkoff \& Whitten, 1963).

Nos estudos com ICS, constatou-se que a maioria dessas crianças está inserida em escola regular, porém com baixo desempenho acadêmico. Schatz et al. (2001) observaram que $74 \%$ da amostra com ICS foi retida ou necessitou de serviço educacional especial, em comparação com $27 \%$ dos alunos com DF sem alteração na IRM, e 6\% dos irmãos saudáveis. Em relação ao rendimento acadêmico, 37\% do Grupo ICS apresentou comprometimento, 
comparado com 27\% do Grupo IRM normal e 6\% dos irmãos, verificando que crianças com ICS têm pelo menos duas vezes mais chance de prejuizo acadêmico do que o grupo DF sem ICS. Outras pesquisas certificaram esse resultado. Wang et al. (2001) referiram que o Grupo ICS com idade entre 6-12 anos apresentou menor desempenho em matemática e leitura com cerca de 9 a 10 pontos a menos do que o Grupo IRM normal no Woodcock-Johnson Revised Tests of Academic Achievement. Gold et al. (2008) relataram que pacientes com IRM normal funcionavam dentro de parâmetros médios e médio-inferiores nos testes de desempenho acadêmico, enquanto o Grupo ICS apresentava tendência a pontuações menores. A maioria desses estudos sugere que o decréscimo no desempenho acadêmico pode ser um importante marcador para identificar ICS. Os achados de Nabors e Freymuth (2002) sugerem que pacientes sem histórico de AVC não são mais propensos a ter prejuizo acadêmico do que irmãos saudáveis. Por consequência, segundo esses autores, aquelas crianças com DF que exibiram dificuldades escolares deveriam ser criteriosamente avaliadas para verificar a possibilidade de ICS.

Outros fatores que vêm sendo associados ao comprometimento do funcionamento neuropsicológico em crianças com DF foram: genótipo, idade cronológica, percentual de hematócrito, nível de hemoglobina e uso de hidroxiuréia.

Em referência aos subtipos genéticos, o grupo de baixo risco apresentou escores significativamente maiores, comparativamente ao grupo de alto risco em: desempenho cognitivo geral (Steen et al., 1999; Puffer et al., 2010), linguagem, habilidades acadêmicas (Puffer et al., 2010; Schatz et al., 2009), índice de organização perceptual (Steen et al., 1999) e habilidade visomotora (Schatz et al., 2009). Nas pesquisas de Puffer et al. (2010) e Schatz et al. (2009), o grupo de baixo risco expressou desempenho semelhante ao Grupo Controle e m todas as medidas cognitivas. De forma divergente, Grueneich et al. (2004) e Brown et al. (1993, 2000) não identificaram diferença entre os genótipos no desempenho cognitivo geral e em habilidades específicas de linguagem e função visomotora. Wang et al. (2001) realizaram igual comparação incluindo somente pacientes com IRM normal, re velando que crianças com $\mathrm{HbSC}$ não tiveram melhor desempenho neuropsicológico do que aquelas com $\mathrm{HbSS}$, em contraste com o risco diminuído para a maioria das outras complicações decorrentes da DF. Para Armstrong et al. (1996) poucas crianças com HbSC tiveram alterações na IRM, sendo que os efeitos no SNC foram encontrados predominantemente em crianças com HbSS, destacando-se a necessidade de priorizar o grupo de alto risco na realização de avaliações neuropsicológicas. Esses autores, alertam que investigações que não considerarem o genótipo podem causar subestimação da frequência e severidade dos déficits neuropsicológicos. 
Em relação à idade, existem evidências de declínio significativo em funções cognitivas com o aumento da idade cronológica, pois crianças mais velhas acometidas por DF apresentaram pior desempenho cognitivo quando comparadas às mais novas. Não está clara a relação entre a idade e o funcionamento cognitivo, e ainda não está determinada em qual idade se inicia esse declínio e o risco de sua progressão. Parece haver efeito cumulativo de séries de microlesões cerebrais que ocorrem ao longo do tempo e alguns domínios cognitivos são especialmente afetados.

Steen et al. (2003, 2005) observaram diminuição do QI total com a idade em pacientes com AF, explicando aproximadamente $11 \%$ da variação nessa medida, sendo verificada também redução no QI verbal, e em índices de compreensão verbal e organização perceptual. Apesar de Wang et al. (2001) não terem constatado mudança ao longo do tempo no QI total e QI de execução em pacientes com IRM normal, houve declínio significativo no QI verbal de aproximadamente 0,5 ponto/ano, na velocidade de processamento de 0,2 ponto/ano e em matemática de 0,9 ponto/ano. Kral et al. (2003, 2006) identifcaram a idade como preditor robusto do desempenho neurocognitivo, respondendo por $31 \%$ a $64 \%$ da variância em medidas de funcionamento intelectual geral, memória verbal de curto prazo, atenção sustentada, função executiva e inte gração visomotora.

Declínio no funcionamento neurocognitivo com o aumento da idade também foi encontrado por Brown et al. (1993) na atenção sustentada e habilidade visomotora e, por Ruffieux et al. (2013), na função executiva, enquanto as outras funções permaneceram relativamente estáveis ao longo dos anos. Wasserman et al. (1991) não encontraram diferença entre grupo DF mais velho (13-16 anos) e Grupo Controle. No entanto, as crianças com DF entre 8-12 anos tiveram pior desempenho do que seus irmãos em sete escalas: visual, linguagem expressiva, leitura, escrita, aritmética, memória e escala patognomônica de disfunção, sugerindo que os déficits apareceram com maior frequência nessa faixa etária, podendo indicar ICS ou predisposição para AVC.

Nos subgrupos ICS e AVC esse declínio cognitivo decorrente da idade apareceu de forma mais substancial, pois apresentaram escores mais baixos do que o Grupo IRM normal, diminuindo em média 1,2 pontos/ano na escala de QI total (Thompson et al., 2003). Alguns pesquisadores têm sugerido que a primeira década de vida, a idade típica de início para o AVC, constitui um período crítico para complicações neurológicas e subseqüente morbidades neurocognitivas (Kral et al., 2006). O resultado do estudo de Wang et al. (2001) permitiu identificar um declínio progressivo em áreas específicas do funcionamento neuropsicológico 
em crianças com DF, mesmo naqueles com IRM normais, sendo provavelmente reflexo do efeito progressivo da DF no cérebro.

Contrariamente, para alguns autores a idade foi positivamente associada a ganhos em pontuação em testes neuropsicológicos específicos. Goonan et al. (1994) observaram, no grupo acima de nove anos, melhora no desempenho da atenção sustentada, incluindo número de respostas corretas, menos erros de omissão e de ação. Esses dados sugeriram tendência dessas crianças se tornarem mais reflexivas com a idade, visto que houve maior latência de resposta no teste de controle inibitório, indicando que essas crianças tinham maior capacidade de retardar a resposta com a idade. McCauley e Pedroza (2010) relataram melhora do desempenho na capacidade de memória retrospectiva e respostas mais rápidas na memória prospectiva, e Hijmans, Fijnvandraat et al. (2011) e Hijmans, Grootenhuis et al. (2011) no planejamento, memória operacional e habilidade visomotora. Demais pesquisas não encontraram efeito da idade no desempenho neurocognitivo (Swift et al., 1989; Steen et al., 1999; Noll et al., 2001; Puffer et al., 2010; Sanchez et al., 2010).

A disfunção cognitiva na DF vem sendo relacionada também ao nível de hematócrito (Ht) que se refere à porcentagem ocupada pelas hemácias no volume total do sangue. $\mathrm{Na} \mathrm{DF}$ há destruição prematura das hemácias, levando a quadros severos de anemia, ou seja, baixo nível de Ht. Nessa revisão bibliográfica, a média do Ht foi de aproximadamente 24 a 27\%, com variação entre 7 a 39\% nos diferentes pacientes (Steen et al., 1999, 2003; Thompson et al., 2003; Kral et al., 2003, 2006; Schatz et al., 2004, 2010, Schatz e Roberts, 2005). Contudo, Puffer et al. (2010) destacaram que a diferença no percentual de Ht está associado ao subtipo genético, encontrando no grupo alto risco média de $23,8 \% \mathrm{Ht}$ e, no subtipo baixo risco, média de 31,5\% Ht. Essa discrepância do percentual de Ht entre os genótipos foi confirmada em outras pesquisas (Armstrong et al., 1996; Thompson et al., 2003).

Bernaudin et al. (2000) estratificou o nível de Ht em dois grupos, considerando o ponto de corte de $20 \%$. Pacientes com anemia grave tiveram pontuações significativamente mais baixas no desempenho cognitivo global, QI verbal e de execução, informação, aritmética, dígitos e velocidade de processamento. Nesse grupo, 64,2\% tiveram QI total $<75$, enquanto o grupo com Ht superior a $20 \%$ correspondeu a $24,8 \%$ da amostra. ICS foi relacionado com anemia grave, apresentando desempenhos cognitivos severamente diminuídos. Os pesquisadores enfatizaram que ICS não constitui um fator de risco para déficit cognitivo quando não estiver associado a baixo nível de Ht ou trombocitose. Steen et al., (1999, 2003) estratificaram o $\mathrm{Ht}$ em dois grupos, assumindo $27 \%$ como ponto de corte. No primeiro estudo, Ht baixo foi positivamente associado com deficiência cognitva geral, explicando $56 \%$ da sua 
variância, e com todos os índices fatoriais da escala Wechsler, à exceção de velocidade de processamento. Na segunda investigação, houve associação com QI total, QI verbal, compreensão verbal e resistência à distração, sendo o Ht capaz de explicar cerca de $23 \%$ da variância no QI total e 13\% dos índices fatoriais. Nível de Ht também foi capaz de predizer o desempenho em leitura e matemática, respondendo por $27 \%$ e $39 \%$ da variância explicada, respectivamente (Kral et al., 2003). Demais estudos verificaram relações semelhantes com desempenho cognitivo global (Puffer et al., 2010; Schatz et al., 2004), vocabulário oral e velocidade de processamento visual (Schatz et al., 2004), desempenho acadêmico (leitura e matemática), atenção sustentada e função executiva (flexibilidade mental) (Kral et al., 2006).

Armstrong et al. (1996) demonstraram que pacientes com alteração na IRM apresentaram níveis mais baixos de Ht. De forma antagônica, Steen et al. (2003) não acharam diferença significativa no nível de Ht entre ICS e IRM normal, apontando que resultados da IRM e nível de Ht podem ser preditores independentes da capacidade intelectual. Ht baixo foi considerado como preditor significativo de comprometimento cognitivo, sugerindo associação com hipóxia crônica. Estas descobertas indicam que, embora haja significativa associação entre nível de Ht e funcionamento cognitivo, outras variáveis também se fazem importantes.

A hemoglobina $(\mathrm{Hb})$ está presente nas hemácias, sendo considerada como maior determinante da capacidade de transporte de oxigênio do sangue, relacionando-se com a quantidade de distribuição de oxigênio no cérebro. Brown et al. (1993) referiram que crianças com DF com baixo nível de $\mathrm{Hb}$ apresentam maior risco de prejuízo cognitivo, e isso parece estar relacionado com o mecanismo fisiopatológico de isquemia crônica em áreas sem infartos. Nesse estudo, o nível da $\mathrm{Hb}$ revelou previsão de quase $30 \%$ da habilidade motora fina e $10 \%$ do funcionamento intelectuale acadêmico.

Na pesquisa de Ruffieux et al. (2013), 67\% dos pacientes com DF apresentaram anemia grave $(<7 \mathrm{~g} / \mathrm{dl})$ e $33 \%$ anemia moderada $(7-12 \mathrm{~g} / \mathrm{dl})$. O nível de $\mathrm{Hb}$ foi associado positivamente com funcionamento executivo, mas não com outros domínios cognitivos. Hijmans, Grootenhuis et al. (2011) verificaram que a $\mathrm{Hb}$ foi o único preditor dentre as variáveis clínicas para o desempenho em memória verbal de curto prazo. Demais estudos aqui identificados não encontraram relação entre $\mathrm{Hb}$ e QI total (Swift et al., 1989), atenção e impulsividade (Goonan et al., 1994) ou outras medidas neuropsicológicas (Grueneich et al., 2004).

Dentre as medicações utilizadas por crianças com DF, a hidroxiuréia (HU) tem sido associada com melhora cognitiva. Uma possibilidade é que essa medicação inverta diretamente as anormalidades cerebrais causadas pela DF, como anemia grave ou 
trombocitose, podendo prevenir ou reverter anormalidades cerebrais funcionais. Puffer, Schatz e Roberts (2007) relacioram a HU com pontuação mais alta na capacidade cognitiva global, compreensão verbal e raciocínio espacial. Não houve associação com velocidade de processamento, memória operacional alça fonológica e fluência verbal. Apesar da indicação da HU ser, em geral, para crianças que apresentam mais fatores de risco neurológico, a constatação de melhor desempenho em algumas funções cognitivas, sugere efeito benéfico desse fármaco, embora seu mecanismo de ação seja ainda incerto.

Complementando os estudos sobre o funcionamento neuropsicológico, autores trouxeram dados relevantes sobre o domínio de comportamento, apesar desse aspecto não ter sido foco de investigação direta dessa revisão bibliográfica. Diferentes estudos utilizaram o CBCL (Child Behavior Checklist) como instrumento para investigação do comportamento, no entanto, sem relatos de problemas de comportamento clinicamente significativos no grupo DF, e sem associação relevante com resultados da IRM ou idade cronológica (Swift et al., 1989; Goonan et al., 1994; Armstrong et al., 1996; Thompson et al., 2003). O CSSCD (Thompson et al., 2003) realizou estudo longitudinal por nove anos para avaliar relação entre dificuldade comportamental, funcionamento intelectual e funcionamento familiar de 222 pacientes com DF. O risco de transtornos do comportamento mostrou relação direta com nível de conflito familiar e inversa com nível inicial de funcionamento intelectual, porém houve baixo percentual da amostra com problema comportamental consistente $(9 \%)$, em comparação com $51 \%$ com bom ajustamento. Utilizando o instrumento do Desenho da Figura Humana, Chodorkoff e Whitten (1963) também não identificaram sinais de transtornos emocionais ou graves disfunções de personalidade.

O conjunto das investigações científicas, até o momento identificadas, aponta para prejuízos cognitivos importantes nas crianças com DF, justificando-se atenção especial a este Grupo Clínico. Há necessidade de esclarecimentos adicionais sobre os processos neuropsicológicos envolvidos, visto que as investigações científicas realizadas chegaram a resultados ainda iniciais e, muitas vezes, contraditórios.

No Brasil, a DF tem alta prevalência, e essa população infantil pode se beneficiar com investigações mais amplas e precisas a respeito de seu desenvolvimento cognitivo, por meio de instrumentos neuropsicológicos normatizados e validados. Conhecer o perfil neuropsicológico dessas crianças possibilitará maior investimento em intervenções preventivas e na formulação de programas de reabilitação. Dessa forma, tornar-se-á possível oferecer oportunidades para que essas crianças recebam estímulos e intervenções a fim de 
favorecer seu desenvolvimento cognitivo, emocional e social. A presente investigação científica pauta-se por esses objetivos. 
2. OBJETIVOS 


\subsection{Geral}

Caracterizar o desempenho neuropsicológico e comportamental de crianças com doença falciforme, na faixa de 7 a 12 anos.

\subsection{Específicos}

2.2.1. Avaliar e descrever as principais funções cognitivas (atenção/função executiva, aprendizagem e memória, linguagem, processamento visoespacial e função sensoriomotora) e identificar possíveis dificuldades comportamentais de crianças com DF por meio de instrumentos de avaliação psicológica.

2.2.2. Comparar o desempenho neuropsicológico de crianças com DF (Grupo Clínico) com um Grupo Controle de crianças saudáveis, pareadas em função do sexo, instituição de ensino pública ou privada e idade.

2.2.3. Correlacionar o perfil neuropsicológico das crianças do Grupo Clínico a variáveis sociodemográficas (idade, sexo, anos de estudo, repetência escolar, nível socioeconômico e escolaridade dos pais) e a variáveis clínicas (genótipo, hemograma e presença de alteração cerebral pela IRM e velocidade de fluxo sanguíneo cerebral pelo DTC).

2.2.4. Realizar revisão de literatura sobre alterações neuropsicológicas em crianças com doença falciforme. 
3. MÉTODO 


\subsection{Participantes}

Estudo transversal do tipo caso-controle com 60 crianças de 7 a 12 anos de idade, de cidade do interior do estado de São Paulo, selecionadas para compor dois grupos pareados:

- Grupo Clínico $(n=30)$ : crianças com DF em tratamento no Hemocentro de Ribeirão Preto/SP da Faculdade de Medicina de Ribeirão Preto - Universidade de São Paulo (FMRPUSP). Selecionadas aquelas que tiveram diagnóstico estabelecido, conforme critérios específicos da equipe médica do referido serviço institucional.

- Grupo Controle $(n=30)$ : crianças com indicadores de desenvolvimento típico, pareadas aos casos clínicos em função da idade, sexo, origem escolar (pública versus particular) e nível socioeconômico.

Critérios de exclusão: deficiência intelectual (identificada a partir do QI Estimado do WISC III e das Matrizes Progressivas Coloridas de Raven), visto que o prejuízo no funcionamento global poderia dificultar análise específica das funções neuropsicológicas; histórico de complicações neonatais; TCE; AVC; doença crônica que não DF; uso de medicações com efeito negativo sobre a cognição (por exemplo: medicação sedativa e anticonvulsivante).

As crianças do Grupo Clínico passaram por ampla investigação médica clínica e neurológica, para excluir aquelas em tratamento de hemotransfusão crônica e com alterações clínicas sugestivas de AVC, de modo a limitar possíveis variáveis de confusão nos dados. No Grupo Controle foram excluídas crianças com dificuldades de aprendizagem ou de comportamento (conforme relato dos pais e professores), visto que para composição desse grupo buscou-se escolares com indicadores de desenvolvimento típico para a faixa etária e o rendimento acadêmico.

A coleta de dados do Grupo Clínico ocorreu entre os casos tratados no Hemocentro de Ribeirão Preto, ligado à FMRP - USP, sendo um serviço de referência no atendimento a DF na região de Ribeirão Preto e no interior do Estado de São Paulo. Houve perda amostral de pacientes que concederam o aceite para participação em função de seu local de moradia (grande parte dos casos residia fora de Ribeirão Preto), o que dificultou completar o processo de avaliação do Grupo Clínico. Algumas das crianças voluntárias realizaram apenas a sessão de triagem, conforme detalhado a seguir.

A equipe do Hemocentro disponibilizou uma planilha com dados de 60 crianças com DF entre 7 a 12 anos de idade. Posteriormente, foram incluídos mais 13 pacientes que iniciaram tratamento nesse serviço durante o período da realização do estudo. Do total desses 
73 casos potenciais, foram excluídas 19 crianças pelos seguintes critérios: duas por AVC, uma por parada cardiorrespiratória (PCR), seis com diagnóstico de outras variantes de doenças hematológicas, uma por crise convulsiva, uma por alteração na IRM compatível com doença neurodegenerativa e oito por estarem em hemotransfusão. Dos 54 restantes, 39 foram convidados a participar do estudo, pois somente estes compareceram à consulta no Hemocentro durante o período da coleta de dados (transcorrido no período de junho de 2011 a junho de 2012).. Os demais casos não foram contatados.

Entre as 39 crianças convidadas, duas não aceitaram participar da pesquisa, uma faltou à primeira sessão de triagem e 36 realizaram a triagem intelectual. Do grupo que realizou a triagem, quatro crianças descontinuaram a avaliação psicológica e 32 a finalizaram. Duas crianças tiveram que ser excluídas posteriormente, pelo uso de anticonvulsivante e uma por PCR aos oito meses de vida (Fluxograma 1).

Todas essas crianças passaram por exame clínico neurológico realizado por médico neurologista colaborador, com o objetivo de avaliar possíveis alterações neurológicas e excluir aquelas com DF com sinais de AVC. Duas crianças apresentaram sinais neurológicos leves (pequenas alterações cerebelares e hiperreflexia patelar à esquerda) que não comprometeram a inserção nesse estudo.

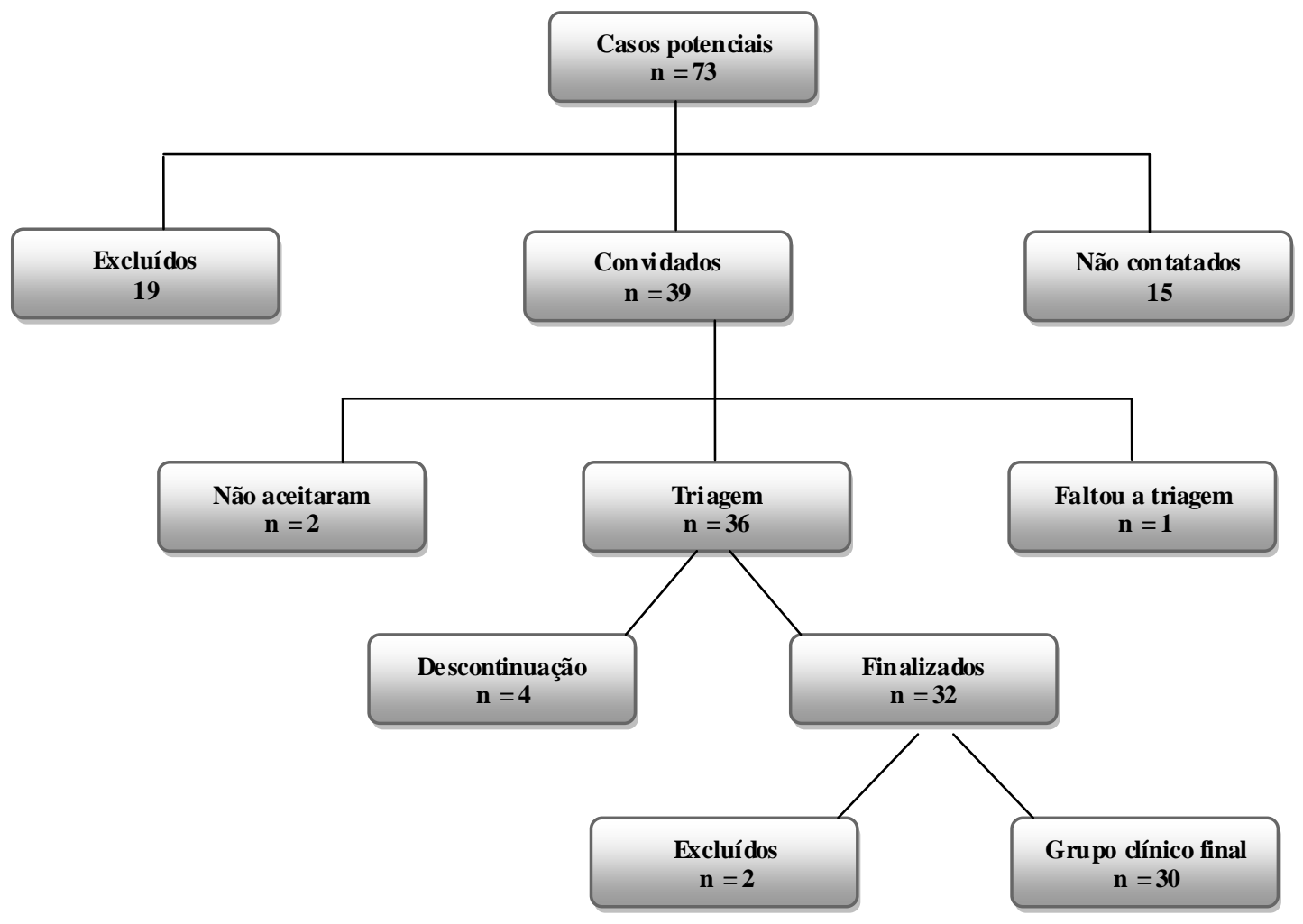

Fluxograma 1. Percurso amostral do Grupo Clínico $\quad(n=30)$ 
A maioria do Grupo Clínico residia em cidades diferentes de Ribeirão Preto (SP), o que dificultou a composição do Grupo Controle na mesma rede social. Optou-se por buscar crianças desse grupo a partir da instituição escolar (pública ou privada) em Ribeirão Preto, constituindo em amostra por conveniência. Os participantes do Grupo Clínico estudavam em escola pública, com exceção de um menino. Assim, instituições públicas do Ensino Fundamental (EF) foram convidadas a colaborar, respeitando-se a similaridade do contexto sociocultural e viabilidade prática (recepção do projeto pela coordenação das escolas). Desses contatos institucionais, duas delas concordaram com a pesquisa. A primeira escola de EF I (Escola 1) era mantida por uma Fundação de Ribeirão Preto (SP), a qual também oferece diversos tipos de cursos e modalidades esportivas para crianças do EF II no contraturno da escola regular. Dada à rotina acadêmica destas crianças, foi necessário maior número de sessões de menor duração para completar o processo de avaliação neuropsicológica. $\mathrm{Na}$ Escola 1, foram avaliados 22 participantes. Os casos restantes foram coletados numa segunda instituição escolar $(n=6)$ e na rede social da pesquisadora $(n=2)$.

Na Escola 1 foram convidadas 30 crianças, entretanto, cinco não tiveram a participação autorizada pelos responsáveis e duas foram excluídas (doença neurológica prévia e dificuldade de aprendizagem). Vinte e três foram avaliadas, mas uma não concluiu o processo. Na Escola 2 foi realizado o convite a 10 alunos, indicados pela professora como não possuidores de dificuldades de aprendizagem. Destas, quatro não foram autorizados a participar e seis completaram a avaliação. Da rede social, as duas crianças finalizaram o processo avaliativo (Fluxograma 2).

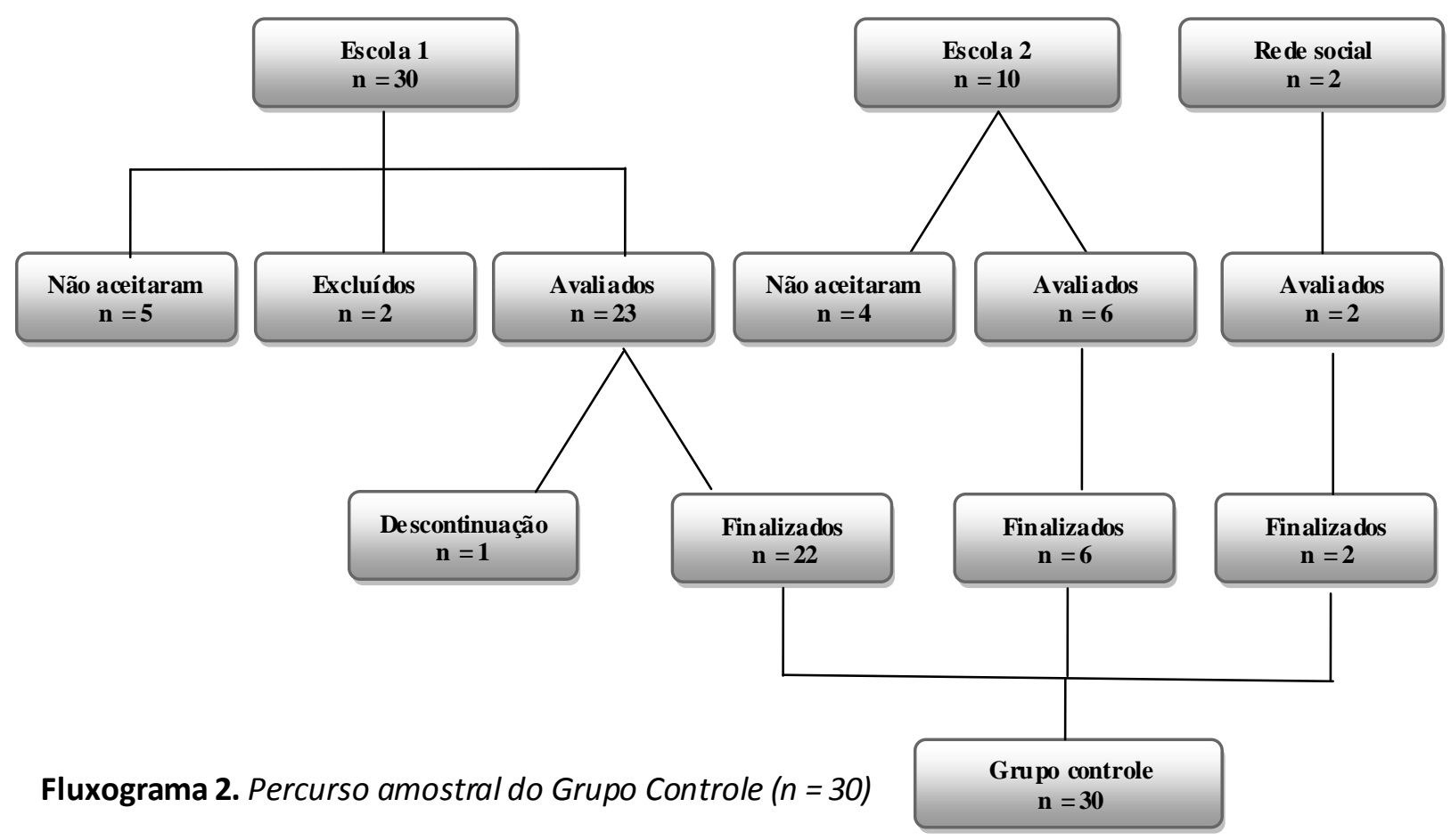


Após aplicação dos critérios de seleção aqui apontados, chegou-se a amostra de 60 crianças, conforme inicialmente delineado, descritas na Tabela 1.

Tabela 1 - Distribuição dos participantes por sexo e idade

\begin{tabular}{ccc|ccc}
\hline \multirow{2}{*}{ Idade } & \multicolumn{2}{c|}{$\begin{array}{c}\text { Grupo Clínico } \\
(\mathbf{n}=\mathbf{3 0})\end{array}$} & \multicolumn{2}{c}{$\begin{array}{c}\text { Grupo Controle } \\
(\mathbf{n}=\mathbf{3 0})\end{array}$} & \multirow{2}{*}{ TOTAL } \\
\cline { 2 - 5 } & Masculino & Feminino & Masculino & Feminino & \\
$\mathbf{7}$ & 2 & 3 & 2 & 3 & 10 \\
$\mathbf{8}$ & 1 & 3 & 1 & 3 & 8 \\
$\mathbf{9}$ & 1 & 1 & 1 & 1 & 4 \\
$\mathbf{1 0}$ & 2 & - & 2 & - & 4 \\
$\mathbf{1 1}$ & 9 & 2 & 9 & 2 & 22 \\
$\mathbf{1 2}$ & 3 & 3 & 3 & 3 & 12 \\
TOTAL & $\mathbf{1 8}$ & $\mathbf{1 2}$ & $\mathbf{1 8}$ & $\mathbf{1 2}$ & $\mathbf{6 0}$ \\
\hline
\end{tabular}

A amostra ficou, então, composta por 60 crianças entre 7 a 12 anos com idade média de 9,9 anos com desvio padrão (DP) $\pm 1,8$, sendo $60 \%$ do sexo masculino. Nenhuma criança foi excluída pelo critério de deficiência intelectual em ambos os testes de desempenho intelectual, conforme descrito na Tabela 2.

Tabela 2 - Distribuição do desempenho intelectual no WISC III e Raven nos Grupos Clínico e Controle

\begin{tabular}{|c|c|c|c|c|c|c|c|c|}
\hline & \multicolumn{4}{|c|}{$\begin{array}{l}\text { Grupo Clínico } \\
(n=30)\end{array}$} & \multicolumn{4}{|c|}{$\begin{array}{c}\text { Grupo Controle } \\
(n=30)\end{array}$} \\
\hline & \multicolumn{2}{|c|}{ WISC III } & \multicolumn{2}{|c|}{ Raven } & \multicolumn{2}{|c|}{ WISC III } & \multicolumn{2}{|c|}{ Raven } \\
\hline & $f$ & $\%$ & $\boldsymbol{F}$ & $\%$ & $\boldsymbol{F}$ & $\%$ & $f$ & $\%$ \\
\hline $\begin{array}{l}\text { Superior/ muito } \\
\text { superior }\end{array}$ & 3 & 10 & - & - & 7 & 23,4 & 6 & 20,0 \\
\hline Médio superior & 4 & 13,3 & 16 & 53,3 & 10 & 33,3 & 15 & 50,0 \\
\hline Médio & 12 & 40,0 & 7 & 23,3 & 13 & 43,3 & 7 & 23,3 \\
\hline Médio inferior & 8 & 26,7 & 6 & 20,0 & - & - & 2 & 6,7 \\
\hline Limítrofe & 3 & 10,0 & - & - & - & - & - & - \\
\hline Deficiente & - & - & 1 & 3,3 & - & - & - & - \\
\hline
\end{tabular}

As características escolares (ano e rendimento) das crianças da amostra estão expostas na Tabela 3. 
Tabela 3 - Distribuição dos participantes em relação ao desempenho escolar

\begin{tabular}{|c|c|c|c|c|}
\hline \multirow[t]{2}{*}{$\begin{array}{l}\text { Ano escolar } \\
\text { (em curso) }\end{array}$} & \multicolumn{2}{|c|}{$\begin{array}{l}\text { Grupo Clínico } \\
(n=30)\end{array}$} & \multicolumn{2}{|c|}{$\begin{array}{l}\text { Grupo Controle } \\
\qquad(n=30)\end{array}$} \\
\hline & $f$ & $\%$ & $f$ & $\%$ \\
\hline 10. & 1 & 3,3 & 1 & 3,3 \\
\hline 2‥ & 5 & 16,7 & 4 & 13,3 \\
\hline 3ㅇ. & 5 & 16,7 & - & - \\
\hline 4ㅇ. & 6 & 20,0 & 5 & 16,7 \\
\hline 5ㅇ. & 5 & 16,7 & 3 & 10,0 \\
\hline $6 \circ$. & 6 & 20,0 & 11 & 36,7 \\
\hline 70. & 2 & 6,7 & 5 & 16,7 \\
\hline 8‥ & - & - & 1 & 3,3 \\
\hline Repetência & 10 & 33,3 & - & - \\
\hline $\begin{array}{l}\text { Dificuldade de } \\
\text { aprendizagem }\end{array}$ & 8 & 26,7 & - & - \\
\hline
\end{tabular}

A análise comparativa entre os grupos mostrou que a média do ano escolar naqueles com DF foi de 4,17 anos (DP $\pm 1,66$ ) e no Grupo Controle de 5,10 anos (DP $\pm 1,82$ ) com diferença estatisticamente significativa $(p=0,031)$. O Grupo Clínico apresentou menor nível escolar, alto índice de repetência escolar (33,3\%) e dificuldades de aprendizagem (26,7\%). Destaca-se que a taxa de repetência e dificuldade de aprendizagem foi nula no Grupo Controle, pois por definição do atual estudo, esse grupo foi formado por crianças com sinais de desenvolvimento típico, sendo excluída qualquer alteração que pudesse sugerir dificuldade cognitiva.

A caracterização do nível socioeconômico (NSE) aferida pelos critérios da Associação Brasileira de Empresa de Pesquisa (ABEP, 2012) e a escolaridade dos pais ou responsáveis estão apresentadas na Tabela 4.

Tabela 4 - Distribuição dos Grupos Clínicos e Controle em função do NSE e escolaridade dos pais

\begin{tabular}{|c|c|c|c|c|c|c|}
\hline & \multicolumn{2}{|c|}{ Grupo Clínico } & \multicolumn{2}{|c|}{ Grupo Controle } & \multirow[b]{2}{*}{ Teste $\chi^{2}$} & \multirow[b]{2}{*}{$p$} \\
\hline & $f$ & $\%$ & $f$ & $\%$ & & \\
\hline \multicolumn{7}{|l|}{ Escolaridade pai } \\
\hline Funda mental & 21 & 70 & 14 & 46,6 & \multirow{3}{*}{6,26} & \multirow{3}{*}{$0,01^{*}$} \\
\hline Média/Superior & 5 & 16,6 & 15 & 50,0 & & \\
\hline Não informada & 4 & 13,3 & 1 & 3,3 & & \\
\hline \multicolumn{7}{|l|}{ Escolaridade mãe } \\
\hline Funda mental I & 22 & 73,3 & 10 & 33,3 & \multirow{3}{*}{10,75} & \multirow{3}{*}{$0,001^{*}$} \\
\hline Média/Superior & 7 & 23,3 & 20 & 66,6 & & \\
\hline Não informada & 1 & 3,3 & - & - & & \\
\hline \multicolumn{7}{|c|}{ Nível socieconômico } \\
\hline$A B$ & 2 & 6,7 & 12 & 40,0 & \multirow{2}{*}{9,32} & \multirow{2}{*}{$0,002^{*}$} \\
\hline $\mathrm{CDE}$ & 28 & 93,3 & 18 & 60,0 & & \\
\hline
\end{tabular}


A escolaridade mostrou-se estatisticamente inferior no pai $(p=0,01)$ e na mãe $(p=$ 0,001) dos pacientes com DF. O NSE sinalizou-se estatisticamente inferior no Grupo Clínico ( $p=0,002)$, embora a Classe C tenha predominado nos Grupos Clínico (63,3\%) e Controle (60,0\%), existiram casos de crianças no Grupo Clínico com NSE inferior (D e E), o que não ocorreu no Grupo Controle.

As variantes genéticas da amostra com DF foi: $17 \mathrm{SS}, 11 \mathrm{SC}, 1 \mathrm{~S} \beta+\mathrm{e} 1 \mathrm{~S} \beta^{\circ}$. Para fins de análise, as crianças foram subdivididas em dois grupos em função do risco para desenvolveram complicações clínicas e neurológicas, a saber: a) subgrupo de maior risco: SS e $S \beta^{\circ}(n=18)$; b) subgrupo de menor risco: $\mathrm{SC}$ e $\mathrm{S} \beta+(\mathrm{n}=12)$.

Em síntese, esta amostra preencheu os critérios de pareamento proposto para esse estudo, exceto para NSE, viabilizando a análise caso-controle.

\subsection{Materiais}

\subsubsection{Instrumentos de avaliação psicológica}

Foram selecionados quatro instrumentos de avaliação psicológica. Para triagem a intelectiva, o teste das Matrizes Progressivas Coloridas de Raven e o QI Estimado da Escala de Inteligência Wechsler para Crianças (WISC III). Para avaliação neuropsicológica, o NEPSY II: Avaliação Neuropsicológica do Desenvolvimento e o Child Behaviour Checklist $C B C L / 6-18$ para avaliação do comportamento.

\subsubsection{Matrizes Progressivas Coloridas de Raven - Escala Especial (Raven, Raven \& Court,} 1993)

Utilizada a versão brasileira com padronização elaborada por Angelini et al. (1999). Esse teste estima o potencial geral de inteligência, por meio de atividades de raciocínio não verbal. A tarefa é encontrar o pedaço que falta para completar um desenho, sendo a prova composta por três séries de 12 problemas com nível de dificuldade crescente. Na análise dos resultados, considerou-se como "intelectualmente deficiente" escore menor ou igual ao percentil $5(\mathrm{P} \leq 5)$.

\subsubsection{Escala de Inteligência Wechsler para Crianças - WISC III (Wechsler, 1991)}

Utilizada forma abreviada da versão brasileira do WISC III (Figueiredo, 2002), composta pelos subtestes "Cubos" e "Vocabulário", estimando-se o equivalente ao quociente 
intelectual (QI estimado), obtido por meio da soma dos pontos ponderados desses dois subtestes. No subteste "Cubos", a criança deve construir modelos usando cubos de duas cores e tem como objetivo avaliar o raciocínio abstrato e a habilidade de visoconstrução. Em "Vocabulário" é solicitada a definição oral de cada palavra lida pelo examinador com intuito de investigar o desenvolvimento da linguagem por meio do conhecimento semântico. De acordo com Mello et al. (2011), o QI Estimado pode ser adotado como triagem de desempenho intelectual em crianças brasileiras, utilizando-se a tabela americana modificada de Sattler (1992) para a classificação dos resultados, conforme especificado por Spreen e Strauss (1998). O desempenho inferior ao QI 70 (QI < 70) foi considerado deficiência intelectual.

\subsubsection{NEPSY II: Avaliação Neuropsicológica do Desenvolvimento (Korkman, Kirk \&} Kemp, 2007)

A avaliação neuropsicológica foi realizada com o NEPSY II, de acordo com a versão adaptada por Argollo et al. (2010) que contém 32 subtestes e quatro tarefas tardias. Esses subtestes estão agrupados em seis domínios cognitivos: atenção/função executiva, aprendizagem e memória, linguagem, percepção social, processamento visoespacial e função sensoriomotora (Quadro 1).

Diante da complexidade e da extensão desta bateria neuropsicológica, foram selecionados 19 subtestes considerando a faixa etária incluída nessa pesquisa e visando cobrir cinco domínios cognitivos de forma mais sintética do que sua totalidade. Não foram utilizados os subtestes do domínio de percepção social, recomendado para avaliação de crianças com dificuldade de habilidades sociais. A forma de aplicação utilizada no estudo foi a recomendada pelos autores originais (Korkman et al., 2007) para crianças com suspeita de lesão ou disfunção cerebral, hipótese a ser investigada no estudo. Os subtestes utilizados e sua descrição encontram-se no Quadro 2.

Segundo Argollo (2010), no Brasil foram realizados dois estudos pilotos com a versão brasileira do NEPSY I, demonstrando que os escores ponderados dos subtestes dessa bateria se mantiveram dentro da variabilidade da normatização americana de $10 \pm 3$, com exceção apenas do subteste "Pseudopalavras" que necessitou de revisão, pois alcançou média brasileira acima do esperado $(13,47)$. Os estudos relativos às qualidades psicométricas da versão brasileira do NEPSY II encontram-se em curso (comunicação pessoal da autora), mas os trabalhos até o momento apresentados sugerem sua adequação técnica. Embora esta versão 
não esteja comercializada e autorizada para uso clínico no Brasil, sua adaptação brasileira foi gentilmente cedida e autorizada para o presente trabalho (ANEXO A).

\begin{tabular}{|c|c|c|}
\hline Domínio & Subteste & $\begin{array}{c}\text { Idade } \\
\text { (anos) }\end{array}$ \\
\hline \multirow{6}{*}{$\begin{array}{c}\text { Atenção/ fun ção } \\
\text { executiva }\end{array}$} & Classificando Animais & $7-16$ \\
\hline & Atenção Auditiva e Conjunto de Repostas & $5-16$ \\
\hline & Relógios & 7- 16 \\
\hline & Fluência em Desenhos & $5-12$ \\
\hline & Inibindo Repostas & $5-16$ \\
\hline & Estátua & $3-6$ \\
\hline \multirow{7}{*}{$\begin{array}{l}\text { Aprendizagem e } \\
\text { memória }\end{array}$} & Memória para Lista (imediata e tardia) & $7-12$ \\
\hline & Memória para Desenhos (imediata e tardia) & $3-16$ \\
\hline & Memória para Faces (imediata e tardia) & $5-16$ \\
\hline & Memória para Nomes (imediata e tardia) & $5-16$ \\
\hline & Memória Narrativa & $3-16$ \\
\hline & Repetindo Frases & $3-6$ \\
\hline & Lista de Palavras-Interferência & $7-16$ \\
\hline \multirow{7}{*}{ Linguagem } & Nomeando e Identificando Partes do Corpo & $3-4$ \\
\hline & Compreendendo Instruções & $3-16$ \\
\hline & Sequências Oromotoras & $3-12$ \\
\hline & Processamento Fonológico & $3-16$ \\
\hline & Rep etindo Pseudopalavras & $5-12$ \\
\hline & Nomeando Rápido & $3-16$ \\
\hline & Produzindo Palavras & $3-16$ \\
\hline \multirow{2}{*}{ Percepção social } & Reconhecen do Emoções & $3-16$ \\
\hline & Teoria da Mente & $3-16$ \\
\hline \multirow{6}{*}{$\begin{array}{l}\text { Processamento } \\
\text { visoespacial } \\
\text { (VE) }\end{array}$} & Flechas & $5-16$ \\
\hline & Construindo com Blocos & $3-16$ \\
\hline & Copiando Desenhos & $3-16$ \\
\hline & Quebracabeça Geométrico & $3-16$ \\
\hline & Quebracabeça de Imagens & $7-16$ \\
\hline & Encontrando Caminhos & $5-12$ \\
\hline \multirow{4}{*}{$\begin{array}{l}\text { Sensoriomotor } \\
\text { (SM) }\end{array}$} & Tocando nas Pontas dos Dedos & $5-16$ \\
\hline & Imitando as Posições da Mão & $3-12$ \\
\hline & Sequencias Motoras Manuais & $3-12$ \\
\hline & Precisão Visomotora & $3-12$ \\
\hline
\end{tabular}

Quadro 1. NEPSY II: Domínios cognitivos e subtestes 
Subtestes

\begin{tabular}{|c|c|c|c|}
\hline & Subtestes & Descriçao & Funçao cognitıva \\
\hline \multirow{3}{*}{ 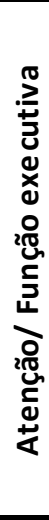 } & $\begin{array}{l}\text { Atenção Auditiva e } \\
\text { Conjunto de } \\
\text { Respostas }\end{array}$ & $\begin{array}{l}\text { Composto por duas tarefas: } \\
\text { 1- Consiste em escutar uma série de palavras e tocar } \\
\text { um círculo apropriado diante da palavra-alvo. } \\
\text { 2- Consiste em escutar uma série de palavras, tocar em } \\
\text { diferentes círculos diante de palavras-alvo diferentes da } \\
\text { cor dos círculos. }\end{array}$ & $\begin{array}{l}\text { 1- Atenção auditiva seletiva e } \\
\text { sustentada. } \\
\text { 2- Flexibilidade mental, inibição de } \\
\text { resposta e memória operacional alça } \\
\text { fonológica. }\end{array}$ \\
\hline & Inibindo Respostas & $\begin{array}{l}\text { Composto por três tarefas: } \\
\text { 1- Nomeação: nomear a forma ou a direção da seta. } \\
\text { 2- Inibição: nomear de maneira invertida a forma ou } \\
\text { direção da seta. } \\
\text { 3- Mudança: a nomeação dependerá da cor da forma } \\
\text { ou seta. }\end{array}$ & $\begin{array}{l}\text { 1- Velocidade de nomeação. } \\
\text { 2- Inibição de respostas automáticas em } \\
\text { favor de respostas novas. } \\
\text { 3- Flexibilidade mental para trocar o } \\
\text { tipo de resposta. }\end{array}$ \\
\hline & $\begin{array}{l}\text { Fluência em } \\
\text { Desenhos }\end{array}$ & $\begin{array}{l}\text { Realizar tantos desenhos quanto possível, ligando cinco } \\
\text { pontos, dentro do tempo limite. }\end{array}$ & $\begin{array}{l}\text { Fluência visomotora para gerar } \\
\text { desenhos originais. }\end{array}$ \\
\hline \multirow{4}{*}{ 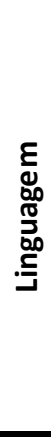 } & Nomeando Rápido & $\begin{array}{l}\text { Deve-se nomear rapidamente uma série de formas, } \\
\text { cores e tamanhos ou letras e números. }\end{array}$ & $\begin{array}{l}\text { Velocidade de acesso semântico e } \\
\text { produção de nomes. }\end{array}$ \\
\hline & $\begin{array}{l}\text { Compreendendo } \\
\text { Instruções }\end{array}$ & $\begin{array}{l}\text { Para cada item, deve-se apontar para o estímulo } \\
\text { apropriado à instrução verbal. }\end{array}$ & $\begin{array}{l}\text { Habilidade de perceber, processar e } \\
\text { executar instruções orais de } \\
\text { complexidade sintática crescente. }\end{array}$ \\
\hline & $\begin{array}{l}\text { Processamento } \\
\text { Fonológico }\end{array}$ & $\begin{array}{l}\text { Composto por duas ta refas: } \\
\text { 1-Identificação de palavras por meio de segmentos } \\
\text { 2- Criação de nova palavra por meio de supressão de } \\
\text { sílabas ou fonemas, ou por substituição de fonema. }\end{array}$ & $\begin{array}{l}\text { Consciência fonológica: } \\
\text { 1- Reconhecimento de segmentos de } \\
\text { palavras } \\
\text { 2-Segmentação fonológica }\end{array}$ \\
\hline & Produzindo Palavras & $\begin{array}{l}\text { Produzir palavras rapidamente em cada categoria: } \\
\text { 1-Semântica (a nimais e, comida e bebida). } \\
\text { 2- Letra inicial (S e F). }\end{array}$ & $\begin{array}{l}\text { Produção verbal para gerar palavras } \\
\text { dentro de categorias específicas. }\end{array}$ \\
\hline \multirow{4}{*}{ 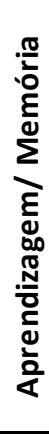 } & Memória Narrativa & $\begin{array}{l}\text { Repetição de história livre. Depois são realizadas } \\
\text { perguntas sobre detalhes esquecidos da história. }\end{array}$ & $\begin{array}{l}\text { Memória para organizar material verbal } \\
\text { em esquema de recordação livre, com } \\
\text { pistas e reconhecimento. }\end{array}$ \\
\hline & $\begin{array}{l}\text { Memória para } \\
\text { Desenhos } \\
\text { (imediata e tardia) }\end{array}$ & $\begin{array}{l}\text { Mostra-se grades com } 4-10 \text { desenhos abstratos. Após } \\
\text { sua remoção, a criança seleciona os desenhos de uma } \\
\text { série de cartões e os coloca no local correto na grade. }\end{array}$ & $\begin{array}{l}\text { Memória imediata e tardia para } \\
\text { material visual e espacial. }\end{array}$ \\
\hline & $\begin{array}{l}\text { Memória para Faces } \\
\text { (imediata e tardia) }\end{array}$ & $\begin{array}{l}\text { A criança olha fotos de uma série de faces. Depois, } \\
\text { seleciona aquela previamente vista dentre três } \\
\text { fotografias. }\end{array}$ & $\begin{array}{l}\text { Codificação de características faciais, } \\
\text { discriminação e reconhecimento } \\
\text { imediato e tardio de faces. }\end{array}$ \\
\hline & $\begin{array}{l}\text { Memória para Lista } \\
\text { de Palavras } \\
\text { (imediata e tardia) }\end{array}$ & $\begin{array}{l}\text { Repetição de uma lista de palavras com cinco ensaios } \\
\text { de aprendizagem, depois repetição de nova lista e } \\
\text { posterior recordação da lista inicial. }\end{array}$ & $\begin{array}{l}\text { Memória verbal imediata e tardia, ritmo } \\
\text { de aprendizagem e a interferência na } \\
\text { recordação. }\end{array}$ \\
\hline \multirow{3}{*}{ 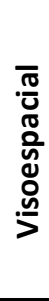 } & Flechas & $\begin{array}{l}\text { Dentre uma série de flechas distribuídas em volta de } \\
\text { um alvo, deve-se indicar a(s) flecha(s) que aponta(m) } \\
\text { para o centro do alvo. }\end{array}$ & $\begin{array}{l}\text { Julgamento visual de linhas e } \\
\text { orientação de ângulo. }\end{array}$ \\
\hline & $\begin{array}{l}\text { Quebracabeças } \\
\text { Geométricos }\end{array}$ & $\begin{array}{l}\text { Mostra-se uma série de grades contendo formas. A } \\
\text { criança deve combinar duas formas do lado de fora da } \\
\text { grade com duas formas de dentro. }\end{array}$ & $\begin{array}{l}\text { Rotação mental, análise visoespacial e } \\
\text { atenção a detalhes. }\end{array}$ \\
\hline & Copiando Desenhos & $\begin{array}{l}\text { Copiar figuras geométricas bidimensionais do caderno } \\
\text { de estímulo. }\end{array}$ & Habilida de motora e visoperceptual. \\
\hline \multirow{4}{*}{ 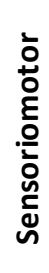 } & Precisão Visomotora & Desenhar rapidamente linhas dentro de uma trajetória. & Velocidade e precisão grafomotora. \\
\hline & $\begin{array}{l}\text { Imitando posições } \\
\text { das mãos }\end{array}$ & $\begin{array}{l}\text { Imitar posições da mão estáticas progressivamente } \\
\text { complexas, demonstradas pelo aplicador. }\end{array}$ & $\begin{array}{l}\text { Análise visoespacial, programação } \\
\text { motora e feedback cinestésico. }\end{array}$ \\
\hline & $\begin{array}{l}\text { Sequências Motoras } \\
\text { Manuais }\end{array}$ & $\begin{array}{l}\text { Imitar uma série de movimentos rítmicos, usando uma } \\
\text { ou ambas as mãos. }\end{array}$ & $\begin{array}{l}\text { Habilidade de imitar sequências de } \\
\text { movimentos rítmicos. }\end{array}$ \\
\hline & $\begin{array}{l}\text { Tocando nas pontas } \\
\text { dos dedos }\end{array}$ & $\begin{array}{l}\text { Imitar rapidamente uma série de movimentos dos } \\
\text { dedos. }\end{array}$ & $\begin{array}{l}\text { Destreza e velocidade motora dos } \\
\text { dedos e, programação motora. }\end{array}$ \\
\hline
\end{tabular}

Quadro 2. Descrição do subtestes do NEPSY II e das funções cognitivas utilizados 
3.2.1.4. Child Behaviour Checklist - CBCL / 6-18 (Achenbach \& Rescorla, 2001)

Para a avaliação do comportamento, utilizou-se o CBCL de 6 a 18 anos, versão brasileira adaptada por Bordin, Silvares, Rocha, Teixeira e Paula (2010). Trata-se de um inventário a ser preenchido pelo responsável da criança, destinado a avaliar problemas comportamentais e emocionais, considerando o período dos últimos seis meses. Cada item possui escala de frequência (de intensidade) que indica, respectivamente: 0 - não verdadeiro; 1 - um pouco verdadeiro/algumas vezes verdadeiro; 2 - muito verdadeiro/ frequentemente verdadeiro.

A análise computadorizada dos itens fornecem oito perfis com indicadores de síndromes comportamentais e emocionais: ansiedade/ depressão; retraimento/ depressão; queixas somáticas; problemas sociais; problemas do pensamento; problemas de atenção; violação de regras; e comportamento agressivo. Os escores $T$ classificam como normal $T \leq$ 64; limítrofe $T$ 65-69; clínico $T \geq 70$. O somatório das três primeiras escalas compõe a Escala de Problemas de Internalização e a soma das duas últimas, a Escala de Problemas de Externalização. A soma de todas as escalas forma a Escala Total. Essas três escalas são classificadas também em escores $T$, como normal $T \leq 59$; limítrofe $T 60-63$; clínico $T \geq 64$. Não foram utilizados, na atual análise os dados do CBCL, as seis escalas elaboradas a partir dos critérios diagnósticos do Manual de Diagnóstico e Estatística de Transtornos Mentais.

\subsubsection{Instrumento de avaliação sociode mográfica}

Informações sobre aspectos sociodemográficos, histórico educacional e do desenvolvimento das crianças foram fornecidas pelos responsáveis mediante respostas ao formulário apresentado no APÊNDICE A. Este formulário foi adaptado pela pesquisadora para esse trabalho, a partir de instrumento original criado no Centro de Pesquisas em Psicodiagnóstico da Faculdade de Filosofia, Ciências e Letras de Ribeirão Preto da Universidade de São Paulo (FFCLRP - USP). Para a avaliação da classe socioeconômica foi utilizado o critério de classificação econômica Brasil (ABEP, 2012).

\subsubsection{Exames médicos}

O histórico médico do Grupo Clínico foi coletado por revisão de prontuários médicos, registrados no Hospital das Clínicas da FMRP-USP. Com este levantamento, foi possível 
sistematizar dados relativos ao quadro clínico das crianças e complementados por exames e fontes informativas médicas, conforme abaixo discriminado.

\subsubsection{Imagens}

\subsection{Doppler Transcraniano (DTC)}

DTC identifica pacientes de risco para acidente vascular cerebral isquêmico (AVC-I). Foram aferidas medidas da circulação intracraniana nos hemisférios direito e esquerdo, na artéria cerebral média (ACM), artéria cerebral anterior (ACA), artéria cerebral posterior (ACP) e artéria basilar (ABAS). Na avaliação da VFSC foram considerados como referência os valores do Guidelines brasileiro (2011) para crianças com DF:

- VFSC redução $<70 \mathrm{~cm} / \mathrm{seg}$

- VFSC normal entre 70 e $170 \mathrm{~cm} / \mathrm{seg}$

- VFSC limítrofe entre 170 e $220 \mathrm{~cm} / \mathrm{seg}$

- VFSC anormal > $220 \mathrm{~cm} / \mathrm{seg}$

\subsection{Imagem por Ressonância Magnética (IRM)}

A IRM do encéfalo foi utilizada para diferenciar o Grupo Clínico com infarto cerebral clínico (AVC), infarto cerebral silencioso (ICS) ou sem infarto (normal). Essa diferenciação clínica serviu ao propósito de seleção dos participantes do estudo. Também foi utilizada para realização de análise comparativa de desempenho nos testes neuropsicológicos entre os subgrupos de crianças com DF: ICS versus normal.

\subsubsection{Exames laboratoriais}

\subsection{Eletroforese de hemoglobina}

A eletroforese da hemoglobina é um exame de sangue para identificar as hemoglobinopatias e as talassemias. Foi realizada pelo método HPLC e alguns casos pela eletroforese em acetato de celulose. Estes detalhes informativos são importantes para comparação entre os tipos genéticos do Grupo Clínico.

\subsubsection{Hemograma}

Foram coletados dados do hemograma referentes aos valores da hemoglobina $(\mathrm{Hb})$ e do hematócrito (Ht) para realizar correlação com os testes neuropsicológicos. 


\subsection{Procedime ntos}

\subsubsection{Cuidados éticos e coleta de dados}

Essa pesquisa foi submetida à avaliação pelo Comitê de Ética em Pesquisa com Seres Humanos da FFCLRP-USP de acordo com o Processo n 573/2011(ANEXO B). Para a coleta de dados relativa ao histórico médico das crianças do Grupo Clínico nos prontuários do HC FMRP - USP, foi necessária solicitar a avaliação complementar do projeto por parte do Comitê de Ética em Pesquisa dessa referida instituição, sendo aprovada a realização da pesquisa (ANEXO C).

A partir dos prontuários médicos do Hemocentro (ANEXOS D e E), foi possível acompanhar os possíveis voluntários ao estudo nas consultas regulares do Ambulatório de DF. Identificados os casos, realizou-se contato com o responsável legal da criança para informar sobre os objetivos do estudo e solicitar a participação nessa pesquisa, bem como de sua criança. Tanto a criança quanto seu responsável foram convidados a participar desse estudo na condição de voluntários, conforme diretrizes da Resolução 196/96 do Conselho Nacional de Ética em Pesquisa (CONEP), sendo comunicados da possibilidade de desistência em qualquer momento, sem ônus ou prejuízo no tratamento no Hemocentro. Aqueles pais ou responsáveis que concordaram com a pesquisa, assinaram o Termo de Consentimento Livre e Esclarecido (APÊNDICE B). Todas as informações relativas aos participantes estão mantidas em sigilo.

O processo de avaliação psicológica do Grupo Clínico realizou-se em sala apropriada no Hemocentro, em sessões individuais. Durante a avaliação, nenhuma criança com DF estava em crise de dor ou outras complicações clínicas. No Grupo Controle, a avaliação psicológica ocorreu, em sua maioria, na própria escola da criança (APÊNDICE C). Em algumas crianças, a aplicação aconteceu em sua própria residência, com a autorização da família. Todas as avaliações neuropsicológicas foram conduzidas pela pesquisadora para excluir viés interaplicadores, contudo não afasta viés sistemático de aplicação. $\mathrm{Na}$ fase da avaliação do Grupo Clínico, a pesquisadora foi cega para os resultados dos exames de imagens, DTC e do exame clínico neurológico. Contudo, não estava cega para o diagnóstico das crianças, por ter sido a própria selecionadora dos casos (Grupo Clínico versus Grupo Controle).

A triagem intelectual foi iniciada com a realização do Raven, seguido pelos subtestes "Vocabulário" e "Cubos" do WISC III. A aplicação ocorreu em uma única sessão de aproximadamente 40 minutos. Em novos encontros, a bateria NEPSY II foi aplicada. A 
administração dos subtestes do NEPSY II não possui uma ordem fixa, de modo que o examinador pode elaborar um plano de trabalho específico para cada criança, procurando garantir sua motivação e interesse nas atividades (Korkman, Kirk \& Kemp, 2007). Assim, a realização dos 19 subtestes foi conduzida de maneira flexível e gradual, em função do desempenho da criança, efetivando-se em duas a três sessões de aproximadamente uma hora e meia de duração cada.

Os responsáveis legais do Grupo Clínico responderam aos questionários sociodemográfico e de antecedentes médicos da criança, bem como ao CBCL, durante o período em que a criança estava realizando sua avaliação neuropsicológica. Alguns preferiram responder a esses instrumentos em sua própria residência, o que foi respeitado, entregando-os na sessão subsequente. Nos casos de baixa escolaridade de alguns responsáveis, foi necessário o auxílio da pesquisadora para o correto preenchimento das informações solicitadas. No Grupo Controle, esses instrumentos foram entregues às crianças nas escolas, devendo os responsáveis completá-los em suas residências. Nos casos onde ocorreram dúvidas no tocante ao preenchimento dos dados, a pesquisadora entrou em contato telefônico com os responsáveis dos escolares, conferindo as informações e corrigindo-as se necessário.

A maioria dos responsáveis pelas crianças do Grupo Clínico receberam, por fim, entrevista devolutiva e de orientação a respeito dos resultados da avaliação neuropsicológica, realizada pela própria pesquisadora. Apenas duas crianças, cujos familiares não compareceram às sessões agendadas, não receberam esse retorno técnico sobre os casos. Os pais também foram orientados quanto à realização de atividades de estimulação neuropsicológica, oferecendo-lhes alternativas de exercícios facilitadores ao desenvolvimento infantil. Em alguns casos, os mesmos foram orientados a buscar auxílio profissional em serviços específicos de Saúde, sendo fornecidos relatórios da avaliação psicológica. Portanto, esse amplo processo de avaliação neuropsicológica implicou, dentro de suas condições de exequibilidade, em atividade de intervenção profissional, integrando pesquisa e ação profissional.

No tocante ao processo de produção dos dados médicos do Grupo Clínico, o exame de hemograma é rotineiramente realizado em cada retorno do paciente ao Hemocentro. O DTC é efetuado regularmente em intervalos de seis meses a um ano, conforme critérios médicos, sendo realizados no próprio Hemocentro, no mesmo dia da consulta no ambulatório de DF. A IRM foi solicitada pela neurologista responsável pelos pacientes do Hemocentro, sendo realizada no Serviço de Neurorradiologia do HC-FMRP-USP. 
Todas as crianças do Grupo Clínico realizaram exame clínico neurológico com um segundo neurologista (colaborador do estudo). Assim, foi possível assegurar que nenhuma criança com DF tivesse histórico de AVC de acordo com seu histórico médico, entrevista com o responsável e resultado de seu exame neurológico clínico.

\subsubsection{Sistematização e análise dos dados}

Os resultados dos testes psicológicos foram corrigidos e interpretados conforme respectivos manuais técnicos. Vale ressaltar que a pontuação ponderada dos subtestes do NEPSY II foi baseada no manual americano, visto que o estudo brasileiro de validação e normatização dessa bateria encontra-se em andamento. Foi necessário excluir da análise os resultados obtidos em dois subtestes do NEPSY II, a saber: "Tocando na Ponta do Dedo" (devido a grande discrepância verificada entre a população brasileira e americana) e "Copiando Desenho" (foram realizadas alterações em alguns desenhos da versão americana que poderão influenciar a pontuação geral na versão brasileira desse subteste). As respostas do CBCL foram computadas por meio do software Assessment Data Manager (ADM), programa desenvolvido pela equipe dos instrumentos ASEBA para correção desse instrumento (Achenbach \& Rescorla, 2001).

Os dados coletados foram sistematizados em planilhas computacionais e analisados pelo programa estatístico software Statistical Package for Social Sciences (SPSS), versão 16,0. A sistematização das análises estatísticas centrou-se em indicadores específicos para cada instrumento. No Raven foi utilizada a pontuação bruta, ou seja, a quantidade de itens corretos efetuado pela criança, visando possibilitar análises correlacionais com outroas variáveis. Nos subtestes de "Cubos" e "Vocabulário" do WISC III foram considerados os escores ponderados. No NEPSY II foram analisados os seguintes indicadores: a) nos subtestes de “Atenção Auditiva" e "Conjunto de Respostas": escores ponderados para o número de acertos totais e o escore combinado (associação entre total de acertos e percentil de e rros de ação); b) nos subtestes "Inibindo Resposta", "Nomeando Rápido" e "Precisão Visomotora": escores combinados que relacionam o número total de erros e o tempo de realização da tarefa; c) no subteste "Sequência Motora Manual" o resultado é oferecido em intervalos de percentil, assim foi classificado percentil $(\mathrm{P}) \geq 25$ como médio e $\mathrm{P}<25$ como abaixo da média; d) para os demais subtestes: escores ponderados. No CBCL foram utilizados Escores $T$ e as classificações clínico, limítrofe e normal. 
A análise das variáveis sociodemográficas (ano escolar, repetência escolar, dificuldade de aprendizagem, NSE e escolaridade dos pais) foi realizada de modo descritivo (frequência simples e porcentagem, média e DP). Em sequência, foi efetuada a análise estatística comparativa dos resultados do Grupo Clínico e Controle em relação a essas variáveis, utilizando-se Teste $U$ de Mann-Whitney e Qui-dradrado $\left(\chi^{2}\right)$.

As variáveis relativas aos testes neuropsicológicos e comportamentais foram analisadas por estatística descritiva e inferencial por meio do Teste $t$ de Student ou Teste $U$, a depender da distribuição normal (ou não) dos resultados em cada subgrupo. No NEPSY II, somente para o subteste "Sequência Motora Manual" essa comparação foi efetuada pelo Teste Exato de Fisher. Os dados do CBCL também foram agrupados de acordo com os resultados compatíveis com o diagnóstico de "caso clínico" ou "limítrofe" (compondo o subgrupo chamado clínico) e "caso normal” (subgrupo normal), realizando comparações entre esses subgrupos por meio do Teste $\chi^{2}$ ou Exato de Fisher para ambos os grupos.

Para investigar possível interferência da escolaridade do pai e da mãe, além do NSE nos resultados dos testes neuropsicológico e comportamental, foi realizada Análise de Regressão Logística multivariada dos dados, com posterior correção dos supostos efeitos dessas variáveis nos resultados. A partir da identificação das diferenças entre os grupos nesses testes e análises, calculou-se o Odds ratio.

$\mathrm{Na}$ tentativa de verificar a influência da variável idade sobre os resultados, cada grupo foi subdividido nas faixas etárias: 7-9 anos e 10-12 anos. Posteriormente, foram calculadas estatísticas descritiva e inferencial em função do subgrupo etário pelo Teste $t$ ou Teste $U$, a depender da distribuição de normalidade (ou não) dos resultados. Para o subteste "Sequência Motora Manual" utilizou-se o Teste Exato de Fisher.

Para avaliar a associação entre a variável idade e os resultados dos testes neuropsicológicos recorreu-se a análises correlacionais (teste de correlação de Spearman $(\rho)$. Foi adotado o critério de Baptista e Campos (2007) para interpretação dos coeficientes de correlação: 0 a 0,20 nula; 0,20 a 0,40 baixa; 0,40 a 0,60 moderada; 0,60 a 0,80 alta; 0,80 a 1,0 muito alta. Análise similar foi realizada referente ao sexo dos participantes.

Apenas no Grupo Clínico, comparou-se a performance cognitiva em função dos genótipos da DF. Foi realizada também análise de possíveis associações dos resultados nos testes neuropsicológicos e nos indicadores comportamentais com variáveis clínicas (medicações, hemograma, DTC e IRM) foram igualmente utilizadas estatísticas descritiva e inferencial utilizando o Teste $U$ e Teste Exato de Fisher, além de análises correlacionais de Spearman. 
Sublinha-se que foi adotado $p \leq 0,05$ como nível de significância em todas as análises estatísticas realizadas. 
4. RESULTADOS 


\subsection{Relativos aos testes neuropsicológicos}

Inicialmente, os resultados apresentados correspondem as médias e DP do QI Estimado, dos subtestes "Vocabulário" e "Cubos" do WISC III e no Raven, comparando-se o desempenho dos dois grupos (Tabela 5).

Tabela 5 - WISC III e Raven: Comparação entre os Grupos Clínico e Controle

\begin{tabular}{|c|c|c|c|c|c|c|}
\hline & Testes & Grupos & Média & DP & Estat. & $P$ \\
\hline \multirow{4}{*}{ 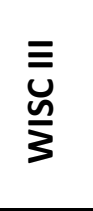 } & QI Estimado & $\begin{array}{l}\text { Clínico } \\
\text { Controle }\end{array}$ & $\begin{array}{r}96,93 \\
110,43 \\
\end{array}$ & $\begin{array}{l}15,39 \\
10,81 \\
\end{array}$ & $-3,932 t$ & $0,001 * *$ \\
\hline & Vocabulário & $\begin{array}{l}\text { Clínico } \\
\text { Controle }\end{array}$ & $\begin{array}{r}9,96 \\
12,13\end{array}$ & $\begin{array}{l}3,22 \\
2,33\end{array}$ & $235 U$ & $0,001^{* *}$ \\
\hline & \multirow{2}{*}{ Cubos } & Clínico & 9 & 2,80 & \multirow{2}{*}{$-3,656 t$} & \multirow{2}{*}{$0,001 * *$} \\
\hline & & Controle & 11,43 & 2,33 & & \\
\hline \multirow[t]{2}{*}{ Raven } & \multirow{2}{*}{ Raven (pontos brutos) } & Clínico & 24,06 & 5,86 & \multirow{2}{*}{$295,5 U$} & \multirow{2}{*}{$0,022 *$} \\
\hline & & Controle & 27,73 & 6,10 & & \\
\hline
\end{tabular}

O Grupo Clínico apresentou desempenho inferior de modo estatisticamente significativo em todos os escores do WISC III $(p=0,001)$ e do Raven $(p=0,022)$. Pode-se inferir, portanto, que a capacidade intelectual desse grupo sinalizou-se como inferior àquela dos não portadores desta patologia.

Os resultados do NEPSY II foram classificados de acordo com as normas americanas, como anteriormente justificado. Estão apresentados em termos de média e DP, seguindo a ordem dos subtestes das funções atenção/função executiva, linguagem, aprendizado e memória, processamento visoespacial e função sensoriomotora (Tabela 6).

O Grupo Clínico obteve desempenho inferior (de modo estatisticamente significativo) em todos os domínios neuropsicológicos, exceto na função sensoriomotora. No domínio atenção/função executiva houve diferença estatisticamente significativa nas três tarefas de "Inibindo Respostas" ( $p \leq 0,05)$ e em "Fluência em Desenho" ( $p=0,01)$. No domínio linguagem, o Grupo Clínico apresentou, de forma estatisticamente significativa, pior resultado em todos os subtestes avaliados $(p \leq 0,01)$ com escores médios abaixo do padrão normativo nesses subtestes, exceto em "Produzindo Palavras - Semântica". No domínio aprendizado/memória, observou-se diferença estatisticamente significativa entre os grupos em todos os subtestes "Memória para Desenho" imediato e tardio $(p \leq 0,01)$ e uma tendência à significância estatística em "Memória para Lista de Palavras" ( $p=0,053)$. Por fim, na habilidade visoespacial, houve diferença estatisticamente significativa entre os grupos no subteste de "Flechas" $(p=0,035)$. 
Tabela 6 - NEPSY II: Comparação entre os Grupos Clínico e Controle nas diferentes funções neuropsicológicas

\begin{tabular}{|c|c|c|c|c|c|c|}
\hline & Testes & Grupos & Média & DP & Estat. & $p$ \\
\hline \multirow{17}{*}{ 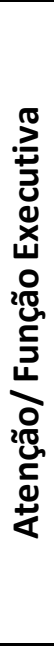 } & Atenção Auditiva & Clínico & $\begin{array}{r}10,93 \\
115\end{array}$ & 2,65 & \multirow[t]{2}{*}{$399,5 U$} & 0,446 \\
\hline & \multirow[b]{2}{*}{ Atenção Auditiva combinado } & $\begin{array}{l}\text { Controle } \\
\text { Clínico }\end{array}$ & $\begin{array}{r}11,5 \\
10,96\end{array}$ & $\begin{array}{l}2,33 \\
2,76\end{array}$ & & \multirow{2}{*}{0,306} \\
\hline & & Controle & 11,6 & 2,34 & $382 U$ & \\
\hline & \multirow{2}{*}{ Conjunto de Respostas } & Clínico & 11,16 & 2,84 & \multirow{2}{*}{$-0,561 t$} & \multirow{2}{*}{0,577} \\
\hline & & Controle & 11,53 & 2,18 & & \\
\hline & \multirow{2}{*}{ Conjunto de Respostas combinado } & Clínico & 11,03 & 2,66 & \multirow{2}{*}{$405,5 U$} & \multirow{2}{*}{0,506} \\
\hline & & Controle & 11,63 & 2,03 & & \\
\hline & \multirow{2}{*}{ Inibindo Respostas- Nomeação } & Clínico & 7,13 & 3,53 & \multirow{2}{*}{$-3,164 t$} & $0,003 * *$ \\
\hline & & Controle & 9,73 & 2,79 & & 0,003 \\
\hline & Inibindo Respostas-Inibição & Clínico & 6,87 & 3,52 & $-2,415 t$ & $0,019 *$ \\
\hline & InIDInao Respostas-Inıdiçao & Controle & 8,93 & 3,09 & $-2,415 t$ & 0,013 \\
\hline & Inibindo Respostas- Mudanca & Clínico & 7,14 & 3,51 & $-2.502 t$ & $0.015 *$ \\
\hline & Imi oInao Kespostas-IVIuaança & Controle & 9,07 & 2,30 & $-2,30<l$ & 0,010 \\
\hline & Inibindo Resnostas - Frro Total & Clínico & 7,31 & 4,36 & & \\
\hline & InI DIndo Respostas- Erro Iotal & Controle & 8,67 & 2,42 & $-1,481 t$ & 0,144 \\
\hline & Fluência em Desenhos & Clínico & 6,3 & 2,48 & 2784 & $0010^{* *}$ \\
\hline & riuencla em ves ennos & Controle & 8,03 & 1,63 & $2 / 80$ & 0,010 \\
\hline & Nomeando Ránido & Clínico & 6,66 & 3,34 & & \\
\hline & Nomeando Rapldo & Controle & 9,83 & 2,07 & $19 / 0$ & $0,001^{* *}$ \\
\hline & & Clínico & 7,1 & 2,83 & $-3.856 t$ & $0.001 * *$ \\
\hline c & Compreendendo Instruçoes & Controle & 9,76 & 2,51 & $-3,850 t$ & $0,001 \cdots$ \\
\hline 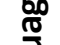 & & Clínico & 4,93 & 3,10 & & \\
\hline مِ & Processamento ronologico & Controle & 7,4 & 1,83 & $215,5 U$ & $0,001^{* *}$ \\
\hline.$气$ & & Clínico & 8,13 & 2,90 & $-3,270 t$ & $0002 * *$ \\
\hline & Produzındo Palavras - Semäntıca & Controle & 10,46 & 2,62 & $-3,2 / 0 t$ & $0,002^{* *}$ \\
\hline & & Clínico & 5,7 & 2,61 & & \\
\hline & Produzındo Palavras - Letra Inıcial & Controle & 8 & 1,98 & $-3,839 t$ & $0,001^{* *}$ \\
\hline & & Clínico & 8,86 & 3,66 & & \\
\hline & Mlemorıa Narrativa Lıvre & Controle & 10,26 & 2,98 & $-1,6<3 t$ & 0,110 \\
\hline & & Clínico & 8,4 & 3,86 & & \\
\hline & Memoria Narrativa Livre + Pista & Controle & 10,16 & 2,80 & 334,50 & 0,086 \\
\hline & & Clínico & 8,5 & 3,14 & & $0,004 * *$ \\
\hline & Memorıa para Desenho Conteudo & Controle & 10,86 & 2,91 & $-3,0<9 t$ & $0,004^{\cdots \omega}$ \\
\hline 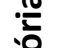 & & Clínico & 8,83 & 3,43 & $216,5 U$ & $0,001 * *$ \\
\hline '을 & IVlemorla para Desenno Espaclal & Controle & 11,9 & 2,47 & 210,50 & $0,001 \cdots$ \\
\hline$\stackrel{\frac{c}{0}}{\underline{c}}$ & Memória nara Desenho Total & Clínico & 8,1 & 3,45 & & \\
\hline$\Sigma$ & Memorıa para Desenho Iotal & Controle & 11,13 & 2,97 & $-3,65<t$ & $0,001 * *$ \\
\hline 으 & & Clínico & 9,03 & 2,93 & & \\
\hline ర్ర & IVlemorıa para Desenno Conteudo tarala & Controle & 11,36 & 2,95 & $241,5 U$ & $0,002^{* *}$ \\
\hline$\frac{N}{2}$ & Memória nara Decenho Fsnacial Tardia & Clínico & 9,43 & 3,36 & 2004 & $0.001 * *$ \\
\hline ⿷ & IVlemorla para Desenno Espaclal Iarala & Controle & 12,43 & 2,01 & 2000 & 0,001 \\
\hline$\frac{0}{2}$ & Memória nara Desenho Total Tardia & Clínico & 9,26 & 3,36 & $-3.392 t$ & $0001 * *$ \\
\hline & IVIemorla para Des enno Iotal Iarala & Controle & 12,13 & 3,18 & $-3,39<t$ & 0,001 \\
\hline & Memória nara Faces & Clínico & 9,6 & 3,08 & 3864 & 0341 \\
\hline & 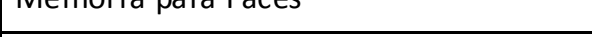 & Controle & 9,06 & 3,38 & & 0,341 \\
\hline & Memória para Faces Tardia & Clínico & 8,4 & 3,47 & 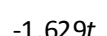 & 0109 \\
\hline & & Controle & 9,83 & 3,34 & & 0,105 \\
\hline & Memória para Lista de Palavras & Clínico & 10,03 & 2,94 & $-1975 t$ & 0053 \\
\hline & 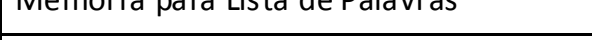 & Controle & 11,46 & 2,67 & $-1,9 / 5 t$ & 0,0כ3 \\
\hline & Flechas & Clínico & 9,76 & 3,76 & $-2.155 t$ & $0.035 *$ \\
\hline ш & riectids & Controle & 11,56 & 2,61 & $-2,15 b t$ & \\
\hline$>$ & Ouebracabeca Geométrico & Clínico & 9,9 & 2,71 & $-1.358 t$ & 0180 \\
\hline & Quebracabeça Geometrıco & Controle & 10,83 & 2,61 & $-1,358 t$ & 0,180 \\
\hline & Precicão Vicomotora & Clínico & 9,53 & 3,37 & 4094 & 0.542 \\
\hline & Precisao visomotora & Controle & 10,6 & 3,61 & 4090 & 0,542 \\
\hline & Imitando Posicão da Mão & Clínico & 8,93 & 3,43 & 35254 & 0145 \\
\hline$\sum_{n}$ & Imi tando posiça da IVIao & Controle & 9,93 & 2,12 & 30,30 & 0,145 \\
\hline & & & Média & Abaixo & & \\
\hline & Sequência Motora Manual & Clínico & 25 & 5 & & \\
\hline & & Controle & 28 & 2 & $F$ & 0,424 \\
\hline
\end{tabular}

Estat. = Estatística; Teste $t$ de Student; $U$ de Mann-Whitney; Exato de Fisher (F); $\mathrm{p}^{* *} \leq 0,01 \mathrm{e}^{*} \leq 0,05 ; \mathrm{VE}=$ Visoespa cial; SM = Sensoriomotor 
Para investigar possível interferência das variáveis demográficas "escolaridade do pai", "escolaridade da mãe" e "NSE" (que sinalizaram influência significativa nos resultados nas análises estatísticas inferenciais prévias), foi realizada Análise de Regressão Logística Multivariada com essas três variáveis independentes (Tabela 7).

Tabela 7 - Análise de Regressão Logística Multivariada entre os Grupos Clínico e Controle a partir de variáveis sociodemográficas

\begin{tabular}{lccr}
\multicolumn{1}{c}{$\begin{array}{c}\text { Variáveis } \\
\text { demográficas }\end{array}$} & $\boldsymbol{p}$ & Exp(B) & \multicolumn{1}{c}{ IC 95\% } \\
\hline Es cola ridade pai & 0,67 & 0,695 & $0,130-3,723$ \\
Escola ridade mãe & $0,05^{*}$ & 0,206 & $0,042-1,003$ \\
NSE & $0,031^{*}$ & 6,774 & $1,192-38,484$ \\
\hline$p^{*} \leq 0,05 ;$ IC = Intervalo de confia nça & &
\end{tabular}

Os resultados apontaram que a variável escolaridade do pai $(p=0,67)$ na presença da escolaridade da mãe $(p=0,05)$ e NSE $(p=0,03)$ deixou de de exercer efeito estatisticamente significativo. sobre os dados das crianças. Portanto, foram utilizadas como variáveis de ajuste e correção para a análise da distribuição dos resultados e das influências das variáveis sociodemográficas sobre o desempenho neuropsicológico, apenas as duas últimas variáveis. Esses resultados estão sistematizados na Tabela 8.

Ao se controlar as variáveis escolaridade da mãe e NSE nos resultados, as diferenças entre Grupo Clínico e Grupo Controle, inicialmente identificadas (Tabela 5 e 6) como estatisticamente significativas, se mantiveram. Detectou-se um padrão diferente de resultados somente no subteste de "Vocabulário", não sendo encontrada discrepância entre os grupos na atual análise $(p=0,068)$. 
Tabela 8 - Resultados da Análise de Regressão Logística Multivariada entre os Grupos Clínico e Controle após correção do modelo em função da escolaridade da mãe e do NSE.

\begin{tabular}{|c|c|c|c|c|}
\hline & Testes & $p$ & Odds ratio & IC 95\% \\
\hline \multirow{4}{*}{ 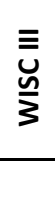 } & QI Estimado & $0,009 * *$ & 0,935 & $0,889-0,94$ \\
\hline & Vocabulário & 0,068 & 0,815 & $0,655-1,016$ \\
\hline & Cubos & $0,009 * *$ & 0,685 & $0,516-0,908$ \\
\hline & Raven (pontos brutos) & 0,018* & 0,863 & $0,763-0,975$ \\
\hline \multirow{9}{*}{ 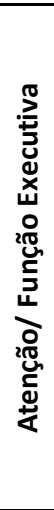 } & Atenção Auditiva & 0,783 & - & - \\
\hline & Atenção Auditiva combina do & 0,843 & - & - \\
\hline & Conjunto de Respostas & 0,323 & - & - \\
\hline & Conjunto de Respostas combinado & 0,867 & - & - \\
\hline & Inibindo Respostas- Nomea ção & $0,010 * *$ & 0,742 & $0,592-0,930$ \\
\hline & Inibindo Respostas- Inibição & $0,025^{*}$ & 0,791 & $0,645-0,971$ \\
\hline & Inibindo Respostas- Mudança & $0,019^{*}$ & 0,742 & $0,578-0,953$ \\
\hline & Inibindo Respostas- Erro Total & 0,101 & - & - \\
\hline & Fluência em Desenhos & $0,038^{*}$ & 0,705 & $0,507-0,981$ \\
\hline \multirow{5}{*}{ 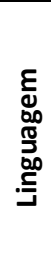 } & Nomeando Rápido & $0,003 * *$ & 0,566 & $0,389-0,823$ \\
\hline & Compreendendo Instruções & $0,008 * *$ & 0,676 & $0,507-0,902$ \\
\hline & Processamento Fonológico & $0,004 * *$ & 0,653 & $0,486-0,876$ \\
\hline & Produzindo Pala vras - Semântica & $0,017^{*}$ & 0,738 & $0,575-0,948$ \\
\hline & Produzindo Pala vras - Letra Inicial & $0,004 * *$ & 0,604 & $0,427-0,855$ \\
\hline \multirow{11}{*}{ 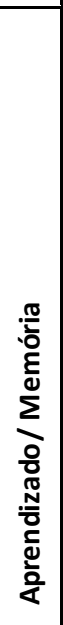 } & Memória Na rra tiva Livre & 0,378 & - & - \\
\hline & Memória Narrativa Livre + Pista & 0,241 & - & - \\
\hline & Memória para Desenho Conteúdo & $0,026^{*}$ & 0,782 & $0,630-0,971$ \\
\hline & Memória para Desenho Espacial & $0,003 * *$ & 0,665 & $0,507-0,871$ \\
\hline & Memória para Desenho Total & $0,011^{*}$ & 0,755 & $0,609-0,936$ \\
\hline & Memória para Desenho Conteúdo Tardia & $0,010 * *$ & 0,719 & $0,559-0,925$ \\
\hline & Memória para Desenho Espacial Ta rdia & $0,005^{* *}$ & 0,667 & $0,504-0,882$ \\
\hline & Memória para Desenho Total Tardia & $0,005 * *$ & 0,724 & $0,577-0,908$ \\
\hline & Memónia para Faces & 0,737 & - & - \\
\hline & Memória para Fa ces Ta rdia & 0,121 & - & - \\
\hline & Memória para Lista de Palavras & 0,322 & - & - \\
\hline \multirow{2}{*}{$\ddot{>}$} & Flechas & $0,019 *$ & 0,786 & $0,643-0,962$ \\
\hline & Quebracabeça Geométrico & 0,849 & - & - \\
\hline \multirow{3}{*}{$\sum_{n}$} & Precisão Visomotora & 0,202 & - & - \\
\hline & Imitando Posição da Mão & 0,286 & - & - \\
\hline & Sequência Motora Manual & 0,134 & - & - \\
\hline
\end{tabular}


A partir da Análise de Regressão Logística pode-se identificar os valores de Odds ratio para cada variável dos subtestes neuropsicológicos que se mostraram estatisticamente significativas, sinalizando informações relevantes para o diagnóstico de casos de DF. Assim, a cada aumento de um ponto no QI estimado do WISC III reduz, em média, 6,5\% a chance da criança ser do Grupo Clínico. Essa mesma direção emergiu da análise dos resultados no subteste Cubos: a cada acréscimo de um ponto nesse subteste sinalizou-se como redutor, em média, de 31,5\% da chance da criança ser do Grupo Clínico. Já no teste de Raven, observouse que a cada ponto alcançado, diminui em $13,7 \%$ (em média) a chance da criança ser portadora de DF. No domínio da atenção/função executiva em "Fluência em Desenho", a cada ponto alcançado promove redução, em média, de $29,5 \%$ de chance da criança ser do Grupo Clínico, enquanto nas três tarefas de "Inibindo Respostas" essa probabilidade de ser portadora de DF diminuiu entre 20,9 a 25,8\%. No domínio linguagem, a cada acréscimo de um ponto nos subtestes dessa área, correspondeu uma redução e ntre 26,2 a 43,4 \% de chance da criança ser portadora de $\mathrm{DF}$, tendo o subteste "Nomeando rápido" o maior efeito $(p=0,003)$. No domínio aprendizado/memória, a cada um ponto nos subtestes "Memória para Desenho" imediato e tardio associou-se à diminuição de 21,8 a 33,5\% de chance da criança ser do Grupo Clínico. Por fim, na habilidade visoespacial, cada ponto alcançado no subteste de "Flechas" sinaliza diminuição de $21,4 \%$ de chance da criança ser portadora de DF.

\subsubsection{Análise da variável idade}

A Tabela 9 mostra os resultados relativos ao WISC III e ao Raven nos subgrupos etários: 7 a 9 anos $(n=11)$ e 10 a 12 anos $(n=19)$. Para fins de análise dos resultados no teste de Raven optou-se por utilizar os pontos brutos desse teste, sendo esperada uma curva crescente de pontuação com o aumento da idade.

Tabela 9 - WISC III e Raven: Comparação entre as faixas etárias de 7-9 anos e 10-12 anos nos Grupos Clínico e Controle

\begin{tabular}{|c|c|c|c|c|c|c|c|c|c|c|}
\hline & \multirow{2}{*}{ Testes } & \multirow{2}{*}{ Idade } & \multicolumn{4}{|c|}{ Grupo Clínico } & \multicolumn{4}{|c|}{ Grupo Controle } \\
\hline & & & Média & DP & Estat. & $p$ & Média & DP & Estat. & $p$ \\
\hline \multirow{5}{*}{ 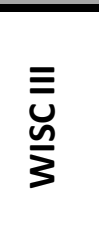 } & QI Estimado & $\begin{array}{r}7-9 \\
10-12\end{array}$ & $\begin{array}{r}107 \\
91,11\end{array}$ & $\begin{array}{l}18,177 \\
10,005\end{array}$ & $2,674 t$ & $0,018^{*}$ & $\begin{array}{r}104,9 \\
113,63\end{array}$ & $\begin{array}{r}7,50 \\
11,29\end{array}$ & $-2,279 t$ & $0,030 *$ \\
\hline & \multirow{2}{*}{ Vocabulário } & $7-9$ & 11,82 & 4,167 & \multirow{2}{*}{$2,193 t$} & \multirow{2}{*}{$0,048^{*}$} & 11 & 1,34 & \multirow{2}{*}{$-2,515 t$} & \multirow{2}{*}{$0,018^{*}$} \\
\hline & & $10-12$ & 8,89 & 1,941 & & & 12,78 & 2,55 & & \\
\hline & \multirow{2}{*}{ Cubos } & $7-9$ & 10,64 & 2,803 & \multirow{2}{*}{$2,679 t$} & \multirow{2}{*}{$0,012^{*}$} & 10,81 & 2,14 & \multirow{2}{*}{$-1,105 t$} & \multirow{2}{*}{0,279} \\
\hline & & $10-12$ & 8,05 & 2,392 & & & 11,78 & 2,42 & & \\
\hline \multirow{2}{*}{ Raven } & \multirow{2}{*}{ Raven (pontos brutos) } & $7-9$ & 21,91 & 4,3 & \multirow{2}{*}{700} & \multirow{2}{*}{0,136} & 21,54 & 4,91 & \multirow{2}{*}{$11,5 U$} & \multirow{2}{*}{$0,001^{* *}$} \\
\hline & & $10-12$ & 25,32 & 5,86 & & & 31,31 & 3,11 & & \\
\hline
\end{tabular}


No WISC III constatou-se que os portadores de DF de 7-9 anos tiverem desempenho estatisticamente superior do que os 10-12 anos em todos os subtestes ( $p \leq 0,05)$. Efetuou-se correlação entre a idade e os resultados obtidos nesses referidos testes, chegando-se aos dados da Tabela 10, onde se evidencia correlação inversa moderada com a idade $(\rho=-0,39$ a $-0,48)$.

Tabela 10 - WISC III e Raven: Correlação com a idade (7 - 12 anos) nos Grupos Clínico e Controle

\begin{tabular}{|c|c|c|c|c|c|}
\hline \multicolumn{2}{|r|}{ Testes } & \multicolumn{2}{|c|}{ Grupo Clínico } & \multicolumn{2}{|c|}{ Grupo Controle } \\
\hline & & Spearman & $p$ & Spearman & $p$ \\
\hline \multirow{4}{*}{ 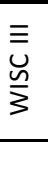 } & QI Estimado & $-0,485^{*}$ & 0,007 & 0,275 & 0,142 \\
\hline & Vocabulário & $-0,395^{*}$ & 0,031 & 0,319 & 0,086 \\
\hline & Cubos & $-0,473$ & 0,008 & 0,127 & 0,504 \\
\hline & Raven (pontos brutos) & 0,308 & 0,098 & $0,756^{* *}$ & 0,001 \\
\hline
\end{tabular}

Ao se considerar os dados das Tabelas 9 e 10 relativos ao Grupo Controle, nota-se resultados não esperados, visto que as crianças de 10-12 anos apresentaram desempenho médio estatisticamente superior no QI Estimado ( $p=0,03)$ e em “Cubos" ( $p=0,018)$, seguindo um padrão de melhor desempenho com o aumento da idade. Contudo, não houve correlação estatisticamente significativa da idade com nenhum subteste do WISC III no Grupo Controle.

Cabe agora focalizar a análise das evidências obtidas a partir do Teste de Raven, nos dois grupos examinados. No tocante aos dados do Grupo Controle, pela Tabela 9 constata-se pontuação (em termos brutos) estatisticamente maior nas crianças de 10-12 anos $(p=0,001)$, enquanto a Tabela 10 mostra que houve direta e elevada correlação (estatisticamente significativa) entre pontos brutos no Raven e a idade $(\rho=0,75)$. No Grupo Clínico esse padrão de resultados no Raven não foi observado, podendo-se apenas notar que as crianças de 10-12 anos alcançaram resultado, na média de pontos brutos, maior que as crianças de 7-9 anos desse grupo, não havendo diferença estatisticamente significativa entre as faixas etárias conforme esperado. Em outras palavras, no Raven, as crianças da amostra clínica de mais idade não obtiveram o padrão de resposta correspondente a sua faixa etária, sugerindo, assim, maior dificuldade na execução dessa prova intelectual.

A continuidade das análises comparativas dos resultados em função dos subgrupos etários deu-se também em relação ao NEPSY II, conforme mostram as Tabelas 11 e 12. 
Tabela 11 - NEPSY II: Comparação entre 7-9 anos e 10-12 anos nos Grupos Clínico e Controle

\begin{tabular}{|c|c|c|c|c|c|c|c|c|c|c|}
\hline \multirow{2}{*}{\multicolumn{2}{|c|}{ Testes }} & \multirow{2}{*}{ Idade } & \multicolumn{4}{|c|}{ Grupo Clínico } & \multicolumn{4}{|c|}{ Grupo Controle } \\
\hline & & & Média & DP & Estat. & $p$ & Média & DP & Estat. & $p$ \\
\hline \multirow{18}{*}{ 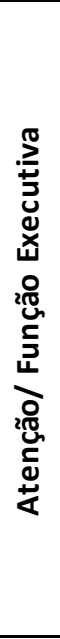 } & \multirow{2}{*}{ Atenção Auditiva } & 7-9 & 10,91 & 3,36 & \multirow{2}{*}{$94,5 U$} & \multirow{2}{*}{0,662} & 12 & 2,14 & \multirow{2}{*}{$72 U$} & \multirow{2}{*}{0,148} \\
\hline & & $10-12$ & 10,93 & 2,24 & & & 11,21 & 2,44 & & \\
\hline & \multirow{2}{*}{ Atenção Auditiva combina do } & $7-9$ & 11,27 & 3,66 & \multirow{2}{*}{$93,5 U$} & 0.633 & 12,27 & 2,45 & $70 U$ & 0.124 \\
\hline & & $10-12$ & 10,79 & 2,17 & & 0,035 & 11,21 & 2,25 & 100 & 0,124 \\
\hline & Coniunto de Resnostas & $7-9$ & 12,27 & 2,83 & $1672 t$ & 0106 & 12,09 & 1,76 & 8611 & 0417 \\
\hline & Conjunto de Respostas & $10-12$ & 10,53 & 2,71 & $1,0 / 2 l$ & 0,100 & 11,21 & 2,37 & 800 & $0,41 /$ \\
\hline & Conjunto de Respostas & $7-9$ & 12,18 & 2,40 & $1877 t$ & 0.071 & 12,09 & 1,38 & $88.5 \mathrm{U}$ & 0.482 \\
\hline & combina do & $10-12$ & 10,37 & 2,62 & 1, & 0,011 & 11,36 & 2,31 & 00,00 & 0,402 \\
\hline & Inibindo Respostas- & $7-9$ & 8,73 & 2,53 & $1973 t$ & 0.058 & 10,82 & 2,71 & $1669 t$ & 0.106 \\
\hline & Nomea ção & $10-12$ & 6,39 & 3,77 & $1,9 / 3 t$ & 0,058 & 9,11 & 2,70 & $1,009 t$ & 0,100 \\
\hline & Inibindo Resnostas - Inibicão & $7-9$ & 9,45 & 3,01 & & & 8,45 & 3,14 & & 0.529 \\
\hline & InıDInao Respostas-Inı DIçao & $10-12$ & 5,50 & 2,93 & $3,660 t$ & $0,001^{*}$ & 9,21 & 3,11 & $-0,638 t$ & $0,5<9$ \\
\hline & Inihindo Recnoctac- Mudanca & $7-9$ & 8,73 & 3,55 & $2005 t$ & 0.055 & 9,27 & 2,45 & $0.367 t$ & 0716 \\
\hline & Imidinao kespostas-IVIudança & $10-12$ & 6,17 & 3,20 & 2,0052 & 0, & 8,95 & 2,27 & $0,30 / i$ & 0,110 \\
\hline & & $7-9$ & 9,27 & 4,17 & $1989 t$ & 0.057 & 9,27 & 2,83 & $1043 t$ & 0306 \\
\hline & InIDindo Respostas-trro Iotal & $10-12$ & 6,11 & 4,14 & 1,9091 & 0,031 & 8,32 & 2,16 & 1,0431 & 0,300 \\
\hline & Fluência em Desenhos & 7-9 & 6,64 & 2,37 & $0.559 t$ & 0.581 & 8,72 & 1,35 & $68 U$ & 0.109 \\
\hline & 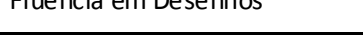 & $10-12$ & 6,11 & 2,58 & הכנכ, & 0,501 & 7,63 & 1,67 & 000 & 0,105 \\
\hline & & 7-9 & 8,55 & 3,35 & $49.5 U$ & $0.016 *$ & 10,18 & 2,36 & $89 U$ & 0,499 \\
\hline & Nomeando Rapıdo & $10-12$ & 5,58 & 2,87 & 49,50 & 0,016 & 9,63 & 1,92 & 890 & 0,499 \\
\hline & Compreendendo Instrucões & 7-9 & 9,09 & 2,94 & $3.430 t$ & $0.002 * *$ & 9,45 & 2,77 & $-0.511 t$ & 0614 \\
\hline$\frac{E}{Q}$ & compreenuetrao ins ur uçoes & $10-12$ & 5,95 & 2,06 & $3,430 l$ & 0,002 & 9,94 & 2,41 & $-0,511 t$ & 0,614 \\
\hline ర్రం & Processamento Fonológico & 7-9 & 7,45 & 2,94 & & & 7,54 & 1,92 & & 0527 \\
\hline$\overbrace{}^{\circ}$ & Processamento ronologico & $10-12$ & 3,47 & 2,11 & 28,50 & 0,001 & 7,31 & 1,83 & 900 & 0,522 \\
\hline.$\subseteq$ & Produzindo Palavras - & 7-9 & 8,27 & 3,13 & & & 10,54 & 2,34 & & 0.903 \\
\hline & Semântica & $10-12$ & 8,05 & 2,83 & $0,19 / t$ & 0,845 & 10,42 & 2,83 & $0,123 t$ & 0,903 \\
\hline & Produzindo Palavras - Letra & $7-9$ & 7,45 & 2,06 & 3.215t & $0003 *$ & 8 & 2,32 & $0000 t$ & 1000 \\
\hline & Inicial & $10-12$ & 4,68 & 2,38 & 3,213 & , & 8 & 1,83 & 0,000 & 1,000 \\
\hline & Memória Narrativa Livre & $7-9$ & 12,27 & 2,61 & & & 11,54 & 2,58 & & \\
\hline & IVIemorla Ivarrativa LIVre & $10-12$ & 6,89 & 2,58 & b,4/9t & $0,001 \times \frac{1}{*}$ & 9,52 & 3,01 & $1,862 t$ & $0,0 / 3$ \\
\hline & Memória Narrativa Livre + & $7-9$ & 11,91 & 2,62 & 19.511 & $0 \cap 001 * *$ & 10,81 & 2,14 & $0967 t$ & 0342 \\
\hline & Pista & $10-12$ & 6,37 & 2,87 & 19,50 & 0,001 & 9,78 & 3,12 & $0,90 / 6$ & 0,342 \\
\hline & Memória para Desenho & $7-9$ & 10 & 2,36 & $2.107 t$ & $0044 *$ & 10,81 & 2,79 & $-0.068 t$ & 0.946 \\
\hline & Conteúdo & $10-12$ & 7,63 & 3,25 & $2,10 / \mathrm{t}$ & 0,044 & 10,89 & 3,05 & $-0,008 t$ & 0,940 \\
\hline & Memória para Desenho & 7-9 & 9,55 & 2,33 & $88.5 \mathrm{U}$ & 0.487 & 12,18 & 3,03 & $90 U$ & 0.51 \\
\hline 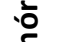 & Espa cial & $10-12$ & 8,42 & 3,93 & & & 11,73 & 2,16 & & \\
\hline ह & Memória para Desenho Total & 7-9 & 9,64 & 2,37 & & & 11 & 2,93 & & \\
\hline$\sum$ & IVIemoria para Desenno lotal & $10-12$ & 7,21 & 3,70 & 590 & $0,049^{\wedge}$ & 11,21 & 3,07 & $-0,184 t$ & $0,8 b 5$ \\
\hline ○ & Memória para Desenho & 7-9 & 10,55 & 1,80 & $2305 t$ & $0,029 *$ & 11,54 & 3,45 & 934 & 0.608 \\
\hline ర్ర & Conteúdo Tardia & $10-12$ & 8,16 & 3,13 & $2,30 b t$ & $0,029^{*}$ & 11,26 & 2,73 & 930 & 0,608 \\
\hline$\stackrel{N}{\stackrel{N}{0}}$ & Memória para Desenho & 7-9 & 10,91 & 2,3 & $69.5 \mathrm{U}$ & 0.126 & 12,54 & 2,77 & 784 & 0.186 \\
\hline 을 & Espa cial Tardia & $10-12$ & 8,58 & 3,62 & 09,30 & 0,120 & 12,36 & 1,50 & 100 & 0,180 \\
\hline$\frac{ \pm}{2}$ & Memória para Desenho Total & 7-9 & 10,82 & 2,82 & $2023 t$ & 0053 & 12,09 & 3,86 & 8411 & 0374 \\
\hline 菂 & Tardia & $10-12$ & 8,37 & 3,38 & $2,0<3 \tau$ & 0,053 & 12,15 & 2,83 & & \\
\hline & Memória para Faces & 7-9 & 9,82 & 3,81 & $84.5 \mathrm{U}$ & 0.385 & 8,81 & 4,00 & $-0,301 t$ & 0.765 \\
\hline & & $10-12$ & 9,47 & 2,67 & & & 9,21 & 3,08 & $-0,301 l$ & \\
\hline & Memória para Faces Tardia & $7-9$ & 10,27 & 3,55 & $45.5 U$ & $0.011 *$ & 11 & 3,16 & $1.484 t$ & 0.149 \\
\hline & & $10-12$ & 7,32 & 3,00 & & & 9,15 & 3,34 & & \\
\hline & Memória para Lista de & 7-9 & 11,27 & 2,19 & $1825 t$ & 0.079 & 13,18 & 2,23 & $3.025 t$ & $0,005 * *$ \\
\hline & Palavras & $10-12$ & 9,32 & 3,12 & $1,8<J$ & $0,0 / 9$ & 10,47 & 2,44 & $3,0 \angle 3 i$ & 0,003 \\
\hline & Flechas & 7-9 & 9,64 & 3,20 & $-0.142 t$ & 0.888 & 10,45 & 3,21 & & 0.122 \\
\hline$\Psi$ & riecnas & $10-12$ & 9,84 & 4,12 & $-0,14<\tau$ & 0,888 & 12,21 & 2,02 & $-1,639 t$ & 0,122 \\
\hline$>$ & Quphracaheca Geomótrico & 7-9 & 11,45 & 1,75 & $2624 t$ & $0014 *$ & 10 & 2,65 & $-1347 t$ & 0189 \\
\hline & Quebraca beça Geometrico & $10-12$ & 9 & 2,78 & $2,0<4 \tau$ & 0,014 & 11,31 & 2,54 & $-1,34 / \tau$ & 0,189 \\
\hline & Precisão Visomotora & $7-9$ & 9,64 & 3,26 & 9011 & 0.529 & 10,63 & 3,96 & 99511 & 0828 \\
\hline & Precisao visomotord & $10-12$ & 9,47 & 3,51 & 900 & $0,5<9$ & 10,57 & 3,50 & 99,50 & $0,8<8$ \\
\hline & Imitando Pocic̃̃ da M̃̃ & $7-9$ & 10,09 & 4,23 & & & 11 & 1,61 & & \\
\hline$\sum_{n}$ & Imıtando Posıça o da IVla o & $10-12$ & 8,26 & 2,78 & $67,5 U$ & 0,105 & 9,31 & 2,16 & $48,5 U$ & $0,014^{*}$ \\
\hline & & & Média & Abaixo & & & Média & Abaixo & & \\
\hline & Sequência Motora Manual & $7-9$ & 11 & - & $\mathrm{F}$ & 0.129 & 10 & 1 & $\mathrm{~F}$ & 1.000 \\
\hline & & $10-12$ & 14 & 5 & & & 18 & 1 & & \\
\hline
\end{tabular}

Estat. = Estatística; Testes $t$ de Student, $U$ de Mann-Whitneye Exato de Fisher (F); $p^{* *} \leq 0,01$ e * $\leq 0,05 ;$ VE $=$ Visoespacial; SM =

Sensoriomotor 
Tabela 12 - NEPSY II: Correlação dos testes neurospicológicos com a idade (7 - 12 anos) nos Grupos Clínico e Controle

\begin{tabular}{|c|c|c|c|c|c|}
\hline \multicolumn{2}{|r|}{ Testes } & \multicolumn{2}{|c|}{ Grupo Clínico } & \multicolumn{2}{|c|}{ Grupo Controle } \\
\hline & & Spearman & $p$ & Spearman & $p$ \\
\hline \multirow{9}{*}{ 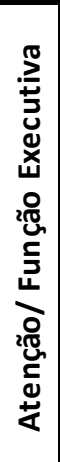 } & Atenção Auditiva & $-0,195$ & 0,303 & $-0,305$ & 0,102 \\
\hline & Atenção Au ditiva combina do & $-0,202$ & 0,283 & $-0,307$ & 0,099 \\
\hline & Conjunto de Respostas & $-0,281$ & 0,132 & $-0,22$ & 0,243 \\
\hline & Conjunto de Respos tas combinado & $-0,208$ & 0,27 & $-0,078$ & 0,68 \\
\hline & Inibindo Respostas- Nomea ção & $-0,446$ & $0,013^{*}$ & $-0,347$ & 0,061 \\
\hline & Inibindo Respostas-Inibição & $-0,685$ & $0,001^{* *}$ & 0,060 & 0,753 \\
\hline & Inibindo Respostas- Mudança & $-0,359$ & 0,056 & $-0,113$ & 0,552 \\
\hline & Inibindo Respostas- Erro Total & $-0,435$ & $0,018^{*}$ & $-0,284$ & 0,129 \\
\hline & Fluência em Desenhos & $-0,195$ & 0,301 & $-0,304$ & 0,102 \\
\hline \multirow{5}{*}{ 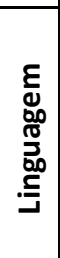 } & Nomeando Rápido & $-0,402$ & $0,027^{*}$ & $-0,136$ & 0,472 \\
\hline & Compreendendo Ins truções & $-0,475$ & $0,008^{* *}$ & $-0,016$ & 0,933 \\
\hline & Processamento Fonológico & $-0,627$ & $0,001^{* *}$ & $-0,042$ & 0,825 \\
\hline & Produzindo Pala vras - Semântica & 0 & 0,997 & $-0,128$ & 0,499 \\
\hline & Produzindo Pala vras - Letra Ini cial & $-0,527$ & $0,003^{* *}$ & $-0,123$ & 0,517 \\
\hline \multirow{11}{*}{ 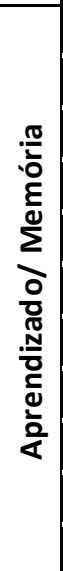 } & Memónia Na rra tiva Livre & $-0,779$ & $0,001^{* *}$ & $-0,47$ & $0,009^{* *}$ \\
\hline & Memória Narrativa Livre + Pista & $-0,733$ & $0,001^{* *}$ & $-0,32$ & 0,085 \\
\hline & Memória pa ra Desenho Conteúdo & $-0,344$ & 0,063 & $-0,013$ & 0,946 \\
\hline & Memória para Desenho Espacial & 0,001 & 0,996 & $-0,151$ & 0,427 \\
\hline & Memória para Desenho Total & $-0,319$ & 0,086 & $-0,036$ & 0,85 \\
\hline & Memória para Desenho Conteúdo Tardia & $-0,33$ & 0,075 & 0,03 & 0,876 \\
\hline & Memória para Desenho Espacial Tardia & $-0,177$ & 0,35 & $-0,231$ & 0,219 \\
\hline & Memória pa ra Desenho Total Ta rdia & $-0,332$ & 0,073 & 0,065 & 0,732 \\
\hline & Memória pa ra Faces & $-0,193$ & 0,306 & $-0,063$ & 0,742 \\
\hline & Memória pa ra Faces Ta rdia & $-0,339$ & 0,067 & $-0,441$ & $0,015^{*}$ \\
\hline & Memória para Lista de Pala vras & $-0,262$ & 0,162 & $-0,551$ & $0,002^{* *}$ \\
\hline \multirow{2}{*}{ 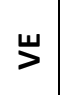 } & Flechas & 0,062 & 0,747 & 0,095 & 0,616 \\
\hline & Quebracabeça Geométrico & $-0,358$ & 0,052 & 0,019 & 0,921 \\
\hline \multirow{2}{*}{$\sum_{n}$} & Precisão Visomotora & $-0,053$ & 0,779 & $-0,036$ & 0,85 \\
\hline & Imitando Posição da Mão & $-0,304$ & 0,102 & $-0,386$ & $0,035^{*}$ \\
\hline
\end{tabular}

Correlaçãosignificativa $p^{* *} \leq 0,01 \mathrm{e}^{*} \leq 0,05 ; \mathrm{VE}=$ Visoes pacial; SM = Sensoriomotor

No domínio da atenção/função executiva, as crianças com DF de 10-12 anos demonstraram desempenho inferior (de modo estatisticamente significativo) no bteste "Inibindo Resposta" na tarefa de "Inibição" $(p=0,001)$ e uma tendência à significância estatística nas demais tarefas desse subteste. Verificou-se também em "Inibindo Resposta" nas tarefas de "Nomeação, Erros Totais e Inibição" correlação inversa de intensidade moderada a alta com a idade $(\rho=-0,44$ a -0,69). Na linguagem, o Grupo Clínico de de 10-12 anos apresentou rendimento estatisticamente pior em relação às crianças de 7-9 anos, 
inclusive com médias abaixo do esperado em quase todos os subtestes, com exceção apenas de "Produzindo Palavras - Semântica". Ademais, houve correlação inversa de moderada a alta ( $\rho=-0,40$ a $-0,63)$ com a idade em todas essas tarefas da área de linguagem. Ressalta-se que no Grupo Controle não houve diferença entre as faixas etárias nos dois domínios acima mencionados do NEPSY II.

No domínio de aprendizado/memória, os portadores de DF com 10-12 anos apresentaram escores médios abaixo do esperado para "Memória Narrativa Livre" e "Livre + Pista", demonstrando diferença estatisticamente significativa $(p=0,001)$ em relação à faixa etária de 7-9 anos, identificando-se alta correlação inversa com a idade nesses subtestes ( $\rho=-$ 0,78 e -0,73, respectivamente). Em "Memória para Desenho", as crianças de mais idade do Grupo Clínico apresentaram desempenho estatisticamente pior em conteúdo imediato ( $p=$ $0,044)$, tardio $(p=0,029)$ e no escore total imeidato $(p=0,049)$ e uma tendência à significância estatística no escore total tardio $(p=0,053)$. No entanto, não foi verificada correlação estatisticamente significativa desse subteste com a idade em nenhum dos grupos. $\mathrm{Na}$ "Memória para Face Tardia" houve diferença estatisticamente significativa entre as faixas etárias $(p=0,011)$, com pior desempenho para crianças de mais idade. No Grupo Controle, as crianças mais novas obtiveram desempenho estatisticamente superior em "Memória para Lista de Palavras" ( $p=0,005)$, verificando-se também moderada correlação inversa em "Memória Narrativa Livre" $(\rho=-0,47)$, "Face Tardia" $(\rho=-0,44)$ e "Lista de Palavras" $(\rho=-0,55)$.

No domínio visoespacial, no Grupo Clínico de 10-12 anos apresentou desempenho estatisticamente inferior em "Quebracabeça Geométrico" ( $p=0,014)$. No Grupo Controle não foi observada nenhuma diferença estatisticamente significativa na comparação entre as faixas etárias aqui consideradas. No domínio sensoriomotor, a amostra clínica não apontou diferença estatisticamente significativa entre as faixas etárias. No Grupo Controle contatou-se desempenho estatisticamente superior para crianças de 7-9 anos em "Imitando Posição da Mão" ( $p=0,014)$, identificando-se baixa correlação inversa com a idade $(\rho=-0,39)$.

\subsubsection{Análise da variável sexo}

Procurou-se examinar eventual influência da variável sexo nos resultados dos testes neuropsicológicos. Inicialmente são apresentados, na Tabela 13, os resultados dessa análise no WISC III e no Raven, enquanto os dados relativos ao NEPSY II estão organizados na Tabela 14. 
Tabela 13 - WISC III e Raven: Comparação entre os Grupos Clínico e Controle em função do sexo

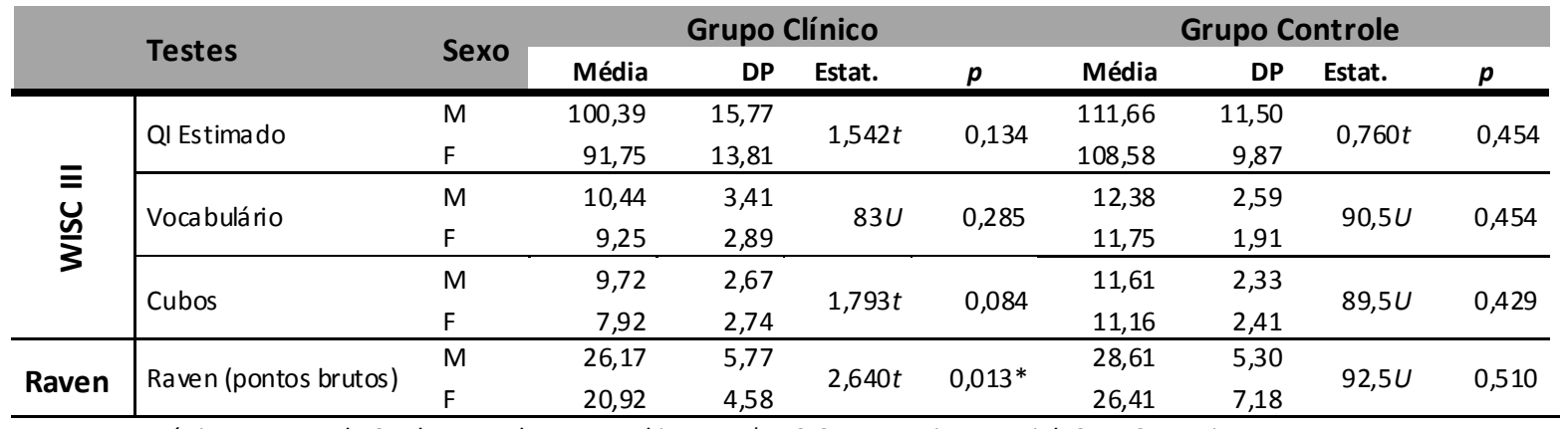

Estat. = Estatística; Testes $t$ de Student e $U$ de Mann-Whitney; $p^{*} \leq 0,05 ; \mathrm{VE}=$ Visoes pacial; SM = Sensoriomotor

Tabela 14 - NEPSY II: entre os Grupos Clínico e Controle em função do sexo (continua...)

\begin{tabular}{|c|c|c|c|c|c|c|c|c|c|c|}
\hline \multirow{2}{*}{\multicolumn{2}{|c|}{ Testes }} & \multirow{2}{*}{ Sexo } & \multicolumn{4}{|c|}{ Grupo Clínico } & \multicolumn{4}{|c|}{ Grupo Controle } \\
\hline & & & Média & DP & Estat. & $p$ & Média & DP & Estat. & $p$ \\
\hline \multirow{18}{*}{ 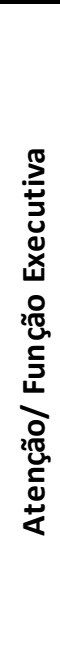 } & \multirow{2}{*}{ Atenção Auditiva } & $\mathrm{M}$ & 10,61 & 2,89 & \multirow{2}{*}{$93,5 U$} & \multirow{2}{*}{0,533} & 11,22 & 2,71 & \multirow{2}{*}{$100,5 \mathrm{U}$} & \multirow{2}{*}{0,743} \\
\hline & & $\mathrm{F}$ & 11,42 & 2,27 & & & 11,91 & 1,62 & & \\
\hline & \multirow{2}{*}{ Atenção Auditiva combina do } & $\mathrm{M}$ & 10,56 & 2,77 & \multirow{2}{*}{$-0,999 t$} & \multirow{2}{*}{0,326} & 11,33 & 2,68 & \multirow{2}{*}{$96,5 U$} & \multirow{2}{*}{0,614} \\
\hline & & $\mathrm{F}$ & 11,58 & 2,74 & & & 12 & 1,76 & & \\
\hline & \multirow{2}{*}{ Conjunto de Res postas } & $\mathrm{M}$ & 10,72 & 2,88 & \multirow{2}{*}{$-1,051 t$} & \multirow{2}{*}{0,302} & 11,11 & 2,40 & \multirow{2}{*}{$86 U$} & \multirow{2}{*}{0,343} \\
\hline & & $\mathrm{F}$ & 11,83 & 2,75 & & & 12,16 & 1,70 & & \\
\hline & \multirow{2}{*}{$\begin{array}{l}\text { Conjunto de Respostas } \\
\text { combinado }\end{array}$} & $\mathrm{M}$ & 10,39 & 2,72 & \multirow{2}{*}{$-1,676 t$} & \multirow{2}{*}{0,105} & 11 & 2,25 & \multirow{2}{*}{$60 U$} & \multirow{2}{*}{$0,038 *$} \\
\hline & & $\mathrm{F}$ & 12 & 2,33 & & & 12,58 & 1,16 & & \\
\hline & \multirow{2}{*}{$\begin{array}{l}\text { Inibindo Respostas- } \\
\text { Nomea ção }\end{array}$} & $\mathrm{M}$ & 6,83 & 3,76 & \multirow{2}{*}{$-0,563 t$} & \multirow{2}{*}{0,578} & 9,83 & 2,85 & \multirow{2}{*}{$0,236 t$} & 0.815 \\
\hline & & $\mathrm{F}$ & 7,58 & 3,26 & & & 9,58 & 2,81 & & 0,815 \\
\hline & Inibind Docnocto Libic & $M$ & 6,94 & 3,31 & $0106 t$ & 0005 & 9,11 & 3,06 & $0200+$ & 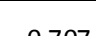 \\
\hline & Inibindo Res postas - Iniıiçao & $\mathrm{F}$ & 6,75 & 3,95 & $0,146 t$ & 0,885 & 8,67 & 3,25 & $0,380 t$ & $0,10 /$ \\
\hline & Inihindo Resnostas-Mudanca & $M$ & 7,61 & 3,74 & $0026+$ & 0363 & 8,94 & 2,31 & $0251+$ & 070 \\
\hline & 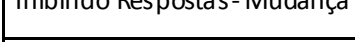 & $\mathrm{F}$ & 6,36 & 3,10 & $0,9<0 l$ & כ ב & 9,25 & 2,37 & ( & $0,1<9$ \\
\hline & Lnibind Dome & $\mathrm{M}$ & 7,89 & 4,66 & $0010 t$ & 0271 & 8,67 & 2,49 & مח00t & 1000 \\
\hline & | IniDinao Respostas-Erro Iotal & $\mathrm{F}$ & 6,36 & 3,85 & $0,910 t$ & $0,3 / 1$ & 8,67 & 2,42 & $0,000 t$ & 1,000 \\
\hline & Flun ncin & $\mathrm{M}$ & 6,67 & 2,56 & 0451 & 0215 & 7,77 & 1,66 & 10501 & 0201 \\
\hline & Fiuencla em Desennos & $\mathrm{F}$ & 5,75 & 2,34 & 84,50 & 0,315 & 8,41 & 1,56 & $-1,054 \tau$ & 0,301 \\
\hline & Nomeando Ránido & $M$ & 6,5 & 3,58 & $0330 t$ & 0709 & 9,55 & 2,01 & $0000 t$ & 0277 \\
\hline & Nomeando Raplao & $\mathrm{F}$ & 6,92 & 3,05 & $-0,330 t$ & 0,144 & 10,25 & 2,18 & $0,898 \tau$ & $0,3 / 1$ \\
\hline & Comprondond lnctur & $\mathrm{M}$ & 7,11 & 3,21 & $0026 t$ & 0000 & 9,33 & 2,33 & $1162+$ & 0255 \\
\hline & Compreendendo ins truçoes & $\mathrm{F}$ & 7,08 & 2,27 & $0,0<b t$ & 0,980 & 10,41 & 2,75 & $-1,163 t$ & 0,235 \\
\hline 兽 & Prococcamento Eonolórir & $M$ & 4,94 & 3,24 & $002 \Delta t$ & 0981 & 6,94 & 1,16 & $1725+$ & 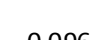 \\
\hline$\vec{D}_{0}$ & 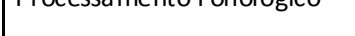 & $\mathrm{F}$ & 4,92 & 2,99 & $0,0<4 i$ & , & 8,08 & 2,43 & $-1,1<\Delta$ & , \\
\hline 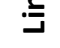 & Produzindo Palavras - & M & 8,61 & 2,61 & $1111 t$ & 0276 & 9,94 & 2,67 & $-1.355 t$ & 0186 \\
\hline & Semântica & $\mathrm{F}$ & 7,42 & 3,26 & & & 11,25 & 2,45 & & \\
\hline & Produzindo Palavras - Letra & $\mathrm{M}$ & 5,72 & 2,94 & $0056 t$ & 0056 & 7,72 & 2,02 & $0020+$ & 0256 \\
\hline & Inicial & $\mathrm{F}$ & 5,67 & 2,14 & $0,056 \tau$ & 0,956 & 8,41 & 1,93 & $-0,938 t$ & 0,356 \\
\hline
\end{tabular}


Tabela 14 - NEPSY II: entre os Grupos Clínico e Controle em função do sexo (conclusão)

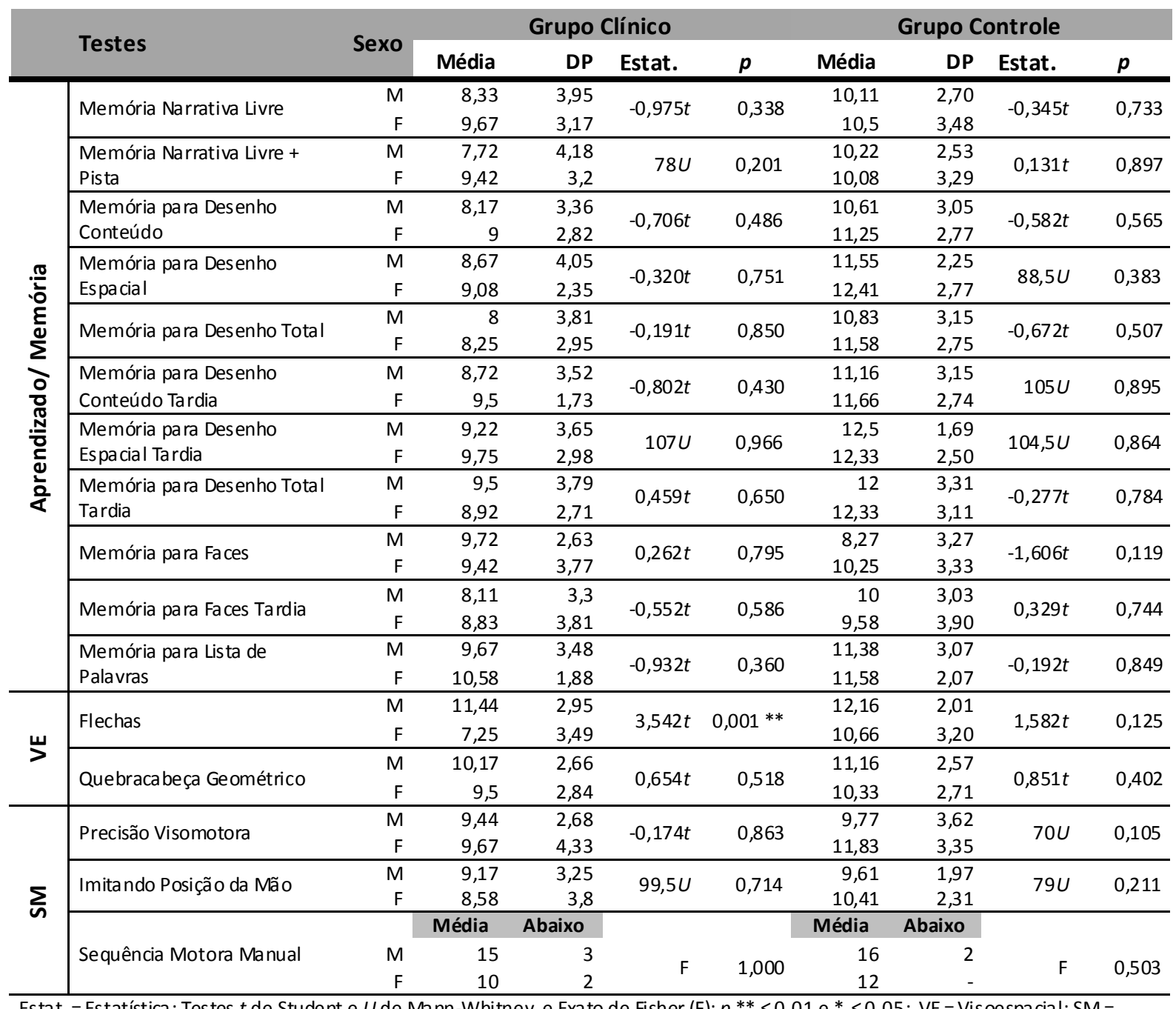

Estat. = Estatística; Testes $t$ de Student e $U$ de Mann-Whitney e Exato de Fisher (F); $p^{* *} \leq 0,01 \mathrm{e}^{*} \leq 0,05$; VE =Visoespacial; SM = Sensoriomotor

Nos resultados das análises comparativas em função do sexo, em ambos os grupos, as diferenças estatisticamente significativas identificadas foram bastante pontuais. $\mathrm{Na}$ amostra clínica observou-se diferença estatisticamente significativa no Raven $(p=0,013)$ e no subteste "Flechas" do NEPSY II $(p=0,001)$, sendo que o sexo masculino apresentou melhor desempenho. No Grupo Controle, o sexo feminino demonstrou escore mais alto em "Conjunto de Resposta combinado" no NEPSY II $(p=0,038)$. Pode-se, portanto, ponderar como pouco relevante a influência da variável sexo nos resultados dos testes neuropsicológicos utilizados nas crianças dessa pesquisa. 


\subsubsection{Análise da variável genótipo na DF}

Especificamente no Grupo Clínico, buscou-se dividir as crianças em função de seu subtipo genético, a saber: $\mathrm{SS}$ e $\mathrm{S} \beta^{\circ}$ (casos de maior gravidade clínica, $\mathrm{n}=18$ ) ou SC e $\mathrm{S} \beta+$ (casos de menor gravidade clínica, $\mathrm{n}=12$ ). Foi, então, efetuada comparação estatística dos desempenhos médios entre esses subgrupos no WISC III e no Raven (Tabela 15).

Tabela 15 - WISC III e Raven: Comparação entre subgrupos genéticos da amostra clínica

\begin{tabular}{|c|c|c|c|c|c|c|}
\hline & Testes & Genótipo & Média & DP & Estat. & $p$ \\
\hline \multirow{6}{*}{$\begin{array}{l}\equiv \\
\text { Un } \\
3\end{array}$} & \multirow{2}{*}{ QI Estimado } & $\mathrm{SS}, \mathrm{S} \beta^{\circ}$ & 99 & 16,723 & \multirow{2}{*}{$0,898 t$} & \multirow{2}{*}{0,377} \\
\hline & & $\mathrm{SC}, \mathrm{S} \beta+$ & 93,83 & 13,21 & & \\
\hline & \multirow{2}{*}{ Vocabulário } & $\mathrm{SS}, \mathrm{S} \beta^{\circ}$ & 10,22 & 3,135 & \multirow{2}{*}{$90,5 U$} & \multirow{2}{*}{0,454} \\
\hline & & $\mathrm{SC}, \mathrm{S} \beta+$ & 9,58 & 3,45 & & \\
\hline & \multirow{2}{*}{ Cubos } & $S S, S \beta^{\circ}$ & 9,44 & 3,294 & \multirow{2}{*}{$1,194 t$} & \multirow{2}{*}{0,243} \\
\hline & & $\mathrm{SC}, \mathrm{S} \beta+$ & 8,33 & 1,775 & & \\
\hline \multirow[t]{2}{*}{ Raven } & \multirow{2}{*}{ Raven (pontos brutos) } & $\mathrm{SS}, \mathrm{S} \beta^{\circ}$ & 23,5 & 6,071 & \multirow{2}{*}{$-0,642 t$} & \multirow{2}{*}{0,526} \\
\hline & & $\mathrm{SC}, \mathrm{S} \beta+$ & 24,92 & 5,68 & & \\
\hline
\end{tabular}

Nota-se que não foram identificadas diferenças estatisticamente significativas entre os subtipos genéticos de crianças com DF em nenhum dos testes psicológicos utilizados no processo de triagem intelectual dos participantes.

A seguir, realizou-se a mesma comparação dos subtipos genéticos com os resultados méd ios do NEPSY II (Tabela 16).

Verificou-se diferença estatisticamente significativa apenas no subteste "Precisão Visomotora" ( $p=0,015)$, sendo que o subgrupo de menor gravidade clínica (SC e S $\beta+$ ) apresentou pior desempenho. Em síntese, pode-se notar que os subtipos de genótipo da DF aqui considerados não se mostraram relevantes o suficiente para gerar evidências de resultados específicos nos testes neuropsicológicos utilizados no presente trabalho. 
Tabela 16 - NEPSY II: Comparação entre subgrupos genéticos da amostra clínica

\begin{tabular}{|c|c|c|c|c|c|c|}
\hline & Testes & Genótipo & Média & DP & Estat. & $p$ \\
\hline \multirow{11}{*}{ 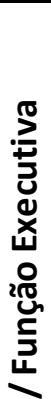 } & \multirow{2}{*}{ Atenção Auditiva } & $\mathrm{SS}, \mathrm{S} \beta^{\circ}$ & 10,39 & 3,013 & \multirow{2}{*}{$80,5 U$} & \multirow{2}{*}{0,237} \\
\hline & & $\mathrm{SC}, \mathrm{S} \beta+$ & 11,75 & 1,815 & & \\
\hline & \multirow{2}{*}{ Atenção Auditiva combina do } & $\mathrm{SS}, \mathrm{S} \beta^{\circ}$ & 10,56 & 3,053 & \multirow{2}{*}{$\begin{array}{r}- \\
0,999 t\end{array}$} & \multirow{2}{*}{0,326} \\
\hline & & $S C, S \beta+$ & 11,58 & 2,234 & & \\
\hline & \multirow{2}{*}{ Conjunto de Respostas } & $\mathrm{SS}, \mathrm{S} \beta^{\circ}$ & 11,78 & 2,798 & \multirow{2}{*}{$1,471 t$} & \multirow{2}{*}{0,152} \\
\hline & & $\mathrm{SC}, \mathrm{S} \beta+$ & 10,25 & 2,768 & & \\
\hline & \multirow{2}{*}{ Conjunto de Respostas combinado } & $\mathrm{SS}, \mathrm{S} \beta^{\circ}$ & 11,72 & 2,445 & \multirow{2}{*}{$68,5 U$} & \multirow{2}{*}{0,092} \\
\hline & & $\mathrm{SC}, \mathrm{S} \beta+$ & 10 & 2,73 & & \\
\hline & \multirow{2}{*}{ Inibindo Respostas- Nomeação } & $\mathrm{SS}, \mathrm{S} \beta^{\circ}$ & 7,28 & 3,86 & \multirow{2}{*}{$0,270 t$} & 0780 \\
\hline & & $\mathrm{SC}, \mathrm{S} \beta+$ & 6,92 & 3,11 & & 0,789 \\
\hline & & $\mathrm{SS}, \mathrm{S} \beta^{\circ}$ & 7,33 & 3,51 & $0886 t$ & 383 \\
\hline 0 & Inıbındo Respostas-Inıbıção & $\mathrm{SC}, \mathrm{S} \beta+$ & 6,17 & 3,56 & $0,886 t$ & 0,383 \\
\hline rש্ভে & & $\mathrm{SS}, \mathrm{S} \beta^{\circ}$ & 7,17 & 3,73 & & \\
\hline 듬 & Inıbındo Respostas-Mudança & $\mathrm{SC}, \mathrm{S} \beta+$ & 7,09 & 3,30 & $0,055 t$ & 0,956 \\
\hline$\stackrel{ \pm}{+}$ & Inihindo Posnoctse Frro Total & $\mathrm{SS}, \mathrm{S} \beta^{\circ}$ & 7,72 & 4,43 & 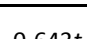 & 050 \\
\hline & Inıbındo Respostas-trro Iotal & $\mathrm{SC}, \mathrm{S} \beta+$ & 6,64 & 4,38 & $0,643 t$ & 0,526 \\
\hline & Elû̂ncis om Reconhoc & $\mathrm{SS}, \mathrm{S} \beta^{\circ}$ & 6,39 & 2,638 & $0237 t$ & 0815 \\
\hline & Fluencla em Desennos & $\mathrm{SC}, \mathrm{S} \beta+$ & 6,17 & 2,329 & $0,23 / t$ & 0,815 \\
\hline & & $\mathrm{SS}, \mathrm{S} \beta^{\circ}$ & 6,56 & 3,535 & $0 G$ & $0 \in 0$ \\
\hline & Nomeando Rapıdo & $\mathrm{SC}, \mathrm{S} \beta+$ & 6,83 & 3,157 & 960 & 0,606 \\
\hline & Compronondendo lnctrurõec & $\mathrm{SS}, \mathrm{S} \beta^{\circ}$ & 7,44 & 3,072 & $0911 t$ & 020 \\
\hline$\frac{E}{\alpha}$ & Compreendendo Instruçoes & $\mathrm{SC}, \mathrm{S} \beta+$ & 6,58 & 2,466 & $0,811 t$ & 0,424 \\
\hline م్ర & Procecsamento Fonológico & $\mathrm{SS}, \mathrm{S} \beta^{\circ}$ & 4,94 & 3,244 & $002 \Delta t$ & 0981 \\
\hline כ) & Processamento Fonologıco & $\mathrm{SC}, \mathrm{S} \beta+$ & 4,92 & 2,999 & $0,024 t$ & 0,981 \\
\hline . & Produzindo Palavras - Semântica & $\mathrm{SS}, \mathrm{S} \beta^{\circ}$ & 8,39 & 1,883 & $0.511 t$ & 0617 \\
\hline & & $\mathrm{SC}, \mathrm{S} \beta+$ & 7,75 & 4,048 & $0,511 t$ & 0,617 \\
\hline & & $\mathrm{SS}, \mathrm{S} \beta^{\circ}$ & 6,06 & 2,733 & 0 909t & 0271 \\
\hline & Produzindo Palavras - Letra Inicial & $\mathrm{SC}, \mathrm{S} \beta+$ & 5,17 & 2,443 & $0,909 t$ & $0,3 / 1$ \\
\hline & Memória Narrativa livro & $\mathrm{SS}, \mathrm{S} \beta^{\circ}$ & 9,28 & 3,923 & $0717+$ & $0: 61$ \\
\hline & IVlemorla Narratıva Livre & $\mathrm{SC}, \mathrm{S} \beta+$ & 8,25 & 3,306 & $0, / 4 / t$ & 0,461 \\
\hline & & $\mathrm{SS}, \mathrm{S} \beta^{\circ}$ & 9 & 4,187 & 8211 & 0287 \\
\hline & Memória Narrativa Livre + Pista & $\mathrm{SC}, \mathrm{S} \beta+$ & 7,5 & 3,261 & 830 & 0,287 \\
\hline & Momória mom Dosonhe Contóid & $S S, S \beta^{\circ}$ & 8,72 & 3,754 & 020 & 002 \\
\hline & IVlemorıa para Desenho Conteudo & $\mathrm{SC}, \mathrm{S} \beta+$ & 8,17 & 1,992 & $0,526 t$ & 0,603 \\
\hline 辇 & 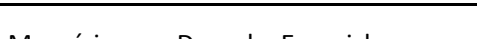 & $\mathrm{SS}, \mathrm{S} \beta^{\circ}$ & 9 & 3,181 & 0200 & 0751 \\
\hline '̄o & Memoria para Desenho Espacial & $\mathrm{SC}, \mathrm{S} \beta+$ & 8,58 & 3,919 & $0,320 t$ & $0, / 51$ \\
\hline$\frac{c}{0}$ & AMomóriz mam Dosonho Totol & $\mathrm{SS}, \mathrm{S} \beta^{\circ}$ & 8,39 & 4,031 & 024 & 0106 \\
\hline$\Sigma$ & IVlemorla para Desenno Iotal & $\mathrm{SC}, \mathrm{S} \beta+$ & 7,67 & 2,425 & 920 & 0,496 \\
\hline 0 & Memória nam Decenhe Conteúdo Tardia & $\mathrm{SS}, \mathrm{S} \beta^{\circ}$ & 8,94 & 3,226 & - & 0812 \\
\hline ర్ర & Miemorla pard Desenno conteudo larala & $\mathrm{SC}, \mathrm{S} \beta+$ & 9,17 & 2,552 & $0,200 t$ & 0,843 \\
\hline$\frac{N}{2}$ & Memória nara Desenho Fsnacial Tardia & $\mathrm{SS}, \mathrm{S} \beta^{\circ}$ & 9,39 & 3,449 & - & 0931 \\
\hline 을 & Memoria para Desenho Espacial Tardia & $\mathrm{SC}, \mathrm{S} \beta+$ & 9,5 & 3,371 & $0,087 t$ & 0,931 \\
\hline Ф் & Momória man Roconho Tota L Tardia & $\mathrm{SS}, \mathrm{S} \beta^{\circ}$ & 9,44 & 3,823 & $0319+$ & 0730 \\
\hline$\frac{0}{4}$ & IVlemorla para Desenno Iotal Iarala & $\mathrm{SC}, \mathrm{S} \beta+$ & 9 & 2,663 & $0,349 t$ & 0,130 \\
\hline & Mamṕria nam & $S S, S \beta^{\circ}$ & 9,83 & 2,975 & $0502+$ & 0,020 \\
\hline & IVemorıa para races & $\mathrm{SC}, \mathrm{S} \beta+$ & 9,25 & 3,334 & $0,50<t$ & 0,620 \\
\hline & Memória mam Eaces Tandia & $\mathrm{SS}, \mathrm{S} \beta^{\circ}$ & 9,33 & 3,531 & $1007+$ & 000 \\
\hline & IVlemorla para races Iarala & $S C, S \beta+$ & 7 & 2,985 & $1,882 t$ & $0,0 / 0$ \\
\hline & & $\mathrm{SS}, \mathrm{S} \beta^{\circ}$ & 10,56 & 3,053 & $1200+$ & 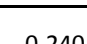 \\
\hline & Memoria para Lista de Palavras & $S C, S \beta+$ & 9,25 & 2,701 & $1,200 t$ & 0,240 \\
\hline & Flechac & $\mathrm{SS}, \mathrm{S} \beta^{\circ}$ & 9,83 & 3,569 & $0.177 t$ & 0909 \\
\hline س & Hechas & $\mathrm{SC}, \mathrm{S} \beta+$ & 9,67 & 4,185 & $0,177 t$ & 0,908 \\
\hline & & $\mathrm{SS}, \mathrm{S} \beta^{\circ}$ & 9,61 & 3,09 & $0 \in{ }_{1}$ & 0600 \\
\hline & Quebracabeça Geométrico & $\mathrm{SC}, \mathrm{S} \beta+$ & 10,33 & 2,06 & 960 & 0,608 \\
\hline & Imitando Posicão da Mão & $\mathrm{SS}, \mathrm{S} \beta^{\circ}$ & 8,28 & 2,986 & 70511 & 210 \\
\hline & & $\mathrm{SC}, \mathrm{S} \beta+$ & 9,92 & 3,942 & $79,5 U$ & 0,219 \\
\hline & Drosir̃̃o Visometom & $\mathrm{SS}, \mathrm{S} \beta^{\circ}$ & 10,72 & 2,63 & $2500+$ & $0015 *$ \\
\hline$\sum$ & Precisao Visomotora & $\mathrm{SC}, \mathrm{S} \beta+$ & 7,75 & 3,671 & $2,588 t$ & $0,015^{*}$ \\
\hline & & & Média & Abaixo & & \\
\hline & Sequência Motora Manual & $\mathrm{SS}, \mathrm{S} \beta^{\circ}$ & 15 & 3 & & \\
\hline & & $\mathrm{SC}, \mathrm{S} \beta+$ & 10 & 2 & $\mathrm{~F}$ & 1,000 \\
\hline
\end{tabular}

Estat. = Estatística; Testes $t$ de Student e $U$ de Mann-Whitney e Exato de Fisher (F); $p^{*} \leq 0,05$; VE = Visoespacial; SM = Sensoriomotor 


\subsection{Relativos à avaliação do comportamento}

O instrumento de avaliação do comportamento (CBCL) foi respondido por 29 informantes de cada grupo. As mães constituíram a grande maioria dos informantes nos dois grupos avaliados, conforme Tabela 17.

Tabela 17 - Distribuição (em frequência simples e porcentagem) dos informantes do CBCL dos Grupos Clínico e Controle

\begin{tabular}{lcccc}
\hline \multirow{2}{*}{ Informante } & \multicolumn{2}{c}{ Grupo Clínico } & \multicolumn{2}{c}{ Grupo Controle } \\
& F & \% & F & $\%$ \\
\hline Mãe & 27 & 93 & 23 & 79 \\
Pai & 0 & 0 & 5 & 17 \\
Outros & 2 & 7 & 1 & 4 \\
\hline
\end{tabular}

A partir desse padrão de respostas ao CBCL, pode-se considerar que dados advindos desse instrumento avaliativo seriam comparáveis entre os grupos aqui considerados, no tocante à possível identificação de problemas do comportamento. A Tabela 18 apresenta os dados referentes ao CBCL do Grupo Clínico e Controle.

Tabela 18 - Comparação dos problemas comportamentais do CBCL entre os Grupos Clínico e Controle.

\begin{tabular}{lcccccr}
\multicolumn{1}{c}{$\begin{array}{c}\text { Síndromes e } \\
\text { Escalas }\end{array}$} & Média & DP & Média & DP & Estat. & P \\
\hline Ansiedade / depressão & 60,34 & 9,03 & 58,93 & 7,87 & $383,5 U$ & 0,563 \\
\hline Retraimento / depressão & 57,82 & 9,11 & 55,83 & 4,92 & $400 U$ & 0,747 \\
\hline Queixas somáticas & 56,86 & 5,69 & 55,45 & 6,45 & $343 U$ & 0,218 \\
\hline Problemas sociais & 59,31 & 7,73 & 56,34 & 6,10 & $311 U$ & 0,088 \\
\hline Problemas do pensamento & 54,51 & 7,15 & 53,83 & 4,99 & $404 U$ & 0,792 \\
\hline Problemas de atenção & 60,10 & 10,76 & 53,72 & 4,70 & $244,5 U$ & $0,006^{* *}$ \\
\hline Violação de regras & 57,55 & 8,42 & 53,93 & 4,71 & $309 U$ & 0,080 \\
\hline Comportamento agressivo & 62,00 & 9,69 & 57,31 & 8,17 & $288 U$ & $0,038^{*}$ \\
\hline Escala de Internalização & 58,17 & 10,10 & 55,79 & 10,00 & $0,901 t$ & 0,371 \\
\hline Escala de Externalização & 59,55 & 10,11 & 53,24 & 10,53 & $2,328 t$ & $0,024^{*}$ \\
\hline Escala Total & 59,55 & 10,04 & 53,72 & 9,86 & $2,230 t$ & $0,030^{*}$ \\
\hline Estat. = Estatística; Testes $t$ de Student e $U$ de Mann-Whitney; $p^{* *} \leq 0,01 e^{*} \leq 0,05$ & &
\end{tabular}

Nesse inventário foi possível identificar que os resultados médios das oito síndromes comportamentais e emocionais diferiram de modo estatisticamente significativo entre os grupos de crianças em apenas dois aspectos: problemas de atenção $(p=0,006) \mathrm{e}$ comportamento agressivo $(p=0,038)$, sendo maiores no Grupo Clínico. Com relação às 
escalas de avaliação do comportamento, houve escores médios estatisticamente mais elevados no Grupo Clínico em Problemas de Externalização $(p=0,02)$ e Problemas no Funcionamento Total $(p=0,03)$, conforme Tabela 18. Entretanto, após controlar as variáveis escolaridade da mãe e NSE, somente problemas de atenção mantiveram diferença estatisticamente significativa entre os grupos $(p=0,024)$.

Objetivando alcançar uma avaliação mais detalhada dos sintomas comportamentais e emocionais apresentados pelas crianças desse estudo, optou-se por analisar as categorias diagnósticas oferecidas pelo CBCL. Os resultados compatíveis com o diagnóstico de "clínico" ou "limítrofe" formaram o subgrupo "clínico" e aqueles com pontuação dentro do padrão normativo formaram o subgrupo "normal", comparando-se a frequência desses casos entre os Grupos Clínicos e Controle (Tabela 19).

Tabela 19 - Comparação da frequência dos casos "clínicos" identificados no CBCL nos Grupos Clínico e Controle

\begin{tabular}{|c|c|c|c|c|c|c|c|}
\hline \multirow{3}{*}{ Síndromes e Escalas } & \multirow{3}{*}{ Grupos } & \multicolumn{4}{|c|}{ Categoria diagnóstica CBCL } & \multirow[b]{3}{*}{ Estat. } & \multirow[b]{3}{*}{$p$} \\
\hline & & \multicolumn{2}{|c|}{ Normal } & \multicolumn{2}{|c|}{ Clínico } & & \\
\hline & & $f$ & $\%$ & $f$ & $\%$ & & \\
\hline \multirow{2}{*}{ Ansieda de/depressão } & Clínico & 19 & 65,5 & 10 & 34,5 & \multirow{2}{*}{$0,322 x^{2}$} & \multirow[b]{2}{*}{0,570} \\
\hline & Controle & 21 & 72,4 & 8 & 27,4 & & \\
\hline \multirow{2}{*}{ Retraimento/depressão } & Clínico & 25 & 86,2 & 4 & 13,8 & \multirow{2}{*}{$-F$} & \multirow{2}{*}{1,000} \\
\hline & Controle & 26 & 89,7 & 3 & 10,3 & & \\
\hline \multirow{2}{*}{ Queixas somáticas } & Clínico & 25 & 86,2 & 4 & 13,8 & \multirow{2}{*}{$-F$} & \multirow{2}{*}{0,670} \\
\hline & Controle & 27 & 93,1 & 2 & 6,9 & & \\
\hline \multirow{2}{*}{ Problemas socia is } & Clínico & 24 & 82,8 & 5 & 17,2 & \multirow{2}{*}{$-F$} & \multirow{2}{*}{1,000} \\
\hline & Controle & 25 & 86,2 & 4 & 13,8 & & \\
\hline \multirow{2}{*}{ Problemas do pensamento } & Clínico & 27 & 93,1 & 2 & 6,9 & \multirow{2}{*}{$-F$} & \multirow{2}{*}{1,000} \\
\hline & Controle & 28 & 96,6 & 1 & 3,4 & & \\
\hline \multirow{2}{*}{ Problemas de atenção } & Clínico & 19 & 65,5 & 10 & 34,5 & \multirow{2}{*}{$-F$} & \multirow{2}{*}{$0,005^{* *}$} \\
\hline & Controle & 28 & 96,6 & 1 & 3,4 & & \\
\hline \multirow{2}{*}{ Violação de regras } & Clínico & 24 & 82,8 & 5 & 17,2 & \multirow{2}{*}{$-F$} & \multirow{2}{*}{0,194} \\
\hline & Controle & 28 & 96,6 & 1 & 3,4 & & \\
\hline \multirow{2}{*}{ Comporta mento agressivo } & Clínico & 18 & 62,1 & 11 & 37,9 & \multirow{2}{*}{$2,080 x^{2}$} & \multirow{2}{*}{0,149} \\
\hline & Controle & 23 & 79,3 & 6 & 20,7 & & \\
\hline \multirow{2}{*}{ Internalização } & Clínico & 17 & 58,6 & 12 & 41,4 & \multirow{2}{*}{$0,672 x^{2}$} & 0.412 \\
\hline & Controle & 20 & 69,0 & 9 & 31,0 & & 0,412 \\
\hline Externalizacão & Clínico & 14 & 48,3 & 15 & 51,7 & $2559 x^{2}$ & 110 \\
\hline Externa II zaçao & Controle & 20 & 69,0 & 9 & 31,0 & 2,559 X & $0, \perp \perp 0$ \\
\hline Total & Clínico & 16 & 55,2 & 13 & 44,8 & $2747 x^{2}$ & 0,097 \\
\hline Total & Controle & 22 & 75,9 & 7 & 24,1 & & \\
\hline
\end{tabular}

Estat. = Estatística; Testes Qui-quadrado $\left(\mathrm{X}^{2}\right)$ e Exato de Fisher $(\mathrm{F}) ; p^{* *} \leq 0,01$

Essa análise corrobora os resultados anteriores, tornando-se possível confirmar que a diferença mais robusta entre os grupos manteve-se em problemas de atenção $(p=0,005)$. Contudo, a despeito de não ter sido verificada diferença estatisticamente significativa entre os grupos nos demais aspectos avaliados pelo CBCL, chama atenção à elevada frequência de casos com dificuldades comportamentais no Grupo Clínico. Isso ficou mais evidente nas síndromes de ansiedade/depressão (34,5\%) e comportamentos de agressividade (37,9\%), bem 
como nas escalas relativas a problemas de comportamento do tipo de Internalização $(41,4 \%)$, Externalização $(51,7 \%)$ e Funcionamento Total (44,8\%). Apesar disso, não houve qualquer relato dos pais ou responsáveis no tocante a existência de acompanhamento em serviços de saúde mental dessas crianças.

\subsection{Relativos aos exames médicos do Grupo Clínico}

\subsubsection{Doppler Transcraniano}

Relativo aos resultados do DTC, todos os participantes tiveram valores na VFSC < $170 \mathrm{~cm} / \mathrm{seg}$ considerados como normais de acordo com o Guidelines brasileiro (2011). Entretanto, cinco crianças apresentaram pequenas alterações, principalmente inversão de velocidades entre ACM e ACA podendo indicar estenose intracraniana. Essa hipótese diagnóstica pôde ser verificada por meio da AngioRM (Angiografia por ressonância magnética). Foi possível ter acesso a quatro resultados desse exame, detectando-se uma estenose na ACA-E, uma estenose na ACM-D e dois exames normais. Não foram analisados, no presente estudo, todos os resultados da AngioRM, pois alguns não tiveram o laudo definitivo liberado.

\subsubsection{Imagem por Ressonância Magnética}

O exame da IRM foi realizado com 29 participantes. A prevalência de ICS foi de $24 \%$ $(n=7)$, os demais exames foram considerados normais $(n=22)$. Diante desse resultado, optou-se por comparar Grupo ICS e IRM normal nas variáveis sociodemográficas, escolares e clínicas (Tabela 20).

\section{- Aspecto sociodemográfico}

O Grupo ICS apresentou média de idade de 11 anos (DP $\pm 1,414)$ sendo estatisticamente diferente significativamente $(U=36,5 ; p=0,03)$ ao Grupo IRM normal, onde a idade média atingiu 9,50 anos (DP $\pm 1,819$ ). Esse dado é corroborado, pela observação de que $85,7 \%(\mathrm{n}=6)$ das crianças com ICS pertenciam ao grupo de maior idade (10-12 anos), apesar de não haver diferença estatisticamente significativa na comparação com o grupo de menor idade. Não houve diferença estatisticamente significativamente entre os grupos relacionada ao sexo e ao genótipo. A despeito disso, verificou-se 85,7\% $(n=6)$ do Grupo ICS possuía o subtipo genético de maior risco clínico (Tabela 20). 
Nos demais dados sociodemográficos (como escolaridade do pai e da mãe, além de NSE) não foram encontradas diferença estatisticamente significativa entre os subgrupos clínicos aqui considerados.

Tabela 20 - Variáveis sociodemógrafica, escolares e clínicas do Grupo Clínico: Comparação entre subgrupos IRM normale ICS

\begin{tabular}{|c|c|c|c|c|c|c|}
\hline \multirow[t]{2}{*}{ Variáveis } & & \multicolumn{2}{|c|}{$\begin{array}{l}\text { Normal } \\
(n=22)\end{array}$} & \multicolumn{2}{|c|}{$\begin{array}{c}\text { ICS } \\
(n=7)\end{array}$} & \multirow{2}{*}{$\begin{array}{c}\text { Teste de } \\
\text { Fisher } \\
\text { p }\end{array}$} \\
\hline & & $\mathbf{f}$ & $\%$ & f & $\%$ & \\
\hline \multirow{2}{*}{ Grupo ida de } & 7-9 a nos & 10 & 45,5 & 1 & 14,3 & \multirow{2}{*}{0,20} \\
\hline & 10-12 a nos & 12 & 54,5 & 6 & 85,7 & \\
\hline \multirow{2}{*}{ Sexo } & Masculino & 13 & 59,1 & 4 & 57,1 & \multirow{2}{*}{1,00} \\
\hline & Feminino & 9 & 40,9 & 3 & 42,9 & \\
\hline \multirow{2}{*}{ Genótipo } & $S S, S \beta^{\circ}$ & 11 & 50 & 6 & 85,7 & \multirow{2}{*}{0,19} \\
\hline & $\mathrm{SC}, \mathrm{S} \beta+$ & 11 & 50 & 1 & 14,3 & \\
\hline \multirow{3}{*}{ Escolaridade pai } & Funda mental & 15 & 68 & 6 & 86 & \multirow{3}{*}{0,30} \\
\hline & Média/Superior & 5 & 22 & - & - & \\
\hline & Não informada & 2 & 10 & 1 & 14 & \\
\hline \multirow{3}{*}{ Escolaridade mãe } & Funda mental & 14 & 64 & 7 & 100 & \multirow{3}{*}{0,14} \\
\hline & Mé dia/Superior & 7 & 32 & - & - & \\
\hline & Não informada & 1 & 4 & - & - & \\
\hline \multirow{2}{*}{ NSE } & $A B$ & 2 & 9,1 & - & - & \multirow{2}{*}{1,00} \\
\hline & $\mathrm{CDE}$ & 20 & 90,9 & 7 & 100 & \\
\hline \multirow{2}{*}{ Reforço escolar } & Não & 18 & 81,8 & 3 & 42,9 & \multirow{2}{*}{0,07} \\
\hline & Sim & 4 & 18,2 & 4 & 57,1 & \\
\hline \multirow{2}{*}{ Dificuldade escolar } & Não & 17 & 77,3 & 4 & 57,1 & \multirow{2}{*}{0,36} \\
\hline & Sim & 5 & 22,7 & 3 & 42,9 & \\
\hline \multirow{2}{*}{ Repetência escolar } & Não & 16 & 72,7 & 3 & 42,9 & \multirow{2}{*}{0,19} \\
\hline & Sim & 6 & 27,3 & 4 & 57,1 & \\
\hline \multirow{2}{*}{ DTC } & Normal & 18 & 81,8 & 6 & 85,7 & \multirow{2}{*}{1,00} \\
\hline & Alte rado & 4 & 18,2 & 1 & 14,3 & \\
\hline \multirow{2}{*}{ Hidroxiureia } & Não & 17 & 77,3 & 7 & 100 & \multirow{2}{*}{0,30} \\
\hline & Sim & 5 & 22,7 & 0 & 0 & \\
\hline
\end{tabular}

\section{- Aspectos escolares}

Em relação às questões escolares, também não houve diferença estatisticamente significativa entre os subgrupos clínicos no tocante à distribuição das ocorrências de repetência escolar, dificuldade na escola e necessidade de reforço escolar.

\section{- DTC}

Não foi detectada diferença estatisticamente significativa entre os resultados do DTC entre os subgrupos clínicos (ICS e IRM normal). Dos exames do DTC que foram sugestivos de estenose $(n=5), 80 \%$ teve IRM normal. A única criança com ICS e alteração no DTC, ao realizar a AngioRM evidenciou estenose crítica da ACM-D. 


\section{- Medicação}

A maioria das crianças com DF utiliza va como medicamentos regulares o ácido fólico $(100 \%)$ e a penicilina $(93,3 \%)$. Em relação a hidroxiureia $(H U)$, somente $16,7 \%(n=5)$ da amostra fazia uso desse fármaco, sendo observado que todos tiveram IRM normal.

\section{- Hemograma}

O Grupo Clínico apresentou nível médio de $\mathrm{Hb}$ igual a 9,23 g/dl (DP $\pm 1,26)$, sem diferença estatisticamente significativa entre ICS e IRM normal $(\mathrm{p}=0,16)$. Em relação ao Ht, a média geral do grupo com DF foi de $29,75 \%$ (DP $\pm 4,51)$, sendo constatada tendência à significância estatístitica $(\mathrm{p}=0,06)$ para o Grupo IRM normal ter maior nível de Ht $(30,67 \pm$ $4,36)$ quando comparado com Grupo ICS $(27,00 \pm 4,04)$. Esses dados podem ser visualizados na Tabela 21.

Tabela 21 - Hemograma do Grupo Clínico: Comparação entre subgrupos IRM Normal e ICS

\begin{tabular}{lllllll} 
Hemograma & Grupos & Média & DP & Mín-Máx & $\boldsymbol{U}$ & $\boldsymbol{P}$ \\
\hline \multirow{3}{*}{ Hb } & Total & 9,23 & 1,259 & $7-12$ & & \\
& Normal & 9,44 & 1,216 & $7-12$ & \multirow{2}{*}{47} & 0,16 \\
& ICS & 8,60 & 1,260 & $7-11$ & & \\
Ht & Total & 29,75 & 4,510 & $22-39$ & & \\
& Normal & 30,67 & 4,363 & $23-39$ & \multirow{2}{*}{38} & 0,06 \\
\hline
\end{tabular}

\section{- Avaliação neuropsicológica}

$\mathrm{Na}$ avaliação neuropsicológica, de uma forma geral, os escores médios do Grupo ICS tiveram tendência a serem menores do que o Grupo IRM normal. As evidências advêm desde a triagem intelectual, como mostra a Tabela 22.

Tabela 22 - WISC III e Raven do Grupo Clínico: Comparação entre subgrupos IRM normal e ICS

\begin{tabular}{|c|c|c|c|c|c|c|}
\hline & Testes & Grupos & Média & DP & $U$ & $P$ \\
\hline \multirow{6}{*}{$\begin{array}{l}\equiv \\
\stackrel{\aleph}{3} \\
3\end{array}$} & \multirow[t]{2}{*}{ QI Estima do } & Normal & 100,59 & 15,915 & \multirow{2}{*}{28,5} & \multirow{2}{*}{$0,013 *$} \\
\hline & & ICS & 85 & 6,403 & & \\
\hline & \multirow[t]{2}{*}{ Vocabulário } & Normal & 10,55 & 3,501 & \multirow{2}{*}{43,5} & \multirow{2}{*}{0,085} \\
\hline & & ICS & 8,14 & 1,464 & & \\
\hline & \multirow[t]{2}{*}{ Cubos } & Normal & 9,68 & 2,784 & \multirow{2}{*}{27,5} & \multirow{2}{*}{$0,011 *$} \\
\hline & & ICS & 6,71 & 1,704 & & \\
\hline \multirow{2}{*}{ Raven } & Raven & Normal & 24,91 & 5,415 & \multirow{2}{*}{41,5} & \multirow{2}{*}{0,070} \\
\hline & (pontos brutos) & ICS & 20,29 & 5,794 & & \\
\hline
\end{tabular}

Verificou-se desempenho estatisticamente inferior do Grupo ICS no "QI Estimado" ( $p$ $=0,013)$ e no subteste "Cubos" $(p=0,011)$. Esses dados podem ser acrescidos com 
informações da Tabela 23, que apresenta a distribuição das crianças do Grupo Clínico em função de sua classificação nas provas intelectuais.

Tabela 23 - Classificação intelectual do Grupo Clínico a partir do QI Estimado do WISC III e do Raven: Comparação entre subgrupos IRM normal e ICS

\begin{tabular}{|c|c|c|c|c|c|c|}
\hline \multirow[b]{2}{*}{ Testes } & \multirow[b]{2}{*}{ Classificação } & \multicolumn{2}{|c|}{ Normal } & \multicolumn{2}{|c|}{ ICS } & \multirow[b]{2}{*}{$P$} \\
\hline & & $f$ & $\%$ & $f$ & $\%$ & \\
\hline \multirow[t]{2}{*}{ QI Estimado } & Média & 17 & 77,3 & 1 & 14,3 & \multirow{2}{*}{$0,006 * *$} \\
\hline & Abai xo da média & 5 & 22,7 & 6 & 85,7 & \\
\hline \multirow[t]{2}{*}{ Raven } & Média & 20 & 90,9 & 2 & 28,6 & \multirow{2}{*}{$0,003^{* *}$} \\
\hline & Abai xo da média & 2 & 9,1 & 5 & 71,4 & \\
\hline
\end{tabular}

A classificação nos testes de inteligência aponta que 71-85\% do Grupo ICS apresentou desempenho intelectual abaixo da média, porporção estatisticamente diferente $(\mathrm{p}<0,01)$ do Grupo IRM normal. Ressalta-se, no entanto, que somente uma criança do Grupo ICS foi considerada com deficiência intelectual, segundo as normas do Raven.

Torna-se, no entanto, necessário ainda examinar o desempenho das crianças do Grupo Clínico na avaliação das funções cognitivas mais específicas. Esses resultados estão sistematizados na Tabela 24.

Pode-se observar que, na maioria dos subtestes dos domínios da função executiva, linguagem e memória, as crianças do Grupo ICS apresentaram resultados considerados abaixo da média normativa. Na comparação com o Grupo IRM normal, as crianças com ICS apresentaram menor rendimento estatisticamente inferior no domínio da memória, no subteste "Memória Narrativa com evocação livre" $(p=0,026)$ e uma tendência à significância estatística nessa mesma tarefa com auxílio de pistas $(p=0,058)$. A memória visoespacial aferida pelo subteste "Memória para Desenho" [nos escores totais imediato $(p=0,017)$ e tardio $(p=0,036)$ ] também apresentam diferença estatisticamente significativa e houve uma tendência à significância estatística nesse subteste na pontuação de "Espacial imediato" ( $p=$ $0,053)$ e "Conteúdo tardio" ( $p=0,055)$. No domínio da linguagem, crianças com ICS tiveram pontuação estatisticamente inferior em "Processamento Fonológico" ( $p=0,047)$. Nos demais domínios cognitivos não foi encontrada diferenças estatisticamente significativa entre os subgrupos.

De modo similiar a análises prévias, foram realizados procedimentos de correlação (Spearman) entre escores neuropsicológicos e níveis de $\mathrm{Hb}$ ou Ht. Os resultados não se mostraram estatisticamente significativos, sinalizando reduzida associação entre essas variáveis. 
Tabela 24 - NEPSY II: Comparação entre subgrupos IRM normal e ICS

\begin{tabular}{|c|c|c|c|c|c|c|}
\hline & Testes & Grupos & Média & DP & $\boldsymbol{U}$ & $\boldsymbol{P}$ \\
\hline \multirow{18}{*}{ 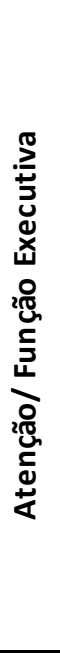 } & \multirow{2}{*}{ Atenção Auditiva } & Normal & 11,41 & 2,462 & \multirow{2}{*}{47,5} & \multirow{2}{*}{0,127} \\
\hline & & ICS & 9,71 & 3,094 & & \\
\hline & \multirow{2}{*}{ Atenção Auditiva combina do } & Normal & 11,50 & 2,614 & \multirow{2}{*}{47,5} & \multirow{2}{*}{0,129} \\
\hline & & ICS & 9,57 & 2,992 & & \\
\hline & \multirow{2}{*}{ Conjunto de Respostas } & Normal & 11,50 & 2,502 & \multirow{2}{*}{50,5} & \multirow{2}{*}{0,174} \\
\hline & & ICS & 9,71 & 3,592 & & \\
\hline & \multirow{2}{*}{ Conjunto de Respostas combina do } & Normal & 11,05 & 2,751 & \multirow{2}{*}{68} & \multirow{2}{*}{0,644} \\
\hline & & ICS & 10,57 & 2,440 & & \\
\hline & \multirow{2}{*}{ Inibindo Respostas- Nomeação } & Normal & 7,23 & 3,422 & \multirow{2}{*}{70} & 0719 \\
\hline & & ICS & 6,86 & 4,375 & & ה \\
\hline & & Normal & 7,50 & 3,377 & & \\
\hline & ImIDInao kes postas - InIDiçao & ICS & 5,43 & 3,690 & 50,5 & $0,1 / 5$ \\
\hline & Inihindo Resnostas - Mudanca & Normal & 7,67 & 3,596 & 485 & 0181 \\
\hline & 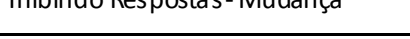 & ICS & 5,43 & 3,155 & 40,3 & 0,101 \\
\hline & Inibindo Resnostas - Erro total & Normal & 7,95 & 4,642 & 485 & 0.182 \\
\hline & ImIIna kespostas-erro total & ICS & 5,29 & 3,302 & 48,3 & 0,102 \\
\hline & Fluência em Desenhos & Normal & 6,41 & 2,443 & 75 & 0918 \\
\hline & riveticla elli veserilius & ICS & 6,14 & 2,911 & 20 & 0,510 \\
\hline & Nomeando Ránido & Normal & 7,27 & 3,298 & 43 & 0.079 \\
\hline & INOTednao kaplao & ICS & 4,57 & 2,992 & 43 & $0,0 / 9$ \\
\hline & Comnreendendo Instrurões & Normal & 7,64 & 2,904 & 405 & 0060 \\
\hline$\frac{\varepsilon}{0}$ & compreeriderino mis truçoes & ICS & 5,43 & 2,225 & 40,3 & 0,000 \\
\hline ప్రా & Processamento Fonológico & Normal & 5,50 & 3,248 & 38,5 & $0.047 *$ \\
\hline م & 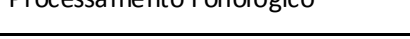 & ICS & 3,00 & 1,915 & So,J & \\
\hline .气 & & Normal & 8,41 & 3,096 & 53 & 0218 \\
\hline & Prounzinuo rdadids -semidmicd & ICS & 7,00 & 2,160 & כ3 & 0,210 \\
\hline & Produzindo Palavras -Letra inicial & Normal & 5,82 & 2,557 & 74 & 0,877 \\
\hline & 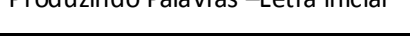 & ICS & 5,57 & 3,101 & 14 & 0,017 \\
\hline & & Normal & 9,82 & 3,660 & 335 & \\
\hline & IVIemorid Ivarrativa Livie & ICS & 6,14 & 2,340 & 33,3 & $0,0<0^{\circ}$ \\
\hline & Memória Narrativa livre + Pista & Normal & 9,18 & 4,019 & 40 & 0.058 \\
\hline & 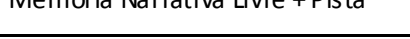 & ICS & 6,00 & 2,517 & 40 & U,U \\
\hline & Memória nara Desenho Conteúdo & Normal & 8,95 & 2,984 & 48 & 0136 \\
\hline & 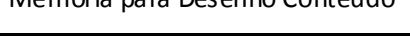 & ICS & 6,71 & 3,302 & 40 & 0,130 \\
\hline & Memória para Desenho Espacial & Normal & 9,27 & 3,693 & 395 & 0.053 \\
\hline 'ำ & IVlemor la pard Desentio es pactal & ICS & 7,14 & 2,116 & 39,3 & U,Uכ3 \\
\hline$\frac{E}{0}$ & Memória nara Decenho Total & Normal & 8,77 & 3,250 & & \\
\hline$\Sigma$ & IVIemor la pard Desenno Told & ICS & 5,43 & 2,820 & 30,5 & $0,01 /^{\top}$ \\
\hline ○ & Memória para Desenho Conteúdo & Normal & 9,45 & 3,066 & 39.5 & 0.055 \\
\hline ర్d & Tardia & ICS & 7,43 & 2,070 & 39,5 & U,USל \\
\hline$\frac{7}{\mathrm{~N}}$ & Memória para Desenho Espacial & Normal & 9,91 & 3,265 & 43 & 0079 \\
\hline 而 & Tardia & ICS & 7,43 & 3,101 & 40 & 0,019 \\
\hline$\frac{\omega}{2}$ & Memória para Desenho Total & Normal & 9,86 & 3,342 & 36 & $0,036 *$ \\
\hline $\bar{\alpha}$ & Tardia & ICS & 7,00 & 2,646 & & \\
\hline & Memória nara Faces & Normal & 9,41 & 3,187 & 63 & 0471 \\
\hline & IVIetrion la pald races & ICS & 10,43 & 2,992 & ב & $0,4 / 1$ \\
\hline & Memória para Faces & Normal & 7,95 & 3,748 & 61 & 0,412 \\
\hline & Tardia & ICS & 9,29 & 2,289 & & \\
\hline & Memória nara lista de Palayrac & Normal & 10,23 & 3,023 & 49 & 0149 \\
\hline & 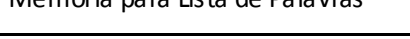 & ICS & 8,71 & 1,890 & 45 & 0,143 \\
\hline & Flechas & Normal & 9,95 & 4,134 & & \\
\hline س & rlecnas & ICS & 8,86 & 2,545 & 60,5 & 0,398 \\
\hline$>$ & Quebracabeca Geométrico & Normal & 10,32 & 2,102 & 48 & 0136 \\
\hline & Quen dea veça Geurretrico & ICS & 8,43 & 4,077 & 40 & 0,130 \\
\hline & Precisão visomotora & Normal & 9,18 & 3,459 & 61 & 0,411 \\
\hline & Precisao vis ormotord & ICS & 10,71 & 3,302 & 61 & 0,411 \\
\hline & Imitando Pocicãn da M̃̃ก & Normal & 9,55 & 3,789 & 485 & 0139 \\
\hline$\sum_{n}$ & 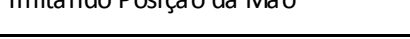 & ICS & 7,14 & 1,215 & 40,3 & 0,135 \\
\hline & & & Média & Abaixo & $\mathbf{F}$ & \\
\hline & Sequência Motora Manual & Normal & 18 & 4 & - & 100 \\
\hline & & ICS & 6 & 1 & & 1,00 \\
\hline
\end{tabular}

Estat. = Estatística; Testes $U$ de Mann-Whitney e Exato de Fisher (F); $p^{*} \leq 0,05$; VE = Visoespacial; SM = Sensoriomotor 


\section{-Avaliação de comportamento}

A distribuição dos resultados do Grupo Clínico no CBCL, subdividido em função da presença de ICS ou não, encontra-se na Tabela 25.

Tabela 25 - CBCL do Grupo Clínico: Comparação entre subgrupos IRM normal e ICS

\begin{tabular}{|c|c|c|c|c|c|}
\hline Síndromese Escal as & Grupos & Média & DP & $\boldsymbol{U}$ & $\boldsymbol{P}$ \\
\hline \multirow{2}{*}{ Ansieda de/depressão } & Normal & 60,48 & 9,978 & \multirow{2}{*}{66} & \multirow{2}{*}{0,690} \\
\hline & ICS & 61,29 & 5,765 & & \\
\hline \multirow{2}{*}{ Retraimento/depressão } & Normal & 58,76 & 10,363 & \multirow{2}{*}{69,5} & \multirow{2}{*}{0,831} \\
\hline & ICS & 56,14 & 3,532 & & \\
\hline \multirow{2}{*}{ Queixas somáticas } & Normal & 57,43 & 6,145 & \multirow{2}{*}{66} & \multirow{2}{*}{0,686} \\
\hline & ICS & 55,71 & 4,461 & & \\
\hline \multirow{2}{*}{ Problemas sociais } & Normal & 60,43 & 8,669 & \multirow{2}{*}{59} & \multirow{2}{*}{0,439} \\
\hline & ICS & 56,86 & 3,237 & & \\
\hline \multirow{2}{*}{ Problemas do pensamento } & Normal & 56,05 & 7,915 & \multirow{2}{*}{39,5} & \multirow{2}{*}{0,062} \\
\hline & ICS & 50,57 & 0,535 & & \\
\hline \multirow{2}{*}{ Problemas da atenção } & Normal & 59,86 & 12,005 & \multirow{2}{*}{47} & \multirow{2}{*}{0,158} \\
\hline & ICS & 62,29 & 6,130 & & \\
\hline \multirow{2}{*}{ Violação de regras } & Normal & 58,86 & 9,254 & \multirow{2}{*}{57,5} & \multirow{2}{*}{0,394} \\
\hline & ICS & 54,57 & 4,685 & & \\
\hline \multirow{2}{*}{ Comportamento agressivo } & Normal & 62,76 & 10,677 & \multirow{2}{*}{73} & \multirow{2}{*}{0,979} \\
\hline & ICS & 61,43 & 5,653 & & \\
\hline \multirow{2}{*}{ Escala de Internalização } & Normal & 58,38 & 11,469 & \multirow{2}{*}{69} & \multirow{2}{*}{0,811} \\
\hline & ICS & 59,00 & 4,397 & & \\
\hline \multirow{2}{*}{ Escala de Externalização } & Normal & 60,38 & 11,020 & \multirow{2}{*}{70,5} & \multirow{2}{*}{0,873} \\
\hline & ICS & 59,29 & 5,407 & & \\
\hline \multirow{2}{*}{ Escala Total } & Normal & 60,19 & 11,007 & \multirow{2}{*}{67} & \multirow{2}{*}{0,730} \\
\hline & ICS & 60,14 & 3,716 & & \\
\hline
\end{tabular}

A análise desses resultados do CBCL apontam que não foi qualquer diferença estatisticamente significativa entre os Grupos IRM normal e ICS na escala de sintomas comportamentais e emocionais. Desse modo, dentro do Grupo Clínico, não houve evidências de diferenciação entre características do comportamento e vivências afetivas das crianças com DF. 
5. DISCUSSÃO 
Diante dos objetivos propostos para o presente trabalho, foi possível reunir evidências empíricas relevantes sobre características do funcionamento neuropsicológico e comportamental de crianças com DF. Esse tema central foi tomado para investigação diante da complexidade de variáveis que acometem os portadores de DF, levando a transtornos no desenvolvimento.

As primeiras considerações são dirigidas a versão brasileira da bateria NEPSY II. As médias dos escores ponderados em quase todos os subtestes avaliados no grupo de crianças saudáveis estiveram dentro da variabilidade da normatização americana de $10 \pm 3$, somente no subteste processamento fonológico a média ficou um pouco abaixo do esperado $(7,4$ com DP $\pm 1,83$ ). Cabe aqui fris ar que esse subteste necessitou de ampla adaptação, não sendo possível sua tradução por se tratar de um subteste do domínio da linguagem (Argollo et al., 2009). Em termos gerais, esses resultados apontam para adequação psicométrica da versão do NEPSY II para população brasileira entre 7 a 12 anos e ratifica m a possibilidade de sua aplicação prática em grupos clínicos, como crianças com DF.

Referente aos resultados dos exames médicos realizados, todas as crianças com DF apresentaram DTC considerado dentro da faixa normal. Contudo, em cinco pacientes houve indício de estenose cerebrovascular devido a inversão de velocidades entre ACM e ACA, sendo possível confirmar esse diagnóstico em dois pacientes pela AngioRM. Em relação à IRM cerebral, no presente estudo a prevalência de ICS foi de $24 \%(n=7)$ na amostra clínica, correspondendo ao mesmo percentual médio encontrado na revisão de literatura realizada. Não houve sinais de relevantes associação entre os exames DTC e IRM, visto que a maioria das crianças com ICS teve DTC normal. Esse achado aponta para a importância dos portadores de DF serem avaliados de forma regular pelos dois tipos de exames neurológicos, já que avaliam aspectos diferentes dessa patologia e são essenciais para acompanhar a progressão e riscos inerentes da DF.

Concernente às características dos participantes desse estudo, chama atenção o rendimento escolar da amostra alcançada. A despeito das crianças terem a mesma idade e similares condições escolares, em termos gerais, o Grupo Clínico alcançou média significativamente inferior em anos de estudo em relação ao Grupo Controle. O atraso da escolarização das crianças com DF pode ser atribuído ao alto percentual de repetência escolar desse grupo, tendo ocorrido em um terço dessas crianças. Essa alta prevalência de repetência escolar também foi encontrada em outros estudos (Strouse et al., 2006; Kral et al., 2006). Atrelado a isso, muitas apresentaram queixa de dificuldade de aprendizagem, estando associada às disfunções neuropsicológicas encontradas, entre outros fatores do contexto de 
vida, como a necessidade de faltas escolares para tratamentos e hospitalizações frequentes. Ressalta-se que não houve diferença estatisticamente significativa quanto aos aspectos escolares entre os pacientes com ICS e aqueles com IRM normal, contrastando com os dados de Schatz et al. (2001) que verificaram maior repetência e necessidade de serviço educacional nas crianças com ICS.

No tocante as variáveis sociodemográficas, procurou-se compor amostra pareada entre os dois grupos, sendo a grande maioria dos participantes advindos de instituições públicas de ensino e de padrão socioeconômico médio (clas se C). Apesar disso, constatou-se que o Grupo Clínico continha mais casos de menor NSE (classe D e E), ocasionando alguma discrepância com relação ao Grupo Controle nessa variável. Algumas considerações a respeito desses fatores merecem aqui a devida análise e discussão. A maioria das mães do Grupo Clínico não trabalhava $(53.3 \%)$, sendo o pai o único provedor da família. Estudos apontam que mediante o diagnóstico da DF, ocorre uma reestruturação da dinâmica familiar, pois a criança portadora dessa patologia demanda maior atenção, já que devem ser acompanhadas em centro de tratamento especializado ao longo da vida, com avaliações clínicas periódicas e internações hospitalares em situações de risco (Rodrigues, Araújo \& Melo, 2010; Tweel et al., 2008). Principalmente as mães assumem os cuidados dessas crianças, ficando impossibilitadas de exercer atividades externas, sendo levadas a abdicar de outras funções, como sua profissão (Guimarães, Miranda \& Tavares, 2009; Assimadi, Gbadoé \& Nyadanu , 2000; Macharia, Shiroya \& Njeru , 1997). Existe, ainda, um aumento dos gastos familiares com compra de medicações, adicionadas a maiores despesas quando necessárias internações hospitalares da criança doente. Esta realidade foi confirmada por Assimadi et al. (2000) que verificaram que 65\% dos pais de crianças com DF refere experienciar dificuldade econômica.

Outro fator que pode estar associado ao menor status socioeconômico do Grupo Clínico refere-se à diferença de origem dos participantes desse estudo. Todos do Grupo Controle residiam em Ribeirão Preto (SP), cidade que possui o sexto maior Índice de Desenvolvimento Humano (IDH) do Estado de São Paulo (FIESP, 2000). Já as crianças do Grupo Clínico foram provenientes de Ribeirão Preto, mas também de outras cidades do interior paulista e mineiro que, em geral, possuem IDH menor. Ademais, foi evidenciado menor grau de escolaridade do pai e da mãe no Grupo Clínico, sendo esse aspecto relevante para contribuir com o menor NSE familiar.

No perfil neuropsicológico, o Grupo Clínico apresentou menor rendimento em diversas funções cognitivas quando comparado ao Grupo Controle. Na capacidade intelectual geral, $46 \%$ das crianças com DF apresentaram desempenho abaixo da média normativa no 
Raven e 36\% quando utilizado o QI Estimado, constatando defasagem cognitiva de aproximadamente 13-14 pontos em relação às crianças saudáveis. Esses dados são corroborados por uma série de estudos que verificaram desempenho intelectual inferior no Grupo Clínico (Schatz et al., 2004; Steen et al., 2005; Hijmans, Fijnvandraat et al., 2011; Noll et al., 2001), encontrando diferença no QI total de quase 19 pontos na comparação com irmãos saudáveis (Swift et al, 1989). Ressalta-se que, na atual investigação, dados os critérios de seleção adotados na composição da amostra, apenas uma criança $(3,3 \%)$ teve desempenho intelectual inferior no Raven, porém seu resultado no QI Estimado do WISC III foi médio inferior, razão de sua inclusão no atual estudo. Nas demais pesquisas, foi encontrado maior percentual de deficiência intelectual, Steen et al. (1999) e Hijmans, Fijnvandraat et al. (2011), alcançando aproximadamente 33\%, enquanto em Swift et al (1989) a estimativa de déficit cognitivo atingiu $19 \%$ em crianças com DF. Os resultados do presente trabalho foram bastante claros ao apontar que o aumento de cada ponto nos testes intelectuais (QI Estimado e Raven) mostrou-se como fator protetor, havendo redução de 6,5 e 13,7\% (respectivamente), em média, da chance da criança pertencer ao Grupo Clínico.

$\mathrm{Na}$ análise mais apurada do Grupo Clínico, os sinais de prejuízo no desempenho intelectual tornaram-se mais evidente. As crianças com ICS apresentaram maior percentual de baixo funcionamento intelectual geral, correspondendo a aproximadamente $71-85 \%$ desse subgrupo (Raven e QI Estimado respectivamente), sendo o único caso de deficiência intelectual pertencente a esse grupo. Já as crianças com IRM normal evidenciaram prevalência de limites cognitivos em menor proporção (9-23\% a depender do instrumento de avaliação), apresentando, em média, 15 pontos a mais no QI Estimado do que o Grupo ICS. Essa tendência dos dados foi anteriormente identificada por Steen et al. (1999, 2003) e Thompson et al. (2003), porém a discrepância de resultados entre os subgrupos avaliados foi mais marcante no atual trabalho do que em investigações anteriores que verificaram diferença média de 4-5 pontos (Wang et al., 2001; Thompson et al., 2003).

Deve-se ressaltar que a diferença de classificações entre os coeficientes de inteligência do QI Estimado do WISC III e do Raven possivelmente estão relacionadas às funções psíquicas e aos construtos por eles avaliados. De qualquer modo, os resultados nesses dois testes de inteligência foram consistentes ao demonstrar que a DF constitui um fator de risco importante para a criança desenvolver prejuízos na funcionalidade intelectual geral, sendo esse risco ainda maior para crianças com ICS.

$\mathrm{Na}$ avaliação dos domínios cognitivos mais específicos, nos subtestes de atenção/função executiva as crianças com DF apresentaram baixo escore em velocidade de processamento, 
controle inibitório e flexibilidade mental. O acréscimo de cada ponto nesses subtestes foi considerado como fator de proteção, em média de 21 a 29\%. O baixo desempenho em testes voltados para função executiva foi encontrado em outros estudos na literatura científica, em diferentes processos cognitivos como resolução de problema, flexibilidade mental e velocidade de processamento (Berg et al, 2012) e memória operacional alça fonológica (Schatz et al., 2004; Schatz \& Roberts, 2005; Ruffieux et al., 2013). Contrariamente aos nossos resultados, alguns autores não encontraram alteração em controle inibitório (Goonan et al., 1994; Hijmans, Fijnvandraat et al., 2011; Berg et al., 2012). Vale ressaltar ainda que na avaliação mais específica da atenção seletiva e sustentada não houve diferença marcante entre o Grupo Clínico e Grupo Controle, sendo esse resultado também verificado por Goonan et al. (1994), Nabors e Freymuth (2002) e Scantlebury et al. (2011). Todavia, contraria outras pesquisas sobre a atenção na DF que consideraram essa função como especialmente prejudicada (Swift et al., 1989; Brown et al., 1993; Hijmans, Fijnvandraat et al., 2011, Strouse et al., 2006). No entanto, deve-se pontuar que nesse estudo foi avaliada principalmente a atenção auditiva, não sendo investigada mais especificamente a atenção visual, principal via de avaliação da atenção utilizada pelos estudos científicos anteriormente citados.

Ainda no domínio da atenção/função executiva, não foi constatada nenhuma discrepância nos escores entre os Grupos IRM normal e ICS. Essas evidências contrariam achados de outras investigações científicas na área que apontam, inclusive, esse domínio como o mais vulnerável na DF, por envolver lesões principalmente no circuito frontocortical e na substância branca (Craft et al.,1993; Schatz et al., 2001; Wang et al. 2001; Brandling-Bennett et al, 2003). Alguns trabalhos consideram esse domínio cognitivo como o mais sensível para discriminar crianças portadoras de DF com ICS (DeBaun et al., 1998). Pode-se ponderar, entretando, que uma possível diferença, principalmente na função executiva, entre esses grupos não pôde ser identificada no presente estudo, pois mesmo as crianças com IRM normal apresentaram baixo rendimento nesse processo cogntivo quando comparadas às crianças saudáveis. Outros estudos também não constataram diferença na atenção sustentada de crianças com DF e saudáveis (Scantlebury et al., 2011) e também em sua função executiva (Berg et al., 2012; Brown et al., 2000).

Diferentemente dos estudos anteriormente referidos (que consideram a atenção/ função executiva como domínio cognitivo mais afetado na DF), no presente estudo o domínio da linguagem mostrou-se como o mais comprometido. Em quase todos os subtestes de linguagem o Grupo Clínico apresentou resultados estatisticamente inferiores à média, sendo também significativamente inferior ao Grupo Controle. Pode-se constatar baixa performance 
em atividades que requerem consciência fonológica, produção de palavras, compreensão verbal e velocidade de nomeação. Apenas a velocidade de produção de conhecimento semântico se manteve dentro da média normativa, embora ainda com pontuação inferior as crianças saudáveis. Além disso, houve evidência de que a cada aumento de um ponto nos subtestes de linguagem, reduz, em média, 26 a $43 \%$ de chance das crianças serem do Grupo Clínico, principalmente na tarefa de velocidade de nomeação. Pesquisas prévias, também encontraram menor rendimento em portadores de DF nas provas de compreensão verbal (Swift et al., 1989; Steen et al., 2005), vocabulário, processamento auditivo e velocidade de processamento (Schatz \& Roberts, 2005). Vale destacar que a diferença inicialmente identificada entre os Grupos Clínicos e Controle no subtestes de "Vocabulário" do WISC III, desapareceu após o controle das variáveis sociodemográficas. Esse resultado é respaldado no conhecimento de que a extensão e qualidade do vocabulário infantil são influenciadas pelas experiências prévias e refletem aspectos socioeconômicos e de escolaridade formal (Cunha, 2000).

Infere-se ainda que o prejuízo significativo no domínio da linguagem nas crianças com DF pode estar relacionado com a alta frequência de dificuldades de aprendizagem, principalmente em leitura e escrita. Kemp e Korman (2011) apontam dados nessa direção, pois no estudo realizado com crianças com dificuldades de leitura, utilizando o NEPSY II, foi encontrado baixo rendimento em todos os subtestes do domínio de linguagem. Os subtestes "Processamento Fonoló gico" e "Nomeando Rápido" tiveram déficits consistentes na dislexia e foram os mais sensíveis para identificar crianças com dificuldade de leitura.

Outro aspecto que deve ser considerado na avaliação do baixo desempenho no domínio da linguagem é a possibilidade de déficit auditivo associado. A respeito disso, nesse estudo foi possível realizar audiometria de seis crianças, após verificar alteração em subtestes de linguagem, porém não houve nenhuma alteração nesses exames. Cabe sublinhar que não houve uma avaliação mais detalhada da função auditiva, sendo a audiometria um exame de triagem. Silva, Nova e Lucena (2012) efetuaram revisão de literatura sobre DF e déficit auditivo, sendo descritas perdas de grau leve a profundo, numa prevalência de $12 \%$ a $66 \%$, a depender do grupo em estudo. Segundo essas pesquisadoras, o déficit auditivo na DF decorre da vaso-oclusão na cóclea, ocasionando isquemia e anóxia coclear, provocada pela falcização das hemácias que bloqueiam o fluxo de sangue ao epitélio coclear. Os prejuízos causados por essa perda sensorial, muitas vezes, afetam, não apenas o desenvolvimento da linguagem, mas, também, o desenvolvimento global da criança, e seu rendimento escolar. Por isso, as autoras 
citadas destacam a necessidade de prevenção, diagnóstico e tratamento da perda auditiva provocada na DF.

Em referência aos resultados da IRM, houve menor desempenho no Grupo ICS somente na tarefa de consciência fonológica quando comparado com o Grupo IRM normal. Na literatura científica, os três estudos que avaliaram linguagem comparando esses grupos, também não encontraram diferença estatisticamente significativa entre eles (Craft et al., 1993; DeBaun et al., 1998; Schatz et al., 2001). Considera-se importante apontar para o possível efeito-chão das análises estatísticas para os demais subteste de linguagem do presente estudo, visto que quase todos os resultados desse domínio foram muito baixos no Grupo Clínico geral, não sendo possível diferenciar desempenho das crianças com ou sem ICS.

No que concerne ao domínio da memória, foi evidenciado prejuízo nos portadores de DF na memória visoespacial imediata e tardia e forte tendência a perdas em memória de lista de palavras. Contudo, em atividades de memória narrativa e memória para faces, as crianças com DF não apresentaram alteração. De forma semelhante, Swift et al. (1989) também demonstraram desempenho significativamente inferior em memória visoespacial e verbal no Grupo Clínico, sendo mais intenso o prejuízo em memória visoespacial, como presentemente identificado nos atuais resultados. Nossos dados também apontaram que maior escore em memória visoespacial constitui um fator de proteção, sendo que a cada aumento de um ponto nesse teste houve diminuição média entre 22 a $33 \%$ da chance de pertencer ao Grupo Clínico.

Na comparação entre Grupos IRM normal e ICS houve menor rendimento nas crianças com infartos em memória narrativa e em memória visoespacial imediata e tardia. Contudo, não foi verificada diferença estatisticamente significativa na memória para lista de palavras e memória para faces. Esse resultado contradiz informações divulgadas por White et al. (2006) e Brandling-Bennett et al. (2003) que consideraram a tarefa de memória de lista de palavras como melhor preditor para identifcar o Grupo ICS.

Ao focalizar o domínio visoespacial, foram detectados desempenhos inferiores no Grupo Clínico em raciocínio visoespacial, na habilidade de visoconstrução e no julgamento de linhas. Além disso, a cada aumento de um ponto nesses subtestes sinalizou-se como redutor, em média, de 21 a $31 \%$ de chance da criança ser portadora de DF. Esses dados acompanham as conclusões de Puffer et al. (2010) e Hijmans, Fijnvandraat et al. (2011) que evidenciaram alteração nas crianças com DF na habilidade de percepção visual, praxia construcional e coordenação motora. Não foi encontrada, no presente trabalho, diferença estatisticamente significativa nesse domínio entre os grupos com e sem ICS, compartilhando a direção de resultados apresentada por DeBaun et al. (1998). 
Em nenhuma das tarefas realizadas no domínio sensoriomotor foi aqui identificada diferença estatisticamente significativa no desempenho das crianças com DF e aquelas saudáveis, o que também ocorreu na comparação dos subgrupos IRM normal e ICS do Grupo Clínico. Essa tendência dos atuais dados é confirmada pela maioria das pesquisas anteriores que não encontraram discrepância no desempenho entre Grupo Clínico e Controle (Ruffieux et al., 2013; Noll et al., 2001), bem como entre os Grupos ICS e IRM normal (Craft et al., 1993; DeBaun et al., 1998; Armstrong et al., 1996). Ao que tudo indica, a habilidade sensoriomotora na DF parece se manter preservada.

Outro dado interessante foi o declínio cognitivo em distintas funções neuropsicológicas com o aumento da idade cronológica nas crianças com DF. Diversos estudos apontam nessa direção e levantam a possibilidade de existência de microinfartos cerebrais em decorrência do tempo nos portadores de DF (Berkelhammer et al., 2007; Kral et al., 2003, 2006; Steen et al., 2003, 2005; Thompson et al., 2003, Wang et al, 2001). No presente estudo, algumas funções cognitivas pareceram mais vulneráveis ao efeito do aumento da idade no Grupo Clínico como a capacidade intelectual geral, função executiva, diferentes aspectos da linguagem (como vocabulário, compreensão, velocidade de processamento e consciência fonológica), memória narrativa e visoespacial e habilidade visoespacial. Os dois estudos conduzidos por Kral et al. (2003, 2006) encontraram resultados similares com menor desempenho em inteligência geral, atenção sustentada e função executiva, memória verbal imediata, e integração visomotora em crianças portadoras de DF com maior idade. Outras investigações científicas apresentaram evidências nessa mesma direção, podendo-se destacar: no funcionamento intelectual geral o estudo de Steen et al. (2003, 2005), na função executiva o trabalho de Ruffieux et al. (2011) e, na habilidade visomotora, a pesquisa de Brown et al. (1993). Em adição a esses achados, Kral et al. (2003, 2006) e Brown et al. (1993) encontraram alteração no processamento atencional em função da idade, resultado não encontrado na presente pesquisa.

Diante das evidências empíricas presentemente identificadas pode-se apontar que a DF constitui fator de risco considerável para essas crianças desenvolverem quadros progressivos neurodegenerativos, provavelmente em função de possíveis microinfartos cerebrais no decorrer da vida. Essa possibilidade é corroborada também pelo fato de que a maioria das crianças com ICS pertenciam ao grupo de maior idade (10-12 anos). Entretanto, faz-se necessária a condução de estudos longitudinais que investiguem mais amplamente esse aspecto, visto que ainda não há conhecimento suficiente para se determinar qual a faixa etária de maior risco para iniciar esse eventual declínio cognitivo nos portadores de DF. 
No tocante ao Grupo Controle, houve um achado inesperado em função da idade, visto que as crianças de 10-12 anos apresentaram desempenhos médios no QI Estimado e em "Cubos" do WISC III superiores aos das crianças de 7-9 anos. Como o conjunto das crianças presentemente avaliadas possuem indicadores de desenvolvimento típico e diante do fato que os escores ponderados desses instrumentos de avaliação psicológica já consideram (e ponderam) a variável idade para o cálculo da pontuação, esses resultados merecem a devida exploração em estudos futuros, visando verificar a adequação do padrão normativo disponível desses testes e outras variáveis que possam estar interferindo nesses resultados.

A análise da variável sexo não acumulou evidências relevantes para o desempenho neuropsicológico de crianças do Grupo Clínico e Controle. Cabe mencionar apenas que, no Grupo Clínico, foi identificada diferença estatisticamente significativa, associada ao sexo, no desempenho intelectual aferido pela capacidade de raciocínio abstrato e na habilidade de julgamento de linhas. Não foi verificada influência do sexo nos resultados da IRM. Portanto, dentro das informações acumuladas neste estudo, o sexo não pareceu ser variável de destaque entre os resultados.

Em relação ao genótipo vinculado à $\mathrm{DF}$, notou-se que o grupo de menor gravidade clínica ( $\mathrm{SC}$ e $\mathrm{S} \beta+$ ) apresentou pior desempenho em velocidade e precisão grafomotora. Esse resultado contradiz as expectativas teóricas, pois seria esperado desempenho inferior nas atividades neuropsicológicas nas crianças do subgrupo de maior gravidade na DF (SS e $\mathrm{S} \beta^{\circ}$ ). Nas demais funções cognitivas não houve diferença estatisticamente significativa entre os genótipos. Contudo, foi observada tendência do subtipo de maior gravidade clínica na DF apresentar maior risco para ICS. Vale ressaltar, no entanto, que o número de casos avaliados foi reduzido no presente trabalho, fragilizando possíveis inferências a partir destes achados relacionados aos genótipos.

Ao analisar os elementos comportamentais, aqui avaliados por meio de relatos dos pais ou responsáveis das crianças (pelo CBCL), notou-se que as crianças com DF apresentaram sinais de maior frequência de problema de atenção. Além disso, a impressão geral dos resultados indicou alto índice de "perfil clínico" no grupo com DF nas síndromes de ansiedade/depressão e comportamentos de agressividade, bem como nas escalas de Problemas de Internalização, Externalização e Funcionamento Total.

No Brasil, foi realizado estudo sobre problemas de saúde mental em crianças e adolescentes entre 6-17 anos na região metropolitana de baixa renda de São Paulo, sendo encontrada prevalência de $24,6 \%$ de nível clínico pela escala de funcionamento total do CBCL e/ou Youth Self-Report (Paula, Duarte \& Bordin, 2007). Esse resultado foi semelhante 
ao encontrado no atual Grupo Controle $(24,1 \%)$, porém demonstrou que as crianças com DF apresentaram índice superior de problemas $(44,8 \%)$ em relação ao esperado. Esse dado contraria resultados de investigações anteriores nessa área, os quais não identificaram problemas de comportamento nas crianças com DF, mas de forma semelhante com o presente estudo, também não encontraram relação disso com a presença de alteração na IRM (Swift et al., 1989; Goonan et al., 1994; Armstrong et al., 1996; Thompson et al., 2003).

Esse atual resultado deve ser considerado com cautela, pois pode ter sofrido alguma influência do processo de aplicação do próprio CBCL, padronizado como instrumento autoaplicável. Em alguns casos da amostra clínica foi necessário fornecer explicação adicional sobre a adequada forma de preenchimento do instrumento, já que a pesquisadora esteve disponível em forma presencial para dirimir possíveis dúvidas dos respondentes. No entanto, alguns pais preferiram responder esse instrumento na sua residência. Além disso, no Grupo Controle o inventário CBCL foi enviado aos responsáveis por seus próprios filhos, havendo poucos casos em que foi solicitado contato com a pesquisadora para suprimir dúvidas. Partindo da observação que alguns responsáveis do Grupo Clínico apresentaram dificuldade de compreensão do inventário, deve-se questionar se houve a mesma dificuldade para os demais respondentes, hipótese sem a devida comprovação nesse trabalho, dada a ausência do contato direto com a pesquisadora no preenchimento do CBCL pelo Grupo Controle. Ao mesmo tempo, os pais do Grupo Controle possuíam nível de escolaridade mais elevado, o que pode ter contribuído para melhor compreensão do inventário utilizado. De qualquer maneira, percebe-se a necessidade de maior investimento em pesquisas científicas nessa área, para que crianças com DF possam ser compreendidas sob a luz de seu desenvolvimento comportamental e emocional.

As demais variáveis médicas analisadas referem-se ao uso de medicamentos especificamente a hidroxiureia (HU) e aos níveis de $\mathrm{Hb}$ e Ht. No tocante a $\mathrm{HU}$, observou-se que pequena amostra dos pacientes utilizava esse fármaco (16,7\%), destaca-se, no entanto, que todos tiveram IRM normal. A despeito da indicação da HU ser, geralmente, voltada para aquelas crianças que apresentam maiores fatores de risco neurológicos, esse achado, apesar de ser muito pontual, corrobora com o já estabelecido efeito protetor de medicamento na prevenção de vaso-oclusão na DF (Puffer et al., 2007).

No tocante ao nível de Ht, houve tendência do Grupo IRM normal ter maior percentual de Ht quando comparado às crianças com ICS, porém não foi verificada associação estatisticamente significativa com os escores neuropsicológicos. Nessa direção, Armstrong et al. (1996) e Bernaudin et al. (2000) demonstraram que o Grupo ICS apresentou menor nível 
de Ht. Já Steen et al. (2003) não encontraram diferença significativa entre os grupos, no entanto consideraram baixo nível de Ht como preditor do comprometimento cognitivo em crianças com DF. Contrariamente, aos resultados da presente investigação, diversos estudos têm sugerido associação entre nível de Ht com medidas cognitivas (como QI total, QI verbal e de execução), e subtestes de informação, aritmética, dígitos e velocidade de processamento, vocabulário, desempenho acadêmico, atenção sustentada e função executiva (Bernaudin et al., 2000; Puffer et al., 2010; Schatz et al., 2004; Kral et al., 2006).

Sobre o nível de $\mathrm{Hb}$ não foi evidenciada diferença estatisticamente significativa entre os grupos com ou sem lesão cerebral, sem indicadores de correlação dessa variável com pontuações nos testes neuropsicológicos. Pesquisas com medidas de $\mathrm{Hb}$ e desempenho neuropsicológico são ainda iniciais e, talvez por isso, os resultados encontrados até o momento são controversos. De maneira semelhante ao presente estudo, Swift et al. (1989), Goonan et al. (1994) e Grueneich et al., (2004) não constataram associação estatisticamente significativa entre resultados de testes neuropsicológicos e níveis de $\mathrm{Hb}$. Para Brown et al. (1993), baixos níveis de $\mathrm{Hb}$ foram considerados como fator de risco para disfunção neurocognitiva, enquanto nível mais alto de $\mathrm{Hb}$ mostrou-se como fator protetor da memória visual de curto prazo e funcionamento intelectual e acadêmico. Já Ruffieux et al. (2011) encontraram correlação significativa, do ponto de vista estatístico, entre níveis de $\mathrm{Hb}$ e funcionamento executivo em portadores de DF.

A presente pesquisa chega a apontar outros fatores de risco que podem ter contribuído para o baixo desempenho neuropsicológico nas crianças com DF. A própria cronicidade da doença pareceu interferir no funcionamento neuropsicológico desse grupo, que muitas vezes, vivenciam faltas escolares advindas da necessidade de hospitalizações e consultas médicas frequentes, vinculadas a seu seguimento clínico em serviços institucionais de referência. 
6. CONSIDERAÇÕES FINAIS 
Essa pesquisa apresentou resultados empíricos consistentes no tocante ao perfil neuropsicológico e comportamental de crianças com DF, pois utilizou uma ampla bateria de avaliação neuropsicológica integrando também informações socioeconômicas, escolares e clínicas dos participantes. Ficou demonstrado que crianças com DF apresentaram prejuízos no desempenho intelectual geral e déficits em diversos domínios neuropsicológicos específicos, principalmente função executiva, linguagem, memória visoespacial e habilidade visoespacial. Esse comprometimento cognitivo foi ainda mais significativo no Grupo Clínico com ICS nas funções: capacidade intelectual, na memória narrativa e visoespacial, além de processamento fonológico. Essas diversas alterações neuropsicológicas nos portadores de DF tendem a predispor a dificuldades no desempenho acadêmico e maior repetência escolar. Também pode ser observado que as crianças com DF pareceram acumular perdas cognitivas com o avanço da idade, ainda na típica faixa etária escolar (7 a 12 anos), resultado possivelmente relacionado a desenvolvimento de quadro progressivo neurodegenerativo devido a maior tempo de exposição à hipoperfusão cerebral e hipoxemia crônica. Além disso, verificous-e alta prevalência de problemas comportamentais (atingindo níveis clínicos) no funcionamento global das crianças com DF.

Esses resultados trazem relevantes implicações para o tratamento dos portadores de DF, pois ratifica a necessidade do acompanhamento multiprofissional, inclusive por psicólogo. Nesse contexto, a avaliação neuropsicológica torna-se importante auxílio no tratamento de portadores de DF, uma vez que poderá oferecer informações sobre seu funcionamento cognitivo, permitindo adequados planos de intervenção. Para realização dessa avaliação, deve ser incluída ampla bateria neuropsicológica, como o NEPSY II, associados a instrumentos de avaliação comportamental e emocional, para compreensão do funcionamento cerebral dessas crianças, visto o alto risco para desenvolverem prejuízos cognitivos variados e alterações de comportamento. Sugere-se, ainda, que essas investigações sejam realizadas, preferencialmente numa frequência regular, de forma a poder acompanhar a evolução do desenvolvimento neuropsicológico dos portadores de DF, tornando possível a detecção precoce de eventuais danos cerebrais.

Atrelado aos processos de avaliação neuropsicológica, no caso de DF parece imprescindível à elaboração e o oferecimento de serviços de reabilitação neuropsicológica. $\mathrm{O}$ atendimento em centro especializado poderá beneficiar essas crianças no acesso à estimulação cognitiva, visando promover a reestruturação funcional do cérebro e o aproveitamento de sua plasticidade neuronal. Além disso, pode auxiliar a criança a enfrentar questões da própria doença, assim como a lidar com suas limitações pessoais, estimulando a aprendizagem de 
estratégias de compensação vinculadas à valorização de suas potencialidades. O programa de reabilitação pode contribuir para melhorar a qualidade de vida dos portadores de DF, promovendo maior participação em ambiente escolar, social e ocupacional e prevenindo possíveis dificuldades no desenvolvimento cognitivo, emocional e comportamental.

Os serviços de neuropsicologia, desse modo, devem realizar seu trabalho de forma integrada às ações das escolas. Amparados pela lei de inclusão escolar, os professores poderão integrar as informações sobre o funcionamento cognitivo de alunos com DF de modo a compreender essas crianças e seu desempenho acadêmico. Em posse desses dados, torna-se possível desenvolver estratégias interventivas para atender suas necessidades educacionais, buscando maximizar sua aprendizagem, compensar possíveis dificuldades e eventualmente diminuir índices de repetência escolar e a cristalização de dificuldades de aprendizagem.

Futuros estudos longitudinais, no entanto, devem ser realizados visando entender a evolução da DF no percurso neurodesenvolvimental dessas crianças. Para tanto, devem ser incluídas crianças de ampla faixa etária, desde bebês a adolescentes, visto que ainda não é bem conhecida a idade de maior risco para ocasionar prejuízos cognitivos. Com isso, novas formas de tratamento e principalmente de prevenção de dificuldades neuropsicológicas e comportamentais poderão ser alcançadas para esse Grupo Clínico.

Salientam-se, por fim, que as conclusões da presente pesquisa devem ser relativizadas e devidamente contextualizadas ao âmbito desse estudo. Sugere-se que novas investigações sejam realizadas no Brasil, sobretudo envolvendo variados centros de pesquisa para conseguir ampliar a representatividade da amostra clínica, de modo a obter informações robustas sobre o perfil neuropsicológico e comportamental de crianças com DF. Destaca-se, ainda, que as dificuldades de aprendizagem identificadas não foram devidamente investigadas, visto que no presente estudo, esse aspecto foi caracterizado pelo relato dos responsáveis e confrontação com as notas escolares. Assim, indica-se que sejam incluídos, em pesquisas futuras, testes específicos para avaliar habilidades acadêmicas como tarefas de leitura, escrita e cálculo, oferecendo fontes informativas adicionais sobre o rendimento acadêmico, na tentativa de covalidação dos achados.

Cabe frisar, ainda nos limites do presente trabalho, a possibilidade de viéses no processo de seleção dos participantes do Grupo Controle, já que algumas crianças foram previamente indicadas pelos professores, visto ser esta a condição de viabilidade técnica do estudo nesse momento. Dessa forma, indica-se que outras pesquisas possam incluir no grupo de comparação, irmãos ou pares da mesma rede socioeconômica, visando minimizar possíveis 
influências ambientais e socioculturais nos processos de comparação do desempenho cognitivo e comportamental dessas crianças.

Por fim, ressalta-se que o presente trabalho alcançou os objetivos inicialmente propostos, apresentando evidências empíricas relativas ao funcionamento cognitivo, comportamental e emocional de crianças com DF no contexto brasileiro. Em posse dessas informações, enfatiza-se a necessidade de desenvolver políticas públicas que incentivem o cuidado global dessas crianças, levando em consideração não apenas suas questões clínicas, mas, também, aspectos cognitivos e emocionais desse Grupo Clínico. 


\section{REFERENNCIAS $^{1}$}

\footnotetext{
${ }^{1}$ De acordo como padrão APA - A merican Psychological Association, adaptado pelo Sistema Integrado de Bibliotecas - USP
} 
Abreu, N., \& Mello, C. B. (2008). Avaliação dos processos de memória e categorização. In K. Z. Ortiz, L. I. Z. Mendonça, A. Foz., C. B. Santos, D. Fuentes, \& D. A. Azambuja (Orgs.), Avaliação neuropsicológica. Panorama interdisciplinar dos Estudos na Normatização e Validação de Instrumentos no Brasil (pp. 338-351). São Paulo: Vetor.

Ahmad, S. A., \& Warriner, E. M. (2001). Review of NEPSY: A Devolpmental Neuropsychological Assessment. The Clinical Neuropsychologist, 15(2), 240-249.

Alves, L., Morávia, C. B., Campos, F. A., Paula, J. J., \& Malloy-Diniz, L. (2010). Teste de organização visual Hooper e Teste de avaliação de habilidade visuoespacial (TAHLVES). In L. F. Malloy- Diniz, D. Fuentes, P. Mattos, N. Abreu el al., Avaliação neuropsicológica (pp. 421-424). Porto Alegre: Artmed.

Angulo, I. L. (2007). Acidente vascular cerebral e outras complicações do Sistema Nervoso Central nas doenças falciformes. Revista Brasileira de Hematologia e Hemoterapia, 29(3), 262-267.

Argollo, N. (2010). NEPSY II. Avaliação neuropsicológica do desenvolvimento. In L. F. MalloyDiniz, D. Fuentes, P. Mattos, N. Abreu el al., Avaliação neuropsicológica (pp. 367-373). Porto Alegre: Artmed.

Argollo, N., Bueno, O. F., Shayer, B., Godinho, K., Abreu, K., Durán, P. et al. (2009). Adaptação transcultural da bateria NEPSY: Avaliação neuropsicológica do desenvolvimento: Estudo-piloto. Avaliação psicológica, 8(1), 59-75.

Armstrong, F. D., Thompson, R. J. Jr., Wang, W., Zimmerman, R., Pegelow, C. H., Miller, S. et al. (1996). Cognitive functioning and brain magnetic resonance imaging in children with sickle cell disease. Pediatrics, 97(6), 864-870.

Assimadi J. K., Gbadoé A. D., \& Nyadanu M. (2000). The impact on families of sickle cell disease in Togo. Archives de Pédiatrie, 7(6), 615-620.

Associação Brasile ira de Empresa de Pesquisa (2012). Critério de classificação econômica Brasil. São Paulo, SP: Autor. Recuperado em 17 de outubro de 2012, de http://www.abep.org/

Baptista, M. N., \& Campos, D. C. (2007). Metodologia de Pesquisa em Ciências. Análises Quantitativa e Qualitativa. Rio de Janeiro: LTC.

Berg, C., Edwards, D.F., \& King, A. (2012). Executive function performance on the children's kitchen task assessment with children with sickle cell disease and matched controls. Child Neuropsychology, 18(5), 432-448.

Berkelhammer, L. D., Williamson, A. L., Sanford, S. D., Dirksen, C. L., Sharp, W. G. , Margulies, A. S., \& Prengler, R. A. (2007). Neurocognitive sequelae of pediatric sickle cell disease: a review of the literature. Child Neuropsychology, 13, 120-131.

Bernaudin, F., Verlhac, S., Fréard, F., Roudot-Thoraval, F., Benkerrou, M., Thuret, I. et al. (2000). Multicenter prospective study of children with sickle cell disease: radiographic and psychometric correlation. Journal of Child Neurology, 15(5), 333-343.

Bordin, I. A., Silvares, E. F. M., Rocha, M. M., Teixeira, M. C., \& Paula C. S. (2010). Versão brasileira do "Child Behaviour Checklist for ages 6-18". São Paulo: ASEBA. 
Brandling-Bennett, E. M., White, D. A., Armstrong, M. M., Christ, S. E., \& DeBaun, M. (2003). Patterns of verbal long-term and working memory performance reveal deficits in strategic processing in children with frontal infarcts related to sickle cell disease. Developmental Neuropsychology, 24(1), 423-434.

Brickenkamp, R. (1981). Teste D2 de Atenção Concentrada. Manual de instruções, avaliação e interpretação. Adaptação brasileira: Bittencourt, M. S. B. (2000). São Paulo: Centro Editor de Testes e Pesquisas em Psicologia.

Brown, R. T., Davis, P. C., Lambert, R., Hsu, L., Hopkins, K., \& Eckman, J. (2000). Neurocognitive functioning and magnetic resonance imaging in children with sickle cell disease. Journal of Pediatric Psychology, 25(7), 503-513.

Brown, R.T., Buchanan, I., Doepke, K., Echman, J., Baldwin, k., Goonan, B., \& Schoenherr, S. (1993). Cognitive and academic functioning in children with sickle cell disease. Journal of Clinical Child Psychology, 22(2), 207-218.

Burgemeister, B. B., Blum, L. H., \& Lorge, I. (1972). CMMS - Escala de Maturidade Mental Colúmbia. Manual para aplicação e interpretação. Adaptação brasileira: Alves, I. C. B., \& Duarte, J. L. M. (2001). São Paulo: Casa do Psicólogo.

Camargo, C. H. P. (2008). Prefácio. In K. Z. Ortiz, L. I. Z. Mendonça, A. Foz., C. B. Santos, D. Fuentes, \& D. A. Azambuja (Orgs.), Avaliação neuropsicológica. Panorama interdisciplinar dos Estudos na Normatização e Validação de Instrumentos no Brasil (pp. 19-20). São Paulo: Vetor.

Camargo, C. H. P., Bolognani, S. A. P., \& Zuccolo, P.F. (2008). O Exame neuropsicológico e dos diferentes contextos de aplicação. In D. Fuentes, L. Malloy-Diniz, C. H. P. Camargo, R. M. Cosenza et al., Neuropsicologia: teoria e prática. Porto Alegre: Artmed.

Capellini, S. A., \& Smythe, I. (2008). Protocolo de avaliação de habilidades cognitivo-linguísticas: livro do profissional e do professor. Marília, SP: Fundepe.

Capellini, S. A., Oliveira, A. M., \& Cuetos, F. (2010). PROLEC: Provas de avaliação dos processos de leitura. São Paulo: Casa do Psicólogo.

Capovilla, A. G. S., \& Capovilla, F. C. (1998). Prova de Consciência Fonológica: Desenvolvimento de dez habilidades da pré-escola à segunda série. Temas sobre desenvolvimento, 7(37), 14-20.

Capovilla, A. G. S., \& Capovilla, F. C. (2004). Problemas de leitura e escrita: Como identificar, prevenir e remediar numa abordagem fônica (3a. ed.). São Paulo: Memnon, FAPESP.

Capovilla, A. G. S., \& Capovilla, F. C. (2006). Prova de Consciência Sintática normatizada e validada. São Paulo: Memnon.

Capovilla, A. G. S., Capovilla, F. C., \& Soares, J. V. T. (2004). Consciência sintática no ensino fundamental: corre lações com consciência fonológica, vocabulário, le itura e escrita. Psico-USF, 9(1), 39-47.

Capovilla, A. G. S., Montiel, J. M., Macedo, F. C., \& Capovilla, F. C. (2005). Teste de Stroop Computadorizado. Programa de computador. Itatiba, SP: Universidade São Francisco. 
Capovilla, A. G. S. (2007). Contribuições da neuropsicologia cognitiva e da avaliação neuropsicológica à compreensão do funcionamento cognitivo humano. Cadernos de Psicopedagogia [online], 6(11), 00-00.

Capovilla, F. C., \& Capovilla, A. G. S. (1998). O desenvolvimento dos vocabulários receptivo e expressivo em crianças brasile iras. Interamerican Journal of Psychology, 32(2), 33-49.

Capovilla, F. C., Viggiano, K. Q., Capovilla, A. G. S., Raphael, W. D., Bidá, M. R, Neves, M. V., \& Mauricio, A. C. (2004a). Como avaliar o desenvolvimento da compreensão de leitura de sentenças em surdos do Ensino Fundamental ao Médio: Teste de Competência de Leitura de Sentenças. In F. Capovilla, \& W. Raphael (Eds.), Enciclopédia da Língua de Sinais Brasileira, Vol. 3. São Paulo: Edusp, Vitae, Feneis, CAPES, CNPq, FAPESP.

Capovilla, F. C., Viggiano, K. Q., Raphael, W. D., Bidá, M., Capovilla, A. G. S., Neves, M., \& Mauricio, A. (2004b). Como avaliar a competência de leitura em surdos do Ensino Fundamental ao Médio: Teste de Nomeação de Figuras por Escolha. In F. Capovilla, \& W. Raphael (Eds.). Enciclopédia da Língua de Sinais Brasileira, Vol. 4. São Paulo: Edusp, Vitae, Feneis, Capes, CNPq, Fapesp.

Catell, R. B., \& Catell, A. K. S. (s/d). TEI- Teste Equicultural de Inteligência. Escala 2. Adaptação brasileira: Andrade, E. M., \& Alves, D. G. (2002). Rio de Janeiro: Centro Editor de Psicologia.

Chodorkoff, J., \& Whitten, C.F. (1963). Intellectual status of children with sickle cell anemia. The Journal of Pediatrics, 63(1), 29-35.

Ciasca, S. M., Guimarães, I. E., \& Tabaquim, M. L. (2005). Neuropsicologia do Desenvolvimento: Aspectos Teóricos e Clínicos. In C. B. Mello, M. C. Miranda, \& M. Muszkat. Neuropsicologia do Desenvolvimento. Conceitos e Abordagens (pp. 14-25). São Paulo: Memmon.

Conselho Federal de Psicologia (2003). Resolução n ${ }^{\circ} 2$ / 2003. Recuperado em 09 de outubro de 2012, de http://www.pol.org.br

Conselho Federal de Psicologia (2004). Resolução no 2 / 2004. Recuperado em 09 de outubro de 2012, de http://www.pol.org.br

Cosenza, R. M, Fuentes, D., \& Malloy-Diniz, L. (2008). A evolução das ideias sobre a relação entre o cérebro, comportamento e cognição. In D. Fuentes, L. Malloy-Diniz, C. H. P. Camargo, R. M. Cosenza et al., Neuropsicologia: teoria e prática (pp. 15-19). Porto Alegre: Artmed.

Costa, D. I., Azambuja, L. S., Portuguez, M. W., \& Costa, J. C. (2004). Avaliação neuropsicológica da criança. Jornal de Pediatria, 80 (2 supl).

Coutinho, G., Mattos, P., Araújo, C., Borges, M., \& Alfano, A., (2008). Satandardization of the normative group for the third version of the testo $f$ visual attention - TAVIS. Dementia \& Neuropsychologia, 2(1), 20-25.

Craft, S., Schatz, J., Glauser, T. A., Lee, B., \& DeBaun, M. R. (1993). Neuropsychologic effects of stroke in children with sickle cell anemia. The Journal of Pediatrics, 123(5), 712-717.

Crews, K.J., \& D'Amato, R.C. (2010). Subtyping Children's Reading Disabilities Using a Comprehensive Neuropsychological Measure. The International Journal of Neuroscience, 11, $141-158$ 
Cunha, J. A. et al. (2000). Psicodiagnóstico - V (5a ed. ver. amp.). São Paulo: Artmed.

Dancy, C. P., \& Reidy, J. (2006). Estatística sem matemática para psicólogos. Usando SPSS para Windows. Porto Alegre: Artmed.

DeBaun, M. R., Schatz, J., Siegel, M. J., Koby, M., Craft, S., Resar, L. et al. (1998). Cognitive screening examinations for silent cerebral infarcts in sickle cell disease. Neurology, 50(6), 16781682.

Fagan, M. K., Pisoni, D. B., Horn, D. L., \& Dillon, C. M. (2007). Neuropsychological Correlates of Vocabulary, Reading, and Working Memory in Deaf Children with Cochlear Implants. Journal of Deaf Studies and Deaf Education, 12(4), 461-471.

Ferraz, M.H. \& Murao, M. (2007). Diagnóstico laboratorial da doença falciforme em neonatos e após o sexto mês de vida. Revista Brasileira de Hematologia e Hemoterapia, 29(3), 218-222.

Ferreira, F. O., Coutinho, G., Freitas, P. M., Malloy-Diniz, L., \& Haase, V. G. (2010). O exame neuropsicológico na idade pré-escolar. In L. F. Malloy- Diniz, D. Fuentes, P. Mattos, N. Abreu el al. Avaliação neuropsicológica (pp.210-220). Porto Alegre: Artmed.

FIESP (2000). Federação das Indústrias do Estado de São Paulo. Recuperado em 05 de novembro de 2012, de http://apps.fiesp.com.br/regional/DadosSocioEconomicos/RankingIDH.aspx

Figueiredo, V. L. M. (2000). WISC III. In Cunha, J. A. et al. Psicodiagnóstico - V(5a ed. ver. amp.) (pp. 603-614). São Paulo: Artmed.

Fonseca, P. R., Willhelm, A., Rodrigues, M., Bez, M. B., Traub, L., Salomon, J. Parente, M. A. (2008). Avaliação neuropsicológica e uso de testes psicológicos: Neupsilin e instrumentos em estudo. In K. Z. Ortiz, L. I. Z. Mendonça, A. Foz., C. B. Santos, D. Fuentes, \& D. A. Azambuja (Orgs.), Avaliação neuropsicológica. Panorama interdisciplinar dos Estudos na Normatização e Validação de Instrumentos no Brasil (pp. 19-20). São Paulo: Vetor.

Freitas, P. M., Rothe-Neves, R., Chageas, P. P., Amarante, C. L. D., Cardoso, T. S. G., \& Haase. V. G. (2010). Avaliação neuropsicológica do processamento lexical para crianças. In L. F. MalloyDiniz, D. Fuentes, P. Mattos, N. Abreu el al, Avaliação neuropsicológica (pp. 403-412). Porto Alegre: Artmed.

Gold, J. I., Johnson, C. B., Treadwell, M. J., Hans, N., \& Vichinsky, E. (2008). Detection and assessment of stroke in patients with sickle cell disease: neuropsychological functioning and magnetic resonance imaging. Pediatric Hematology and Oncology, 25, 409-421.

Gonsalez, S.M. L., Rocca, C.C.A., Malloy-Diniz, L.F., Rodrigues, C.L. (2005). Teste da Torre de Hanói. In L. F. Malloy- Diniz, D. Fuentes, P. Mattos, N. Abreu el al., Avaliação neuropsicológica (pp. 350-354). Porto Alegre: Artmed.

Goonan, B.T., Goonan, L.J., Brown, R. T., Buchanan, I., Eckman, J.R. (1994). Sustained attention and inhibitory control in children with sickle cell syndrome. Archives of Clinical Neuropsycholog, 9(1), 89-104.

Grueneich, R., Ris, D., Ball, W., Kalinyak, K. A., Noll, R., Vannatta, K., \& Wells, R. (2004). Relationship of structural magnetic resonance imaging, magnetic resonance perfusion, and other disease factors to neuropsychological outcome in sickle cell disease. Journal of Pediatric Psychology 29(2), 83-92. 
Guimarães, T. M. R, Miranda, W. L., Tavares, M. M. F. (2009). O cotidiano das famílias de crianças e adolescentes portadores de anemia falciforme. Revista Brasileira de Hematologia $e$ Hemoterapia, 31(1), 9-14.

Haase, V. G., Pinheiro-Chagas, P., Mata, F. G., Gonzaga, D. M., Silva, J. B. L., Géo, L. A., \& Ferreira, F. O. (2008). Corre lação estrutura-função no diagnóstico neuropsicológico In K. Z. Ortiz, L. I. Z. Mendonça, A. Foz., C. B. Santos, D. Fuentes, \& D. A. Azambuja (Orgs.), Avaliação neuropsicológica. Panorama interdisciplinar dos Estudos na Normatização e Validação de Instrumentos no Brasil (pp. 23-37). São Paulo: Vetor.

Heaton, R. K, Chelune, G. J., Talley, J. L., Kay, G. G., \& Curtiss, G. (1948). WISCONSIN de Classificação de Cartas. Manual. Adaptação e Padronização Brasile ira: Cunha, J. A., Trentini, C. M., Argimon, I. L., Oliveira, M. S., Werlang, B. G., \& Prieb, R. G. (2004). São Paulo: Casa do Psicólogo.

Hijmans, C. T., Fijnvandraat, K., Grootenhuis, M. A., Geloven, N., Heijboer, H., Peters, M., Oosterlaan, J. (2011b). Neurocognitive deficits in children with sickle cell disease: a comprehensive profile. Pediatric Blood \& Cancer, 56(5),783-788.

Hijmans, C. T., Grootenhuis, M. A., Oosterlaan, J., Heijboer, H., Peters, M., \& Fijnvandraat, K. (2011a). Neurocognitive deficits in children with sickle cell disease are associated with the severity of anemia. Pediatric Blood \& Cancer, 57(2), 297-302.

Hutz, C. S. (Org.) (2012). Avanços em avaliação psicológica e neuropsicológica de crianças e adolescentes II. São Paulo: Casa do Psicólogo.

Joly, M. C. R. A. Bateria Informatizada de Linguagem Oral - BILOv3 (Version 3.0) [Computer software]. Núcleo de Avaliação Psicológica Informatizada - Univers idade São Francisco, Itatiba, 2009.

Joseph, R. M., McGrath, L. M., \& Tager-Flusberg, H. (2005). Executive Dysfunction and Its Relation to Language Ability in Verbal School-Age Children With Autism. Developmental Neuropsychology., 27(3), 361-378.

Kemp, S.L., \& Korkman, M. (2011). Essentials of NEPSY II Assessment. Hoboken, New Jersey: John Willey \& Sons.

Korkman, M., \& Pesonen, E. A. (1994). A Comparison Neuropsychological Test Profiles of Children with Attention Deficit-Hyperactivity Disorder and/or Learning Disorder. Journal of Learning Disabilities, 27(6), 383-392.

Korkman, M., Kirk, U., \& Kemp, S. (1998). NEPSY: A Developmental Neuropsychological Assessment. San Antonio, TX: The Psychological Corporation.

Korkman, M., Kirk, U., \& Kemp, S. (2007). NEPSY II: A Developmental Neuropsychological Assessment. San Antonio: Harcourt Assessment.

Kral, M. C., \& Brown, R. T. (2004). Transcranial doppler ultrasonography and executive dysfunction in children with sickle cell disease. Journal of Pediatric Psychology, 29(3), 185-195.

Kral, M. C., Brown, R. T., Curé, J. K., Besenski, N., Jackson, S. M., \& Abboud, M. R. (2006). Radiographic predictors of neurocognitive functioning in pediatric sickle cell disease. Journal of Child Neurology, 21(1), 37-44. 
Kral, M. C., Brown, R. T., Nietert, P. J., Abboud, M. R, Jackson, S. M., \& Hynd, G. W. (2003). Transcranial doppler ultrasonography and neurocognitive functioning in children with sickle cell disease. Pediatrics, 112(2), 324-331.

Lefévre, B. (2004). Avaliação neuropsicológica infantil. In V. M. Andrade, F. H. Santos, \& O.F. Bueno (Orgs.), Neuropsicologia Hoje (pp. 249-264). São Paulo: Artes Médicas.

Lezak, M. D., Howieson, D. B., \& Loring, D. W. (2004). Neuropsychological Assessment. New York: Oxford University Press.

Lind, A., Korkman, M., Lehtonen,L., Lapinleimu, H., Parkkola, R., Matomaki, J., Haataja, L., \& The Pipari Sudy Group (2010). Cognitive and neuropsychological outcomes at 5 years of age in preterm children born in the 2000s. Developmental Medicine \& Child Neurology, 53(3), 256-62

Lobo, C. L., Cançado, R. D., Leite, A. C., Anjos, A. C., Pinto, A. C., Matta, A. P. et al (2011). Brazilian Guidelines for transcranial doppler in children and adolescents with sickle cell disease. Revista Brasileira de Hematologia e Hemoterapia, 33(1), 43-48.

Lopes, F., Capovilla, A. G. S., Berberian, A. A., Capovilla, F. C., \& Macedo, E. C. (2006). Avaliação de rotação mental em crianças de $1^{\mathrm{a}}$ a $4^{\mathrm{a}}$ série: desenvolvimento do teste ImagéticaBaby-Comp. In A. G. S. Capovilla (Ed.), Teoria e pesquisa em avaliação neuropsicológica (pp. 115-124). São Paulo: Memnon.

Macharia, W. M., Shiroya, A, \& Njeru, E. K. (1997). Knowledge, attitudes and beliefs of primary caretakers towards sickle cell anaemia in children. East African Medical Journal, 74(7), 416-419.

Mader-Joaquim, M. J. (2010). O neuropsicólogo e seu paciente. Introdução aos princípios da avaliação neuropsicológica. In L. F. Malloy- Diniz, D. Fuentes, P. Mattos, N. Abreu el al., Avaliação neuropsicológica (pp. 46-57). Porto Alegre: Artmed.

Malloy- Diniz, L. F., Bentes, R. C., Figueiredo, P. M. et al. (2007). Normalización de una bacteria de tests para evaluar las habilidades de comprensión del lenguaje, fluidez verbal y denominación em niños brasileños de 07 a 10 años: Resultados preliminaries. Revista de Neurologia, 44(5), 275280 .

Malloy-Diniz, L. F., Cardoso-Martins, C., Pacheco, E., Levy, A., Leite, W., \& Fuentes, D. (2008). Planning abilities of children aged $4 \frac{1 / 2}{2}$ years to $81 / 2$ years: Effects of age, fluid intelligence and school type on performance in the Tower of London test. Dementia \& Neuropsychologia, 2, 2630.

Malloy-Diniz, L. F., Fuentes, D., Mattos, P., Abreu, N. et al.. (2010). Avaliação neuropsicológica. Porto Alegre: Artmed.

Marlow, N., Hennessy, E. M., Bracewell, M. A., Wolke. D., \& EPICure Study Group. (2007). Motor and executive function at 6 years of age after extremely preterm birth. Pediatrics, 120(4), 793804.

Mata, F. G., Moraes, P. H. P., Campos, A. F., Leite, W. B., Fuentes, D., \& Malloy-Diniz, L. F. (2010). Children Gambling Task. In L. F. Malloy- Diniz, D. Fuentes, P. Mattos, N. Abreu el al., Avaliação neuropsicológica (pp. 378-381). Porto Alegre: Artmed.

McCauley, S. R., \& Pedroza, C. (2010). Event-based prospective memory in children with sickle cell disease: effect of cue distinctiveness. Child Neuropsychology, 16, 293-312. 
Mello, C. B., Argollo, N., Shayer, B. P. M., Abreu, N., Godinho, K., Durán, P., Vargem, F., Muszkat, M., Miranda, M. C., \& Bueno, O. F. A. (2011). Versão Abreviada do WISC III: Correlação entre QI Estimado e QI Total em Crianças Brasileiras. Psicologia: Teoria e Pesquisa, 27(2), 149-155.

Mello, C. B., Miranda, M. C., \& Muszkat, M. (2005). Neuropsicologia do Desenvolvimento. Conceitos e Abordagens. São Paulo: Memmon.

Mikkola, K., Ritari, N., Tommiska, V., Salokorpi, T., Lehtonen, L., Tammela, O., Pääkkönen, L., Olsen, P., Korkman, M., Fellman, M., \& for the Finnish ELBW Cohort Study Group (2005). Neurodevelopmental Outcome at 5 Years of Age of a National Cohort of Extremely Low Birth Weight Infants. Pediatrics, 116, 1391-1400.

Ministério da Saúde (2002). Agência Nacional de Vigilância Sanitária. Manual de diagnóstico e tratamento da doença falciforme. Brasília, DF: Autor. Recuperado em 15 de janeiro de 2013, de http://bvsms.saude.gov.br/bvs/publicacoes/anvisa/diagnostico.pdf

Ministério da Saúde (2006). Secretaria de Atenção à Saúde. Departamento de Atenção Especializada. Manual de anemia falciforme para agentes comunitários de saúde. Brasília, DF: Autor. Recuperado em 05 de novembro de 2010, de http://bvsms.saude.gov.br/bvs/publicacoes/manual_anemia_falciforme_agentes_comunitario.pdf

Ministério da Saúde (2010). Protocolo clínico e diretrizes terapêuticas da doença falciforme. Portaria SAS/MS no 55, de 29 de janeiro de 2010. Brasília, DF: Autor. Recuperado em 15 de janeiro de 2013, de http://portal.saude.gov.br/portal/arquivos/pdf/pcdt_doenca_falciforme_livro_2010.pdf

Miranda, M. C. (2005). Avaliação Neuropsicológica Quantitativa e Qualitativa: Ultrapassando a psicometria. In C. B. Mello, M. C. Miranda, \& M. Muszkat, Neuropsicologia do Desenvolvimento. Conceitos e Abordagens (pp. 127-143). São Paulo: Ed Memmon.

Miranda, M. C., Borges, M., \& Rocca, C. C. A. (2010). Avaliação neuropsicológica infantil. In L. F. Malloy- Diniz, D. Fuentes, P. Mattos, N. Abreu et al., Avaliação neuropsicológica (pp. 221-233). Porto Alegre: Artmed.

Miranda, M. C., Nóbrega, F., Sato, K., Pompéia, S., Sinners, E.G., \& Bueno, O. F. A. (2007). Neuropsicologia e desnutrição: um estudo com crianças de 7 a 10 anos de idade, em uma comunidade carente. Revista Brasileira de Saúde Materno Infantil, 7(1), 45-54.

Miranda, M. C., Sinners, E. G., Pompeia, S., \& Bueno, O. F. A. (2008). A comparative study of performance em the Conner's Continuous Performance Test between Brazilian and American children. Journal of Attention Disorders, 11(5), 588-598.

Montiel, A. G. S., \& Capovilla, F. C. (2006a). Teste de atenção por cancelamento. In A. G. S. Capovilla (Ed.), Teoria e pesquisa em avaliação neuropsicológica (pp. 141-146). São Paulo: Memnon.

Montiel, A. G. S., \& Capovilla, F. C. (2006b). Teste de Trilhas - Partes A e B. In A. G. S. Capovilla (Ed.), Teoria e pesquisa em avaliação neuropsicológica (pp. 109-114). São Paulo: Memnon.

Moojen, S., Lamprecht, R. R., Santos, R. M., Freitas, G. M., Brodacz, R., Sique ira, M., Correa, A., \& Guarda, E. (2003). CONFIAS - Consciência Fonológica: Instrumento de Avaliação Sequencial. São Paulo: Casa do Psicólogo. 
Nabors, N. A., \& Freymuth, A. K. (2002). Attention deficits in children with sickle cell disease. Perceptual and Motor Skills, 95(1), 57-67.

Narzisi, A., Muratori, F., Calderoni, S., Fabbro, F., \& Urgesi, C. (2012). Neuropsychological Profile in High Functioning Autism Spectrum Disorders. Journal of Autism and Developmental Disorder, Dec 8, No Pagination Specified.

Noll, R. B., Stith, L., Gartstein, M. A., Ris, M. D., Grueneich, R., Vannatta, K., \& Kalinyak, K. (2001). Neuropsychological Functioning of youths with sickle cell diseases: comparison with non-chronically peers. Journal of Pediatric Psychology, 26(2), 69-78.

Nunest, S., Miranda, D. L., Reis, A. T., Gramacho, A.M., Lucena, R., \& Argollo, N. (2010). Complicações neurológicas em anemia falciforme: avaliação neuropsicológica do desenvolvimento com o NEPSY. Revista Brasileira de Hematologia e Hemoterapia, 32(2), 181185 .

Oliveira, R., \& Charchat-Fichman, H. (2008). Brazilian children performance on Rey's auditory verbal learning paradigm. Arquivos de Neuro-psiquiatria, 66(1), 40-44.

Pasquali, L. (2005). Manual Técnico e de Aplicação. TNVRI - Teste Não Verbal de Raciocínio para Crianças. São Paulo: Vetor.

Paula, C.S., Duarte, C.S., \& Bordin, I.A.S. (2007). Prevalence of mental health problems in children and adolescents from the outskirts of Sao Paulo City: treatment needs and service capacity evaluation. Revista Brasileira de Psiquiatria, 29 (1), 11-7.

Perner, J., Kain, W., \& Barchfeld, P. (2002). Executive Control and Higher-Order Theory of Mind in Children at Risk of ADHD. Infant and Child Development, 11, 141-158.

Puffer, E. Schatz, J., \& Roberts, C. W. (2007). The association of oral hydroxyurea therapy with improved cognitive functioning in sickle cell disease. Child Neuropsychology,13(2), 142-154.

Puffer, E. Schatz, J., \& Roberts, C. W. (2010). Relationships between somatic growth and cognitive functioning in young children with sickle cell disease. Journal of Pediatric Psychology, 35(8), 892-904.

Raven, J. C., Raven, J., \& Court, J. H. (1987). Matrizes Progressivas Coloridas. Série A, Ab, B. Escala especial. Padronização brasileira: Angelini, A. L., Alves, I. C. B., Custódio, E. M., \& Duarte, W. F. (1999) São Paulo: Casa do Psicólogo.

Rey, André (1959). Figuras Complexas de Rey. Teste de cópia e de reprodução de memória de figuras complexas geométricas. Adaptação brasileira: Oliveira, M. S, \& Rigoni, M. S. (2008). São Paulo: Casa do Psicólogo.

Richard, H. W., \& Burlew, A. K. (1997). Academic performance among children with sickle cell disease: setting minimum standards for comparison groups. Psychological Reports, 81, 27-34.

Rocha, M. M., Pereira, R. F., Arantes, M. C., \& Silvares, E. F. M. (Trad.) (2010). Guia para prof issionais da saúde mental sobre o Sistema Achenbach de Avaliação Empiricamente Baseada (ASEBA). São Paulo. Tradução da obra: Achenbach, T.M., \& Rescorla, L.A. (2010). Mental Health Parctitioners` Guide for Achenbach System of Empirically Based Assessment (ASEBA) (7th Ed.). Burlington, VT: University of Vermont, Research Center of Children, Youth \& Families, Burlinton, VT. Tiragem de circulação interna. 
Rodrigues, C. C. M., Araújo, I. E. M., \& Melo, L. L. (2010). A família da criança com doença falciforme e a equipe enfermagem: revisão crítica. Revista Brasileira de Hematologia $e$ Hemoterapia,32(3), 257-264

Rodrigues, C. L., Rocca, C. C. A., \& Fuentes, D. (2010). Matching Familiar Figures Test 20 (MFFT20). In L. F. Malloy- Diniz, D. Fuentes, P. Mattos, N. Abreu et al., Avaliação neuropsicológica. (pp. 416-420). Porto Alegre: Artmed.

Rosa, H. R., \& Alves, I. C. B. (2000). R2-Teste Não Verbal de Inteligência para Crianças. Manual. São Paulo: Vetor.

Ruffieux , N., Njamnshi, A. K., Wonkam, A., Hauert, C.-A., Chanal, J., Verdon, V., Fonsah, J. Y., Eta, S. C., Doh, R. F., Ngamaleu, R. N., Kengne, A.-M., Fossati, C., \& Sztajzel, R. (2013). Association between biological markers of sickle cell disease and cognitive functioning amongst Cameroonian children. Child Neuropsychology, 19(2),143-60.

Sanchez, C. E., Schatz, J., \& Roberts, C. W. (2010). Cerebral blood fllow velocity and language functioning in pediatric sickle cell disease. Journal of the International Neuropsychological Society, 16, 326-334.

Santos, A. A., Noronha, A. P. P., \& Sisto, F. F. (2006). TONI-3 (Forma A). Teste de Inteligência NãoVerbal: uma medida de habilidade cognitiva independente da linguagem. Manual do examinador. São Paulo: Vetor.

Scantlebury, N., Mabbott, D., Janzen, L., Rockel, C., Widjaja, E., Jones, G., Kirby, M., \& Odame, I. (2011). White Matter Integrity and Core Cognitive Function in Children Diagnosed With Sickle Cell Disease. Journal of Pediatric Hematology/ Oncology, 33, 163-171.

Schatz, J., \& Roberts, C. W. (2005). Short-term memory in children with sickle cell disease: Executive versus modality-specific processing deficits. Archives of Clinical Neuropsychology, 20, 10731085.

Schatz, J., Brown, R. T., Pascual, J. M., Hsu, L., \& DeBaun, M. R. (2001). Poor school and cognitive functioning with silent cerebral infarcts and sickle cell disease. Neurology, 56, 1109-1111.

Schatz, J., Finke, R., \& Roberts, C. W. (2004). Interactions of Biomedical and Environmental Risk Factors for Cognitive Development: A Preliminary Study of Sickle Cell Disease. Developmental and Behavioral Pediatrics, 25(5), 303-310.

Schatz, J., Puffer, E., Sanchez, C., Stancil, M., \& Roberts, C. W. (2009). Language processing deficits in sickle cell disease in young school-age children. Developmental Neuropsychology, 34(1), 122 136

Schatz, J., White, D. A., Moinuddin, A., Armstrong, M., \& DeBaun, M. R. (2002). Lesion burden and cognitive morbidity in children with sickle cell disease. Journal of Child Neurology, 17(12), 890894.

Seabra, A. G., \& Capovilla, F. C. (2010). TCLPP - Teste de Competência de Leitura de Palavras e Pseudopalavras. São Paulo: Memnon.

Seabra, A. G., Macedo, E. C., \& Capovilla, F. C. (2012). Avaliação Neuropsicológica. In C. S. Hutz (Org.). Avanços em avaliação psicológica e neuropsicológica de crianças e adolescentes II (pp. 41-56). São Paulo: Casa do Psicólogo. 
Silva, L.P.A., Nova, C. V., \& Lucena, R. (2012). Sickle Cell anemia and hearing loss among children and youngsters: literature review. Braz J Otorhinolaryngol, 78(1), 126-31.

Simões, M. R. (2002). Avaliação neuropsicológica em crianças e adolescentes. In R. Primi (Org.). Temas em Avaliação Psicológica (pp. 26-34). Campinas, SP: IBAP.

Sistema de Avaliação de Testes Psicológicos (2012). Testes psicológicos aprovados para uso. Recuperado em 19 de outubro de 2012, de http// www2.pol.org.br/satepsi/

Sisto, F. F. (2005). DFH-Desenho da Figura Humana - Escala Sisto. Manual. São Paulo: Vetor.

Sisto, F. F. (2007). RIn - Teste de Raciocínio Inferencial. Manual. São Paulo: Vetor.

Sisto, F. F., Noronha, A. P. P., \& Santos, A. A.. (2006). B-SPG - Teste Gestáltico Visomotor de Bender - Sistema de pontuação gradual. Manual. São Paulo: Vetor.

Spreen, O., \& Strauss, E. (1998). A Compendium of Neuropsychological Tests. Administration, Norms and Commentary ( $2 a$ ed.). New York: Oxford University Press.

Steen, R. G., Fineberg-Buchner, C., Hankins, G., We iss, L., Prifitera, A., \& Mulhem, R. K. (2005). Cognitive deficits in children with sickle cell disease. Journal of Child Neurology, 20(2), 102107.

Steen, R. G., Miles, M. A., Helton, K. J., Strawn, S., Wang, W., Xiong, X., \& Mulhern, R. K. (2003). Cognitive impairment in children with hemoglobin SS sickle cell disease: relationship to MR imaging findings and hematocrit. American Journal of Neuroradiology, 24, 382-389.

Steen, R. G., Xiong, X., Mulhern, R. K., Langston, J. W., \& Wang, W. C. (1999). Subtle brain abnormalities in children with sickle cell disease: relationship to blood hematocrit. Annals of Neurology, 45(3), 279-286.

Stein, L. M. (1994). Teste de Desempenho Escolar: manual para aplicação e interpretação. São Paulo: Casa do Psicólogo.

Strouse, J. J., Cox, C. S., Melhem, E. R., Lu, H., Kraut, M. A., Razumovsky, A., Yohay, K., Zijl, P. C., \& Casella, J. F. (2006). Inverse correlation between cerebral blood flow measured by continuous arterial spin-labeling (CASL) MRI and neurocognitive function in children with sickle cell anemia (SCA). Blood, 108(1), 379-381.

Swift, A. V., Cohen, M. J., Hynd, G. W., Wisenbaker, J. M., McKie, K. M., Makari, G., McKie, V. C. (1989). Neuropsychologic impairment in children with sickle cell anemia. Pediatrics, 84(6), 1077-1085.

Thompson, R. J., Armstrong, D., Link, C. L., Pegelow, C. H., Moser, F., \& Wang, W. C. (2003). A prospective study of the relationship over time of behavior problems, intellectual functioning, and family functioning in children with sickle cell disease: a report from the Cooperative Study of Sickle Cell Disease. Journal of Pediatric Psychology, 8(1), 58-65.

Toni, P. M. (2006). Bateria Piaget-Head de Orientação Direita-Esquerda. Paraná: Vetor.

Tosello, D. J. T. (2005). Contribuições para o estudo normativo do Hooper Visual Organization Test (VOT). Psicologia Hospitalar, 13(2), 59-83. 
Tosi, S. M. V. (2006). TIG-NV - Teste de Inteligência Geral Não Verbal. Instrumento para avaliação psicológica e neuropsicológica. Manual. São Paulo: Casa do Psicólogo.

Tweel, X. W., Hatzmann, J., Ens ink, E., Lee, J. H., Peters, M., Fijnvandraat, K. et al. (2008). Quality of life of female caregivers of children with sickle cell disease: a survey. Haematologica, 93(4), $588-93$.

Wang, W., Enos, L., Gallagher, D., Thompson, R., Guarini, L., Vichinsky, E., Wright, E., Zimmerman, R., \& Armstrong, D. (2001). Neuropsychologic performance in school-aged children with sickle cell disease: A report from the Cooperative Study of Sickle Cell Disease. The Journal of Pediatrics, 139(3), 391-397.

Wasserman, A. L., Wilimas, J. A., Fairclough, D. L., Mulhern, R. K., \& Wang, W. (1991). Subtle neuropsychological deficits in children with sickle cell disease. The American Journal of Pediatric Hematology/Oncology, 13(1),14-20.

Wechsler, D. (1991). WISC-III: Escala de Inteligência Wechsler para Crianças - 3a . ed.. Adaptação e padronização para uma amostra brasileira: Figueiredo, V. L. M. (2002). São Paulo: Casa do Psicólogo.

White, D. A., Moinuddin, A., McKinstry, R. C., Notzel, M., Armstrong, M., \& DeBaun, M. (2006). Cognitive screening for silent cerebral infarction in children with sickle cell disease. Journal of Pediatric Hematology/Oncology, 28(3), 166-169.

Zou, P., Helton, K. J., Smeltzer, M., Li, C.-S., Conklin, H. M., Gajjar, A., Wang, W. C., Ware, R. E., \& Ogg, R. J. (2011) Hemodynamic responses to visual stimulation in children with sickle cell anemia. Brain Imaging and Behavior, 5, 295-306. 
ANEXOS 
ANEXO A - Carta de autorização para uso do instrume nto NEPSY-II
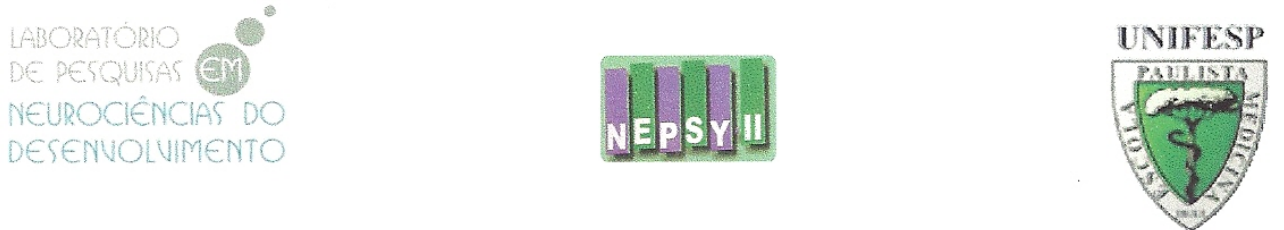

CARTA DE AUTORIZAÇÃO - USO DO INSTRUMENTO NEPSY-II

Autorizo a psicóloga Katiusha Abreu a fazer o uso do instrumento NEPSY-II de tradução e adaptação brasileira sob minha autoria, para a sua dissertação de mestrado. Para o seu treino no referido instrumento haverá a necessidade de treinamento e aplicação em crianças de desenvolvimento normal sob supervisão. Planejamos disponibilizar um kit da bateria a partir do mês de março de 2011.

Salvador, 11 de novembro de 2010

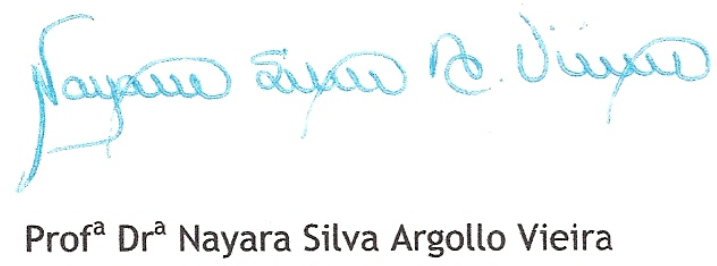

Autora da Validação Nacional do NEPSY-Brasil Laboratório de Pesquisas em Neurociências - FRB

Coordenadora Acadêmica do Curso de Pós-graduação de Especialização em Neuropsicologia - UFBa Ambulatório de Neuropsicologia Infantil e Linguagem do Complexo HUPES 


\title{
ANEXO B - Aprovação do projeto no CEP da FFCLRP - USP
}

\author{
Universidade de São Paulo \\ Faculdade de Filosofia, Ciências e Letras de Ribeirão Preto
}

"Campus" de Ribeirão Preto

\section{Of.CEtP/FFCLRP-USP/055/-jsI}

Ribeirão Preto, 20 de maio de 2011.

Prezada Pesquisadora,

Comunicamos a V. Sa. que o trabalho intitulado "PERFIL NEUROPSICOLÓGICO DE CRIANÇAS COM DOENÇA FALCIFORME" foi analisado pelo Comitê de Ética em Pesquisa da FFCLRP-USP, em sua 95a Reunião, realizada em 19.05.11, e enquadrado na categoria: APROVADO, de acordo com o Processo CEP-FFCLRP n 573/2011 - 2011.1.1170.59.0.

Atenciosamente,

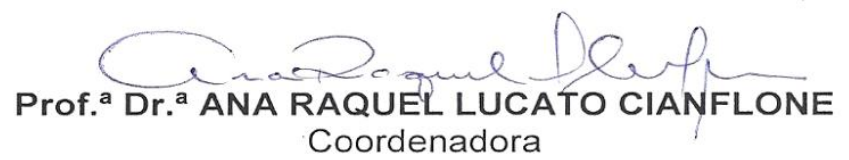

llustríssima Senhora

Katiusha de Cerqueira Abreu

Mestranda do Programa de Pós-Graduação em Psicologia da FFCLRP - USP

Com cópia para a orientadora

Prof. ${ }^{a}$ Dr. ${ }^{a}$ Sonia Regina Pasian

Departamento de Psicologia da FFCLRP - USP

\footnotetext{
CEP - Comitê de Ética em Pesquisa da FFCLRP

Fone: (16) 3602-4681

Fax: (16) 3633-2660 (direto) ou 3633-5015

Avenida Bandeirantes, 3900 - bloco 1 - 14040-901 - Ribeirão Preto - SP - Brasil

Homepage: http://www.ffclrp.usp.br - e-mail: coetp@ffclrp.usp.br
} 


\title{
ANEXO C - Aprovação do projeto no CEP do HC e da FMRP-USP
}

\author{
HOSPITAL DAS CLIINICAS DA FACULDADE DE MEDICINA \\ DE RIBEIRÄO PRETO DA UNIVERSIDADE DE SÃO PAULO
}

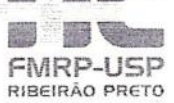

Ribeirão Preto, 04 de julho de 2012

Projeto de pesquisa: "Perfil neuropsicológico de crianças com doença falciforme"

Pesquisadores responsáveis: Katiusha de Cerqueira Abreu e Profa. Dra. Sonia Regina Pasian

Instituição Proponente: Faculdade de Filosofia, Ciências e Letras de Ribeirão Preto - USP.

"O CEP do HC e da FMRP-USP concorda com o parecer ético emitido pelo CEP da Instituição Proponente, que cumpre as Resoluções Éticas Brasileiras, em especial a Resolução CNS 196/96. Diante disso, o HCFMRP-USP, como instituição co-participante do referido projeto de pesquisa, está ciente de suas co-responsabilidades e de seu compromisso no resguardo da segurança e bemestar dos sujeitos desta pesquisa, dispondo de infra-estrutura necessária para a garantia de tal segurança e bem-estar".

Ciente e de acordo:

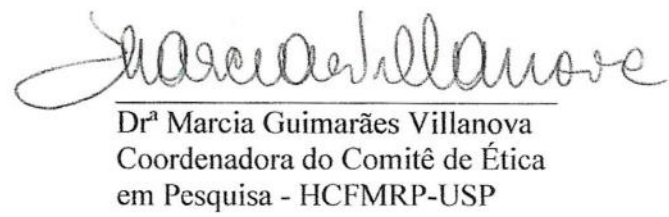

Prof. Dr. José Alexandre de Souza Crippa Coordenador Técnico Científico da Unidade em Pesquisa - HCFMRP-USP de Pesquisa Clínica - HCFMRP-USP 
ANEXO D - Autorização da pesquisa sobre doença falciforme no Hemocentro de Ribeirão Preto
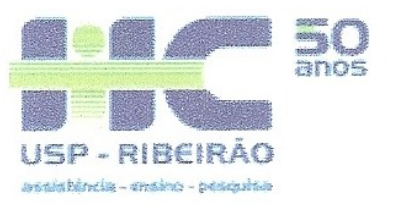
FUNDAÇÃO HEMOCENTRO RIBEIRÃO PRETO HOSPITAL DAS CLÍNICAS

DA FACULDADE DE MEDICINA DE RIBEIRÃO PRETO DA UNIVERSIDADE DE SÃO PAULO

Ribeirão Preto, 16 de março de 2011

A psicóloga Katiusha Abreu está autorizada a realizar sua pesquisa sobre doença falciforme com pacientes em acompanhamento no Hemocentro de Ribeirão Preto, vinculado ao Hospital das Clínicas da Faculdade de Medicina de Ribeirão Preto, desde que atendidas as seguintes premissas:

- Quando executado, o referido projeto deverá estar aprovado pelo Comitê de Ética em Pesquisa do HCFMRP, bem como, o respectivo Termo de Consentimento Livre e Esclarecido a ser utilizado para os sujeitos da pesquisa.

- A pesquisadora deverá se comprometer em respeitar os requisitos da Resolução 196/96 que dispõe sobre as Diretrizes e Normas Regulamentadoras de Pesquisas Envolvendo Seres Humanos.

Fomos informados que os dados por ela coletados serão utilizados na sua dissertação de mestrado pela pós-graduação em psicologia da Faculdade de Filosofia Ciências e Letras de Ribeirão Preto - Universidade de São Paulo.

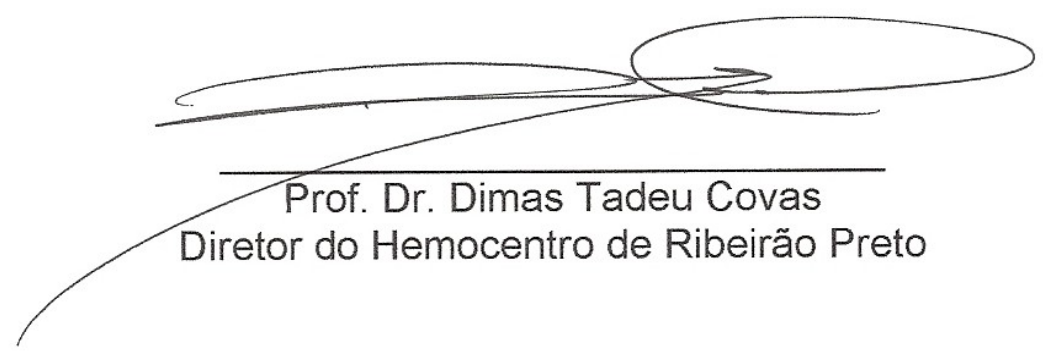

Ciente

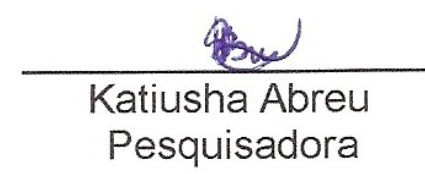




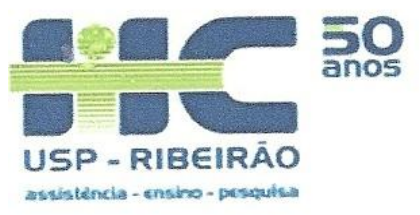

\section{HOSPITAL DAS CLÍNICAS \\ DA FACULDADE DE MEDICINA DE RIBEIRÃO PRETO DA UNIVERSIDADE DE SÃO PAULO}

Ribeirão Preto, 16 de novembro de 2010

A psicóloga Katiusha Abreu fará parte da equipe de pesquisadores do projeto em tramitação sobre doença falciforme do Departamento de Neurociências e Ciências do Comportamento sob minha coordenação. Nessa pesquisa, serão incluídos pacientes em acompanhamento no Hemocentro de Ribeirão Preto vinculado ao Hospital das Clínicas da Faculdade de Medicina de Ribeirão Preto.

Os dados por ela coletados serão utilizados na sua dissertação do mestrado pela pós-graduação de psicologia da Faculdade de Filosofia Ciências e Letras de Ribeirão Preto - Universidade de São Paulo.

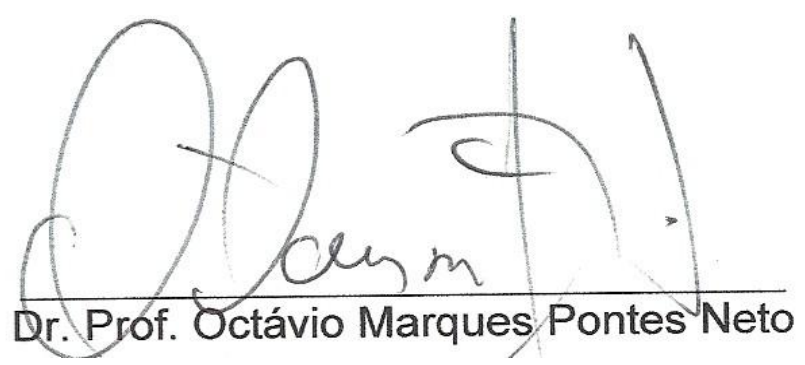


APÊEDICES 


\section{โป Universidade de São Paulo}

Faculdade de Filosofia, Ciência e Letras de Ribeirão Preto

Departamento de Psicologia - Centro de Pesquisas em Psicodiagnóstico (CPP)

\section{FORMULÁRIO PARA PARTICIPAÇÃO NA PESQUISA}

Por favor, Senhores Pais:

- Respondam às questões abaixo da forma mais completa que lhes for possível no momento.

- Reafirmamos nosso objetivo de, como esse levantamento, conhecer melhor as características dos estudantes participantes dessa pesquisa, para poder relacionar seu desenvolvimento pessoal com seu padrão de respostas às atividades propostas.

- Também reafirmamos nosso compromisso de completo sigilo das informações e dos participantes.

- Favor devolver esse questionário juntamente com uma cópia assinada do Termo de Consentimento Livre e Esclarecido para a pesquisa.

- Novamente, agradecemos sua valiosa colaboração!

1. Nome do estudante:

2. Idade:

3. Data de Nascimento:

4. Sexo: ( ) Fem. ( ) Masc.

5. Nome pai:

6. Nome mãe:

7. Telefone para contato:

8. Cor: Branca( ) Preta/negra ( ) Parda/mulata/morena ( ) Amarela/oriental( ) Indígena( )

9. Nome da escola:

10. Tipo de Escola: $\square$ Municipal $\square$ Estadual $\square$ Particular

11. Ano Escolar: Com quantos anos entrou na escola?

12. Necessita de algum serviço de educação especial? ( ) Não ( )Sim.

Qual?

13. Já repetiu de ano? ( )Não ( ) Sim. Quantas vezes? Qual(is) ano(s)

14. Qual a última nota em: Português Matemática Ciências

15. Já ficou internado? ( ) Não ( )Sim. Com que idade? ____ Quanto tempo? Qual o motivo?

16. Já apresentou graves problemas de saúde? ( ) Não ( )Sim. Com que idade?

Qual(is)?

17. Mais especificamente: já apresentou problemas psicológicos ou neurológicos?( )Não ( )Sim Com que idade? Qual(is)?

18. Fez ou faz uso de medicamento por causa desse problema? ( ) Não ( ) Sim.

Qual (is)?

Quando? Por quanto tempo?

20. Estado civil dos pais: ( )solteiro ( )casado ( )viúvo ( )separado/divorciado ( )amasiado 15. Escolaridade do pai:

a) Analfabeto/ $1^{\mathrm{a}}$ a $4^{\mathrm{a}}$ séries incompletas - última série que freqüentou:

b) $1^{\mathrm{a}} \mathrm{a} 4^{\mathrm{a}}$ séries completas (primário ou ensino fundamental I)

c) $5^{\mathrm{a}}$ a $8^{\mathrm{a}}$ séries incompletas - última série que freqüentou:

d) $5^{\mathrm{a}}$ a $8^{\mathrm{a}}$ séries completas (ginasial ou ensino fundamental II)

e) Ensino Médio: $1^{\circ}$ ao $3^{\circ}$ anos incompletos (colegial, científico ou curso técnico). Qual?

Último ano que frequientou. 
f) Ensino Médio: $1^{\circ}$ ao $3^{\circ}$ anos completos (colegial, científico ou curso técnico). Qual?

g) Ensino superior incompleto. Qual? Quantos anos freqüentou.

h) Ensino superior completo. Qual?

16. Escolaridade da mãe ou cuidador:

a) Analfabeto $/ 1^{\mathrm{a}}$ a $4^{\mathrm{a}}$ séries incompletas - última série que freqüentou:

b) $1^{\mathrm{a}} \mathrm{a} 4^{\mathrm{a}}$ séries completas (primário ou ensino fundamental I)

c) $5^{\mathrm{a}}$ a $8^{\mathrm{a}}$ séries incompletas - última série que freqüentou:

d) $5^{\text {a }}$ a $8^{\mathrm{a}}$ séries completas (ginasial ou ens ino fundamental II)

e) Ensino Médio: $1^{\circ}$ ao $3^{\circ}$ anos incompletos (colegial, científico ou curso técnico). Qual?

Último ano que freqüentou.

f) Ensino Médio: $1^{\circ}$ ao $3^{\circ}$ anos completos (colegial, c ientífico ou curso técnico) Qual?

g) Ensino superior incompleto. Qual? Quantos anos freqüentou.

h) Ensino superior completo. Qual?

17. Quem é o chefe de família? ( )Pai （ ) Mãe

18. Número de irmãos:

19. Posição do estudante entre os irmãos (único ou primeiro, etc.)

20. Quais e quantos desses itens sua família possui?

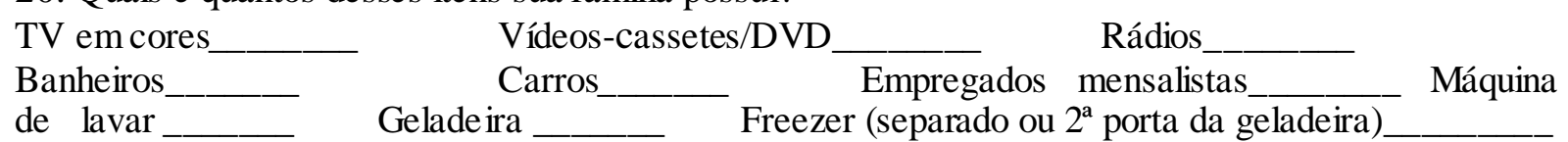

21. Observações que julga importantes sobre seu(sua) filho(a): 


\section{APÊNDICE B - Termo de Consentimento Livre e Esclarecido - Grupo Clínico}

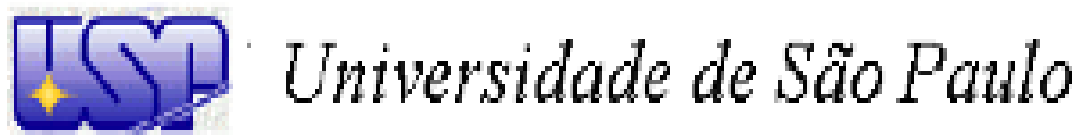

Faculdade de Filosofia, Ciência e Letras de Ribeirão Preto

Departamento de Psicologia Centro de Pesquisas em Psicodiagnóstico (CPP)

Av. Bandeirantes, 3900 - Campus USP

CEP: 14.040-901 - Ribeirão Preto - SP

\section{TERMO DE CONSENTIMENTO LIVRE E ESCLARECIDO Aos pais de crianças do Hemocentro de Ribeirão Preto}

Estamos realizando uma pesquisa em Ribeirão Preto que procura conhecer características do desenvolvimento intelectual e neuropsicológico de crianças de 7 a 11 anos de idade, envolvendo cerca de 60 participantes. Este trabalho será desenvolvido sob responsabilidade da psicóloga KATIUSHA ABREU, aluna do Programa de Pós-Graduação em Psicologia da Faculdade de Filosofia, Ciências e Letras de Ribeirão Preto (FFCLRP) da Universidade de São Paulo (USP) e da Dra. Sonia Regina Pasian, professora do Departamento de Psicologia e Educação desta mesma faculdade. O objetivo desta pesquisa é comparar o desempenho de crianças saudáveis com crianças portadoras de doença falciforme em ativid ades cognitivas e neurológicas, básicas para a aprendizagem.

Foi realizada uma seleção prévia no Ambulatório de Doença Falciforme do Hemocentro de Ribeirão Preto - Hospital das Clínicas, sendo seu (sua) filho(a) préselecionado(a) para participar dessa pesquisa. Caso o senhor (a) permita a participação do seu (sua) filho (a), será realizada uma avaliação psicológica em sala do próprio Hemocentro, sendo a criança convidada a responder exercícios de raciocínio, de atenção, de memória, de percepção e de linguagem (apresentadas oralmente e de forma escrita), não implicando em riscos ou prejuízos à criança, dentro das previsões possíveis implicadas neste tipo de tarefa. Para não cansar a criança, estas atividades serão realizadas em quatro dias, com duração aproximada de 60 minutos cada. A avaliação psicológica será conduzida por Katiusha, em sala específica em horários previamente combinados com os pais para que não haja interferência relevante nas atividades acadêmicas da criança. Aos pais será solicitado que preencham um questionário (que segue em anexo) sobre o desenvolvimento e comportamento de seu (sua) filho (a), caso autorizem sua participação nesta pesquisa. Caso a criança não queira participar ou desista das atividades da pesquisa, sua vontade será respeitada e poderá interromper o trabalho em qualquer momento, sem qualquer prejuízo ou ônus de âmbito pessoal ou em seu tratamento.

Com sua concordância, também serão utilizados dados de exames já realizados previamente com a criança, presentes em seu prontuário médico do Hemocentro, especificamente aqueles relativos aos exames de sangue e exames de Imagem por Ressonância Magnética e Doppler Transcraniano.

Todas as informações desta pesquisa são confidenciais e somente serão utilizadas para investigação científica. Os resultados deste trabalho deverão ser divulgados sob o formato de comunicações científicas orais e escritas, compondo a dissertação de Mestrado de Katiusha, sem nenhuma identificação das pessoas que as forneceram. 
A sua cooperação e a de seu (sua) filho(a) será muito valiosa e necessária para tornar possível esta pesquisa. Não será oferecido aos participantes desta pesquisa nenhum pagamento ou compensação pessoal por sua colaboração neste trabalho. Colaborar com essa pesquisa poderá ajudar a conhecer as características cognitivas e neurológicas de crianças de Ribeirão Preto e isso poderá auxiliar em planejamentos futuros para serviços de ajuda psicológica para esta população.

Desde já, agradecemos sua colaboração e estaremos disponíveis para outras informações, caso necessário.

Atenciosamente,

Katiusha Abreu

CRP: 06/104947
Prof $^{a}$. Dra . Sonia Regina Pasian

CRP: 06/24.018-0

$\mathrm{Eu}$,

declaro que estou ciente dos objetivos do presente estudo e de acordo com a participação de meu

(minha)

filho

(a)

como

voluntário no projeto de pesquisa "PERFIL NEUROPSICOLÓGICO DE CRIANÇAS COM DOENÇA FALCIFORME”, sob responsabilidade da psicóloga Katiusha Abreu e da Profa. Dra. Sonia Regina Pasian, assim como estou ciente de que os registros relativos a esse trabalho serão utilizados como material de trabalho científico e poderão ser divulgados em congressos e publicados em revistas ou livros especializados, resguardando-se o devido sigilo quanto à nossa identificação. Declaro ainda que este documento foi preenchido em duas vias, sendo que uma delas ficará comigo para eventual consulta.

Ribeirão Preto, de de 2011.

(Assinatura do pai ou responsável)

Observação: Se tiver qualquer dúvida, entre em contato com o Departamento de Psicologia da FFCLRP-USP e esclareça-se conosco pelo telefone: (16) 3602.3785 ou pelo celular (16) 97311359. 


\section{APÊNDICE C - Termo de Consentime nto Livre e Esclarecido - Grupo Controle}

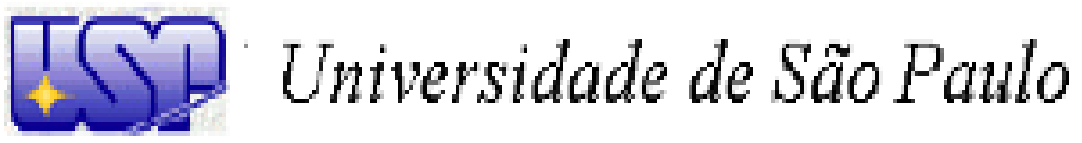

Faculdade de Filosofia, Ciência e Letras de Ribeirão Preto

Departamento de Psicologia Centro de Pesquisas em Psicodiagnóstico (CPP)

Av. Bandeirantes, 3900 - Campus USP

CEP: 14.040-901 - Ribeirão Preto - SP

\section{TERMO DE CONSENTIMENTO LIVRE E ESCLARECIDO \\ Aos pais de crianças escolares}

Estamos realizando uma pesquisa em Ribeirão Preto que procura conhecer características do desenvolvimento intelectual e neuropsicológico de crianças de 7 a 11 anos de idade, envolvendo cerca de 60 participantes. Este trabalho será desenvolvido sob responsabilidade da psicóloga KATIUSHA ABREU, aluna do Programa de Pós-Graduação em Psicologia da Faculdade de Filosofia, Ciências e Letras de Ribeirão Preto (FFCLRP) da Universidade de São Paulo (USP) e da Dra. Sonia Regina Pasian, professora do Departamento de Psicologia e Educação desta mesma faculdade. O objetivo desta pesquisa é comparar o desempenho de crianças saudáveis com crianças portadores de doença falciforme em ativid ades cognitivas e neurológicas, básicas para a aprendizagem.

Seu (sua) filho (a) foi indicação através de pais de crianças com doença falciforme acompanhadas no Hemocentro de Ribeirão Preto, inseridos na sua rede social, para participar dessa pesquisa. Caso o senhor (a) permita a participação do seu (sua) filho (a), será realizada uma avaliação psicológica conduzida por Katiusha, na própria residência ou escola da criança (ambiente mais adequado), sendo a mesma convidada a responder exercícios de raciocínio, de atenção, de memória, de percepção e de linguagem (apresentadas oralmente e de forma escrita), não implicando em riscos ou prejuízos à criança, dentro das previsões possíveis implicadas neste tipo de tarefa. Para não cansar a criança, estas atividades serão realizadas em três a quatro dias, com duração aproximada de 60 minutos cada em ambiente adequado. Aos pais será solicitado que preencham um questionário (que segue em anexo) sobre o desenvolvimento e comportamento de seu (sua) filho (a), caso autorizem sua participação nesta pesquisa.

Caso a criança não queira participar ou desista das atividades da pesquisa, sua vontade será respeitada e poderá interromper o trabalho em qualquer momento, sem qualquer prejuízo ou ônus de âmbito pessoal ou escolar. Os horários da avaliação psicológica serão previamente combinados com o responsável da criança no caso de realizar a própria casa ou com a diretoria da escola no caso da avaliação realizada na escola para que não haja interferência relevante nas atividades acadêmicas da criança.

Todas as informações desta pesquisa são confidenciais e somente serão utilizadas para investigação científica. Os resultados deste trabalho deverão ser divulgados sob o formato de comunicações científicas orais e escritas, compondo a dissertação de Mestrado de Katiusha, sem nenhuma identificação das pessoas que as forneceram.

A sua cooperação e a de seu (sua) filho (a) será muito valiosa e necessária para tornar possível esta pesquisa. Não será oferecido aos participantes desta pesquisa nenhum 
pagamento ou compensação pessoal por sua colaboração neste trabalho. Colaborar com essa pesquisa poderá ajudar a conhecer as características cognitivas e neuroló gicas de crianças de Ribeirão Preto e isso poderá auxiliar em planejamentos futuros para serviços de ajuda psicológica para esta população.

Desde já, agradecemos sua colaboração e estaremos disponíveis para outras informações, caso necessário.

Atenciosamente,

Katiusha Abreu

CRP: 06/104947
Prof $^{\mathrm{a}}$. Dra . Sonia Regina Pasian

CRP: 06/24.018-0

$\mathrm{Eu}$,

declaro que estou ciente dos objetivos do presente estudo e de acordo com a participação de meu (minha)

filho

como

voluntário no projeto de pesquisa "PERFIL NEUROPSICOLÓGICO DE CRIANÇAS COM DOENÇA FALCIFORME”, sob responsabilidade da psicóloga Katiusha Abreu e da Profa. Dra. Sonia Regina Pasian, assim como estou ciente de que os registros relativos a esse trabalho serão utilizados como material de trabalho científico e poderão ser divulgados em congressos e publicados em revistas ou livros especializados, resguardando-se o devido sigilo quanto à nossa identificação. Declaro ainda que este documento foi preenchido em duas vias, sendo que uma delas ficará comigo para eventual consulta.

Ribeirão Preto, de de 2011.

(Assinatura do pai ou responsável)

Observação: Se tiver qualquer dúvida, entre em contato com o Departamento de Psicologia da FFCLRP-USP e esclareça-se conosco pelo telefone: (16) 3602.3785 ou pelo celular (16) 97311359. 